\title{
Evaluating the impacts of supply and demand-side interventions in northern remote and rural community energy systems
}

\author{
by \\ Joe Coady

\begin{abstract}
A thesis submitted to the
Faculty of Graduate and Postdoctoral Affairs

in partial fulfillment of the requirements for the degree of
\end{abstract}

\author{
Master of Applied Science \\ in
}

\section{Sustainable Energy}

Department of Mechanical and Aerospace Engineering

Carleton University

Ottawa, Ontario

August 2020

(C) Copyright

Joe Coady, 2020 


\section{Abstract}

Remote and rural communities located across Canada face several energy system related concerns such as high heating and electricity rates, dependence on imported energy, and low levels of energy security and autonomy. In recent years, significant progress has been made with regards to developing demand and supply-side technology-based interventions that allow remote and rural communities to address these problems in a manner that is both economically viable and environmentally sound. Two prominent interventions that fall within these categories are building-based envelope energy retrofits and biomass driven district heating grids. The former can solve many of these concerns as well as reduce fossil fuel consumption, and improve the communities' housing stock, while the latter is a reliable and dispatchable technology that utilizes a carbon neutral energy source (i.e. biomass) that is abundantly available in heavily forested regions of northern Canada. This research explores the potential benefits and tradeoff of these interventions when implemented in Canada's northern remote and rural communities. The MoCreebec Eeyoud indigenous community of Moose Factory, Ontario is used as the case study in the analysis. Results show that biomass driven district heating grids are an economically attractive alternative for remote community energy systems with reductions in cost of up to $45 \%$ relative to conventional diesel power generation. On the other hand, in rural community energy systems, biomass district heating grids are unable to economically outperform conventional grid electricity unless the true cost of the electrical transmission grid is considered. However, from a purely economic standpoint, it is preferable for these communities to invest in building-based demand-side interventions instead of a biomass driven district heating grid. Building-based demand side interventions such as upgraded 
windows and improvements in insulation to the basement floor resulted in annual energy savings of up to $15 \%$. However, these results vary substantially depending on factors such as the community building layout, state of energy efficiency in community buildings, and the energy rate paid by residents. Results show that biomass driven district heating grids become an economically viable alternative at district heating grid linear heating densities of $0.8 \mathrm{MWh} / \mathrm{m}-\mathrm{yr}$ or greater. 


\section{Preface}

This integrated thesis consists of two journal papers and a conference paper, all of which are either under review, accepted, or complete and awaiting submission. Should readers wish to reference materials from this thesis, the current thesis is required to be cited. The articles in this thesis are as follows:

- Article 1: J. Coady, and J. Duquette, "A techno-economic assessment of residential building energy retrofits in Canada's remote communities: A case study," in Proc. of IBPSA Canada's eSim 2021, Vancouver, Canada. [Accepted]

- Article 2: J. Coady, and J. Duquette, "Quantifying the impacts of biomass driven combined heat and power grids in northern rural and remote communities," Renewable and Sustainable Energy Reviews [Under Review]

- Article 3: J. Coady, and J. Duquette, "Towards a cost-effective remote community energy system model: Evaluating tradeoffs between supply and demand-side interventions," Energy and Buildings [Complete - awaiting submission]

The aforementioned articles have been adapted slightly in each corresponding chapter for ease of flow of the dissertation. The use of copyrighted material from the published articles is acknowledged as per the corresponding publisher's permissions guidelines with respect to the authors' rights. 


\section{Acknowledgments}

First and foremost I would like to thank my supervisor Prof. Jean Duquette. Your support and guidance through these last two years have allowed me to develop and grow my skills as a researcher. I would also like to thank fellow graduate students and travel companions Joshua Russell and Keelia LaFreniere, as well as accompanying mentor Prof. Stephan Schott. To the members of my committee, Prof. Burak Gunay and Prof. Cynthia Cruickshank, thank you for taking the time to review and critique my thesis. To the MoCreebec Eeyoud council, notably Jean-Pierre Chabot, Eric Gunner, and Chief Allan Jolly, thank you for graciously taking us with open arms into your community and for providing us with technical and logistical assistance in carrying out this study. Further, I would like to thank my friends and family for their support as well as a big thank you to Colleen Robb, Danisz Stalinski, and Jamie Nicholson for their constructive reviews and detailed feedback. Lastly, I would like to acknowledge and thank the Borealis Foundation for their financial support. 


\section{Nomenclature}

\begin{tabular}{|c|c|}
\hline Symbols & \\
\hline ACE & Annual carbon dioxide emissions of a community $\left(\mathrm{tCO}_{2} /\right.$ year) \\
\hline AEO & Annual energy output (MWh/year) \\
\hline$A E$ & Annual energy (MWh/year) \\
\hline AES & Annual energy savings (MWh/year) \\
\hline$b$ & Regression coefficient \\
\hline$C A E D$ & $\begin{array}{l}\text { Combined annual energy demand of all community buildings } \\
\text { (MWh/year) }\end{array}$ \\
\hline$C_{\text {bio }}$ & Annual cost of biomass $(\$ / \text { year })^{*}$ \\
\hline$C C$ & Capital cost $(\$)^{*}$ \\
\hline$c E m m$ & Carbon dioxide emission intensity $\left(\mathrm{tCO}_{2} / \mathrm{MWh}\right)$ \\
\hline$C f$ & Community energy rate $(\$ / M W h)^{*}$ \\
\hline$C_{\text {fuel }}$ & Fuel cost $(\$)^{*}$ \\
\hline$C_{O \& M}$ & Operation and maintenance cost $(\$)^{*}$ \\
\hline$C_{\text {Pump }}$ & Pumping electricity cost $(\$)^{*}$ \\
\hline$C R F$ & Capital recovery factor \\
\hline $\operatorname{cTax}$ & Carbon tax $\left(\$ / \mathrm{tCO}_{2}\right)^{*}$ \\
\hline $\operatorname{det} A H D$ & Detached home annual heating load distribution (MWh/year) \\
\hline$E_{\text {Boiler }}$ & Boiler plant fuel requirement $(\mathrm{MWh})$ \\
\hline$E_{C H P}$ & Combined heat and power plant fuel requirement (MWh) \\
\hline$E_{C T}$ & Thermal energy dissipated by cooling tower (MWh) \\
\hline$E_{\text {Diesel }}$ & Diesel plant fuel requirement (MWh) \\
\hline$E_{\text {Grid }}$ & Ontario power plant fleet primary energy requirement (MWh) \\
\hline$i_{d}$ & Discount rate $(\%)$ \\
\hline$L_{D H}$ & District heating grid thermal load (MW) \\
\hline$L E B_{\text {localbio }}$ & $\begin{array}{l}\text { Levelized energy benefit associated with local biomass fuel } \\
\text { production }(\$ / M W h)^{*}\end{array}$ \\
\hline$L E C$ & Levelized energy cost $(\$ / \mathrm{MWh})^{*}$ \\
\hline$L E C_{\mathrm{CO}_{2}}$ & Levelized energy cost associated with $\mathrm{CO}_{2}$ emissions $(\$ / \mathrm{MWh})^{*}$ \\
\hline$L_{\text {Elec }}$ & Community electrical load (MW) \\
\hline$L_{\text {Heating }}$ & Community heating load (MW) \\
\hline$L_{\text {Pump }}$ & District heating grid electrical pump load (MW) \\
\hline$n$ & Project lifetime (years) \\
\hline NPV & Net present value $(\$)^{*}$ \\
\hline$N P V_{c}$ & Net present value of energy cost $(\$)^{*}$ \\
\hline$P_{d}$ & Proportion of detached homes in community (\%) \\
\hline$p_{\text {local }}$ & Proportion of locally sourced biomass feedstock (\%) \\
\hline$P M V$ & Predicted mean vote \\
\hline$\overline{P M V}^{2}$ & Annual mean squared predicted mean vote \\
\hline
\end{tabular}


$P_{S}$

$P_{r}$

$R^{2}$

$r_{h t p}$

rowAHD

semiAHD

$t_{\text {delay }}$

typ $A H D$
Proportion of semi-detached homes in community (\%)

Proportion of row homes in community (\%)

Coefficient of determination

Heat-to-power ratio (\%)

Row home annual heating load distribution (MWh/year)

Semi-detached home annual heating load distribution (MWh/year)

Construction time (years)

Typical community annual heating load distribution (MWh/year)

${ }^{*}$ The Canadian dollar currency is utilized

\begin{tabular}{ll}
\hline Acronyms and abbreviations \\
\hline aFloor & Attic floor \\
AHD & Annual heating load distribution \\
bioBoiler & Biomass boiler \\
BB & Biomass boiler \\
BC & Base case \\
BEM & Building energy model \\
BETS & Building energy transfer station \\
bFloor & Basement floor \\
BG & Biomass gasification \\
BORC & Biomass organic Ranking cycle \\
bWall & Exterior basement below-grade wall \\
CHP & Combined heat and power \\
CI & Combined intervention \\
CO & Carbon dioxide \\
CT & Cooling tower \\
CV & Control valve \\
DCHP & Diesel combined heat and power \\
DG & Diesel generator \\
DH & District heating \\
DHW & Domestic hot water \\
DSI & Demand-side intervention \\
ECB & Education and Capacity Building \\
EPA & U.S. Environmental Protection Agency \\
ER & Energy retrofit \\
exWall & Exterior above-grade wall \\
$f f B o i l e r ~$ & Fossil fuel boiler \\
HDD & Heating degree day \\
HES & Housing efficiency scenario \\
HEX & Heat exchanger \\
\end{tabular}




$\begin{array}{ll}\text { IESO } & \text { Independent Electricity System Operator } \\ \text { LEB } & \text { Levelized energy benefit } \\ \text { LHD } & \text { Linear heating density } \\ \mathrm{MCV} & \text { Modulating control valve } \\ \mathrm{MVSP} & \text { Main variable speed pump } \\ \mathrm{NO}_{\mathrm{x}} & \text { Nitrogen oxides } \\ \mathrm{NRCan} & \text { Natural resources Canada } \\ \mathrm{OLS} & \text { Ordinary least-squares } \\ \text { O\&M } & \text { Operation and maintenance } \\ \text { ORC } & \text { Organic Rankine cycle } \\ \text { OSB } & \text { Oriented strand board } \\ \text { PER } & \text { Packaged energy retrofit } \\ \text { PM10 } & \text { Particulate matter of less than } 10 \text { micrometer in diameter } \\ \text { SO } & \text { Sulphur dioxide } \\ \text { TC } & \text { Thermal comfort } \\ \text { VSP } & \text { Variable speed pump }\end{array}$

\section{Greek letters}

$\eta_{\text {Boiler }}$

$\eta_{C H P, e}$

$\eta_{C H P, t}$

$\eta_{\text {Diesel }}$

$\sigma_{\text {aes }}$

$\sigma_{p m v}$

$\sigma_{n p v}$

$\alpha_{i}$
Boiler plant thermal efficiency (\%)

Combined heat and power plant electrical efficiency (\%)

Combined heat and power plant thermal efficiency (\%)

Diesel plant electrical efficiency (\%)

Multi-objective annual energy savings weight $(0-1)$

Multi-objective predicted mean vote weight $(0-1)$

Multi-objective net present value weight $(0-1)$

Solution to the multi-objective analysis 


\section{Table of Contents}

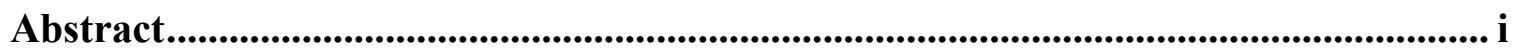

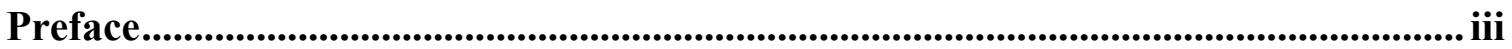

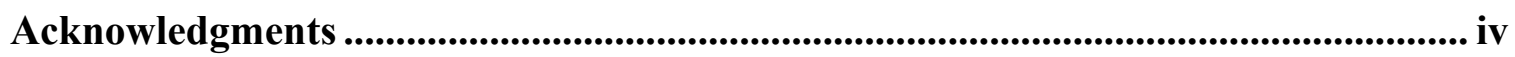

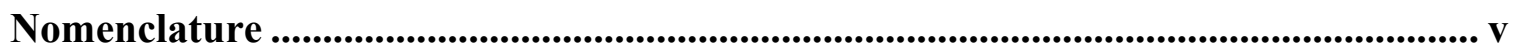

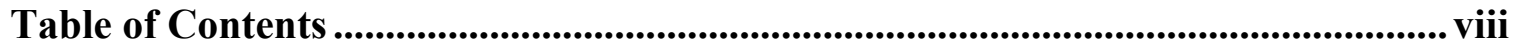

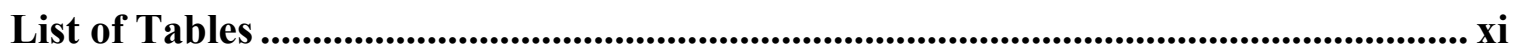

List of Figures................................................................................................................................. xiii

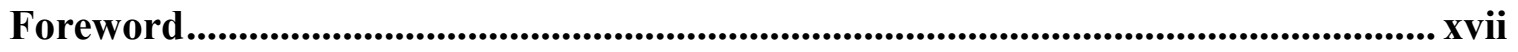

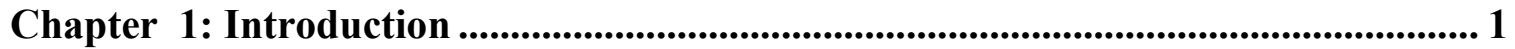

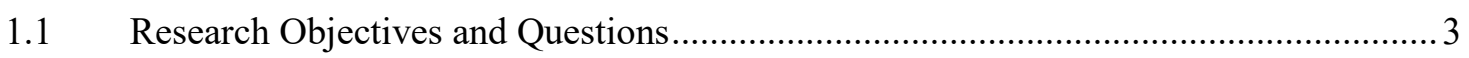

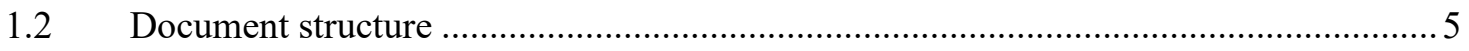

1.3 The MoCreebec Eeyoud community energy system .............................................. 7

Chapter 2: Building-based demand-side interventions: a multi-objective technoeconomic assessment of residential building envelope energy retrofits ..................... 10

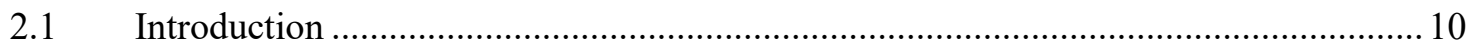

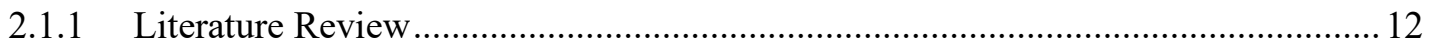

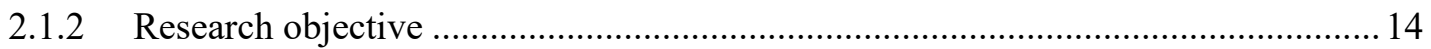

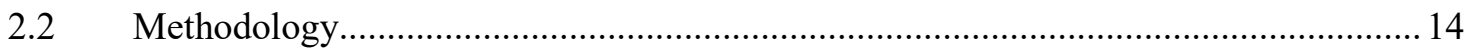

2.2.1 MoCreebec Eeyoud residential building energy models ....................................... 14

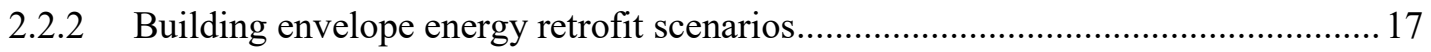

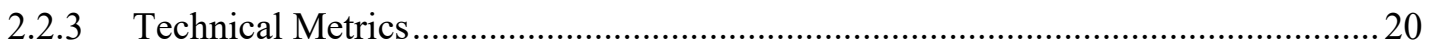

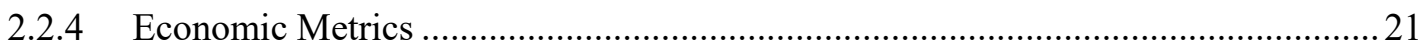

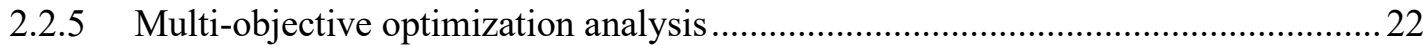

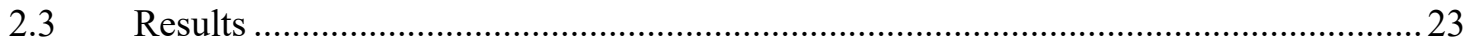




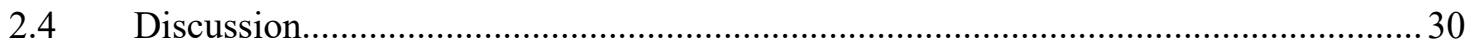

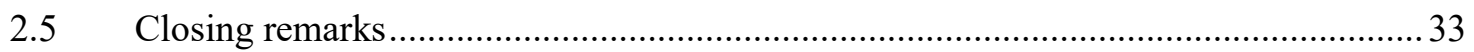

Chapter 3: Supply-side interventions: quantifying the impacts of biomass driven district heating grids ............................................................................................................ 37

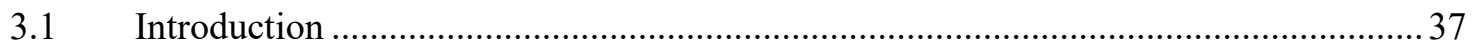

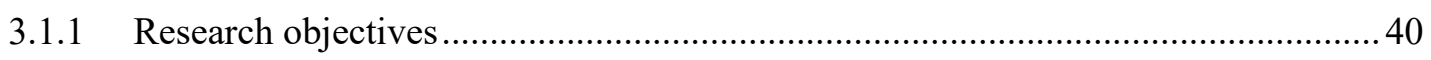

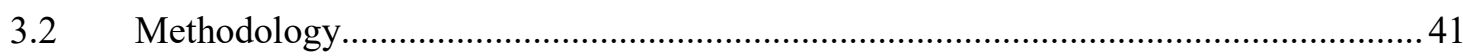

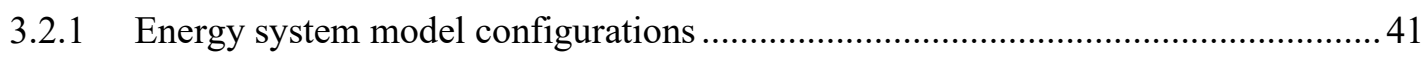

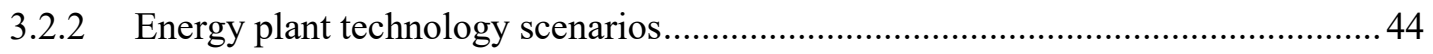

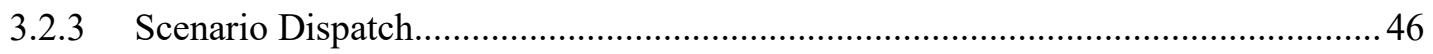

3.2.4 Estimation of community DH grid heat loss and pumping energy requirement ...... 49

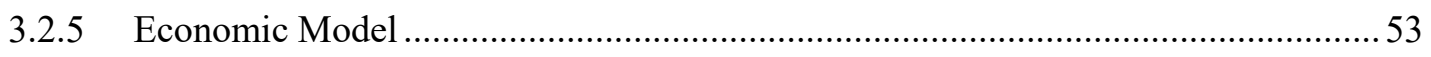

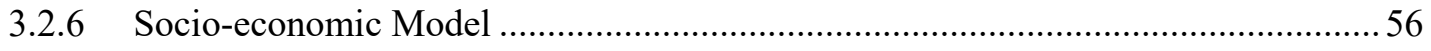

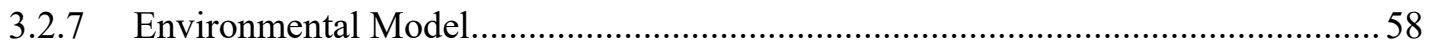

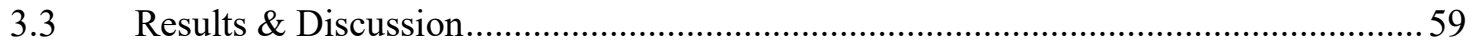

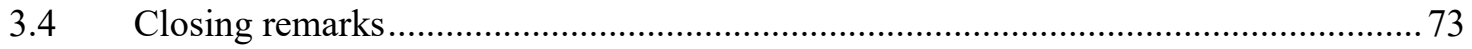

Chapter 4: Towards a cost-effective remote community energy system: the economic trade-offs of building-based DSI implemented within a community-owned biomass

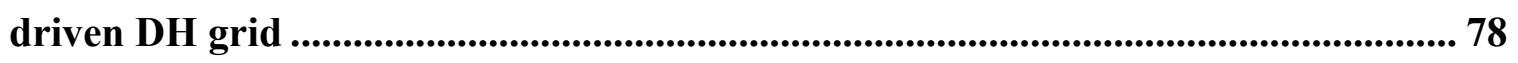

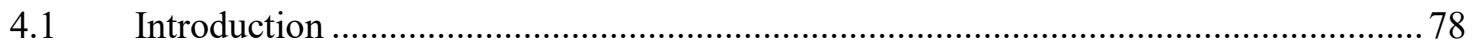

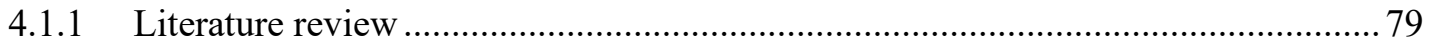

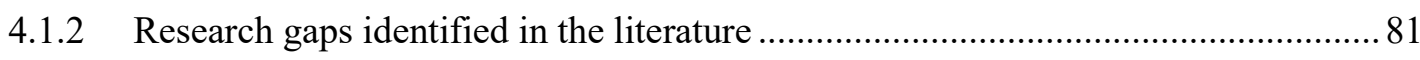

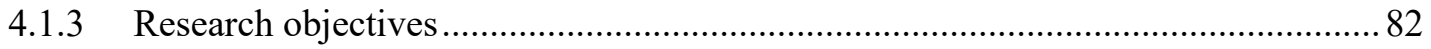

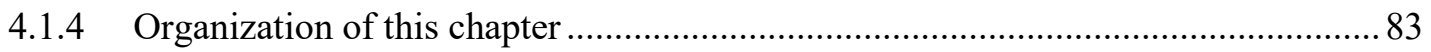

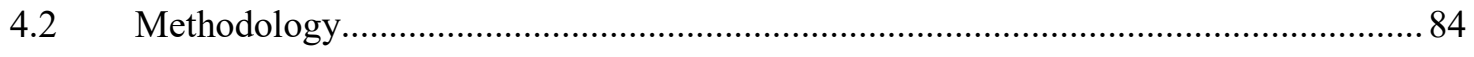

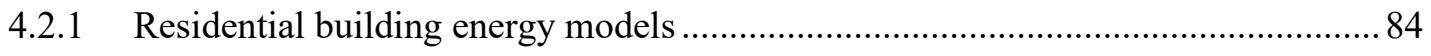


4.2.2 Demand-side interventions within utility-owned energy system - packaged envelope energy retrofits .85

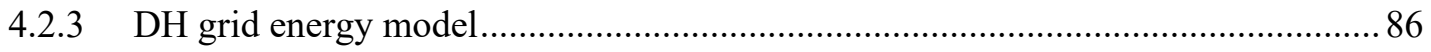

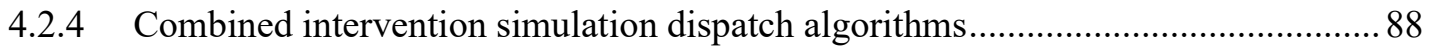

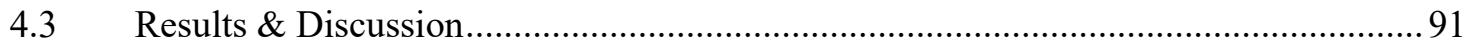

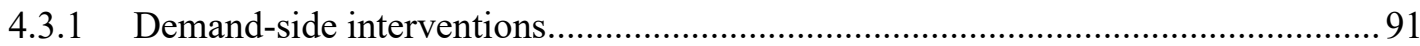

4.3.2 Combined intervention results for community-owned energy system....................97

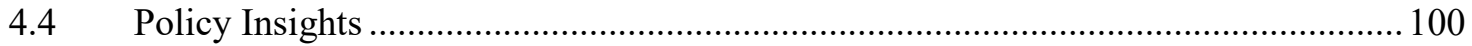

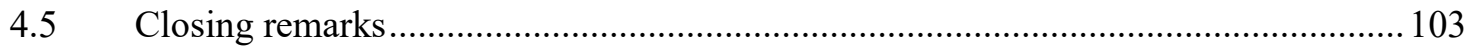

Chapter 5: Summary of contributions ................................................................... 106

5.1 Building-based demand-side interventions: a multi-objective techno-economic

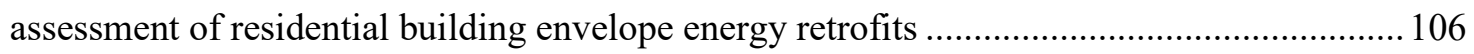

5.2 Supply-side interventions: quantifying the impacts of biomass driven district heating

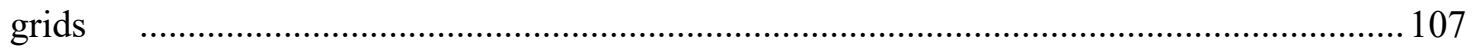

5.3 Towards a cost-effective remote community energy system: the economic trade-offs of building-based DSI implemented within a community-owned biomass driven DH grid........ 109

Chapter 6: Recommendations and future work ..................................................... 111

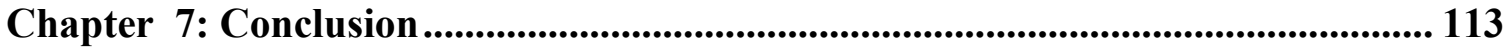

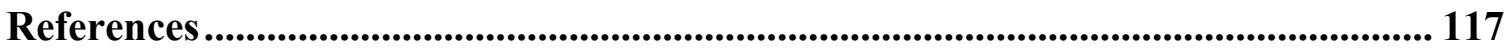




\section{List of Tables}

Table 1-1: MoCreebec Eeyoud residential annual energy use by end-use [16] ............... 8

Table 2-1: Community housing data by building type 16

Table 2-2: Building component construction material details ...................................... 16

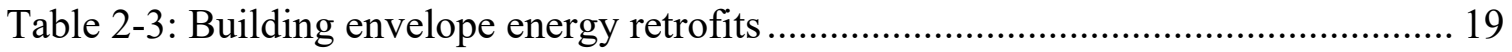

Table 2-4: Economic parameters used in energy retrofit scenarios ................................ 22

Table 2-5: Remote community building retrofit multi-objective optimization results..... 29

Table 3-1: Summary of energy plant technology scenarios. BG and BORC represent biomass gasification and biomass organic Rankine cycle, respectively .................... 45

Table 3-2: Average electrical efficiencies, thermal efficiencies, and CHP heat-to-power ratios for energy plant technologies considered in the current study.........................46

Table 3-3: Fixed inputs to the DH grid model. Parameters are obtained from a typical North American DH grid installation [61], as well as standard specifications for commercially available insulated steel pipes [62]. 53

Table 3-4: Economic parameters used to compare the levelized cost of energy generation for each model scenario considered in the current study. 55

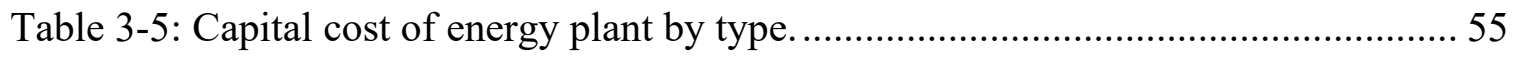

Table 3-6: Capital cost of transmission lines by length and voltage [63]....................... 55

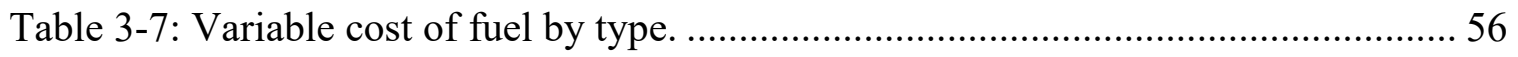


Table 3-8: District heating grid steel piping cost by pipe nominal diameter and length [12].

Table 3-9: Emissions per unit energy output for a variety of fuel types........................ 59

Table 4-1: Envelope insulation value by building component and housing efficiency scenario. Data is obtained from multiple MoCreebec Eeyoud community housing energy audits. 84

Table 4-2: Economic parameters used to compare the NPV from the implementation of building-based DSIs within a utility-owned energy system. 86

Table 4-3: Economic parameters used to compare the NPV from the implementation of building-based DSIs within a community-owned biomass driven $\mathrm{DH}$ grid energy system. 91 


\section{List of Figures}

Figure 1-1: MoCreebec Eeyoud community. Image adapted from Ref [3]. xviii

Figure 2-1: Building archetype profile views. From left to right: detached, semi-detached, and row home 16

Figure 2-2: ENERGY STAR ${ }^{\circledR}$ Canadian climate zones [36]. 20

Figure 2-3: Impact of individual ERs on TC across all PERs comprising the stated ER for a) row homes, b) semi-detached homes, and c) detached homes 24

Figure 2-4: Impact of individual ERs on AES across all PERs comprising the stated ER for a) row homes, b) semi-detached homes and c) detached homes 25

Figure 2-5: Impact of individual ERs on NPV across all PERs comprising the stated ER for a) row homes, b) semi-detached homes, and c) detached homes. 27

Figure 3-1: Energy balance schematic of six distinct energy system model configurations: a) Remote community energy system with electrical heating (M1C1), b) Rural community energy system with electrical heating (M2C1), c) Remote community energy system with DH (M1C2), d) Rural community energy system with DH (M2C2), e) Remote community energy system with DH and CHP (M1C3), f) Rural community energy system with DH and CHP (M2C3). The dotted line and curved arrows in each configuration represent the control volume and energy losses, respectively

Figure 3-2: Scenario dispatch algorithm used for energy system simulation. Labels (i) (vi) correspond to energy system model configurations $\mathrm{M} 1 \mathrm{C} 1-\mathrm{M} 2 \mathrm{C} 3$ in Table 2 in the order stated, respectively. 
Figure 3-3: Schematic representation of MoCreebec Eeyoud district heating grid layout. MCV, CV, VSP, MVSP, HEX, and BETS represent modulating control valve, control valve, variable speed pump, main variable speed pump, heat exchanger, and building energy transfer station, respectively 52

Figure 3-4: Benefits of local biomass fuel production relative to energy imports. 57

Figure 3-5: Levelized energy cost corresponding to energy plant technology scenarios. M1 and M2 represent remote and rural community energy system layouts, respectively.. 60

Figure 3-6: LEC corresponding to proposed rural energy plant technology scenarios as a function of electrical transmission grid extension length. In the current study, construction and maintenance costs associated with the transmission grid extension are not considered. 63

Figure 3-7: Percent change in LEC by energy plant technology scenario as a result of including the levelized energy cost of $\mathrm{CO}_{2}$ emissions, $\mathrm{LEC}_{\mathrm{CO} 2}$, and the levelized energy benefit associated with local biomass fuel production, $\mathrm{LEB}_{\text {localbio, }}$ in the LEC calculation.

Figure 3-8: Percent change in LEC by energy plant technology scenario as a function of a) carbon tax, cTax, and b) percent of biomass feedstock supplied locally, plocal.

Figure 3-9: Percent change in LEC by energy plant technology scenario as a function of a) the discount rate, b) the biomass fuel cost, c) the diesel fuel cost, and d) the grid electricity cost. 70

Figure 3-10: Annual emissions (in tonnes) by energy plant technology scenario of a) $\mathrm{CO}_{2}$, b) $\mathrm{SO}_{2}$, c) $\mathrm{NO}_{x}$, and d) $\mathrm{PM}_{10}$ 72 
Figure 4-1: Combined intervention simulation dispatch algorithm used to assess the economic viability of implementing building-based PERs in remote community based biomass driven DH grids. The algorithm is repeated for each HES: worst, base, and bestcase. 90

Figure 4-2: NPV (in K\$) as a function of AES (MWh) from implementing PERs on the different BEMs (i.e. row, semi-detached, and detached) and HESs (i.e. worst, base, and best) considered in this study. $\mathrm{R}^{2}, \mathrm{y}$-int, $\mathrm{x}$-int(at $\left.\mathrm{y}=0\right)$, and $\mathrm{b}$ represent the coefficient of determination, $\mathrm{y}$-intercept, $\mathrm{x}$-intercept (where $\mathrm{NPV}=0$ ), and regression coefficient, respectively. 93

Figure 4-3: NPV of PERs by BEM (i.e. row, semi-detached, and detached) and HES (i.e. worst, base, and best) as a function of Regional carbon tax rate. 94

Figure 4-4: NPV of PERs by BEM (i.e. row, semi-detached, and detached) and HES (i.e. worst, base, and best) as a function of community energy rate 95

Figure 4-5: Percent decrease in energy system capital cost as a function of the annual energy savings (AES) incurred from implementing a wide range of PERs across each HES and considering three distinct biomass energy plant technologies $(\mathrm{BB}, \mathrm{BG}$, and BORC) 96

Figure 4-6: NPV as a function of the annual energy savings (AES) incurred from implementing a wide range of PERs across each HES and considering three distinct biomass energy plant technologies (BB, BG, and BORC). 98

Figure 4-7: NPV associated with building a DH grid based energy system comprising three distinct biomass energy plant technologies (BB, BG, and BORC) as a function of annual 
heating energy and DH grid length. Corresponding linear heating density (LHD), as well as regions encompassing HES, are also shown for comparison................................ 99 


\section{Foreword}

The MoCreebec Eeyoud community is a rural indigenous community of Cree origin located in northern Ontario, Canada. Approximately 1000 MoCreebec Eeyoud members reside on the island of Moose Factory, which is located near the junction between the Moose river and the bottom tip of James Bay, as depicted in Figure 1-1 [1]. Power to Moose Factory is supplied via an electrical grid that extends roughly $200 \mathrm{~km}$ through dense forest from the closest interconnection point in the South. Outages are typically frequent and longstanding during the winter months as access to these power lines can be extremely difficult for maintenance personnel at this time of year. Due to its far northern location, the community faces steep delivery and regulatory charges imposed by local utilities which leads to exorbitant electricity rates. The community relies almost exclusively on grid electricity for all heating and electrical needs.

Historically, the lack of inexpensive energy sources, combined with aging and degrading housing conditions, and harsh northern winters has resulted in unaffordable energy bills for community residents. It is not uncommon for single family MoCreebec Eeyoud homes to pay sums in excess of $\$ 6,400$ per year for electricity [1]. In an effort to correct these issues, the MoCreebec Eeyoud Chief and Council formed a partnership with Carleton University and initiated a research project in August 2018 focused on sustainable, on-site renewable energy technologies in order to increase local energy security and autonomy. Subsequently, research funding was provided under an Independent Electricity System Operator (IESO) Education and Capacity Building grant (ECB). The IESO-ECB grant was developed to provide funding towards initiatives to support awareness, education, skills, and capacity building around energy related issues [2]. 


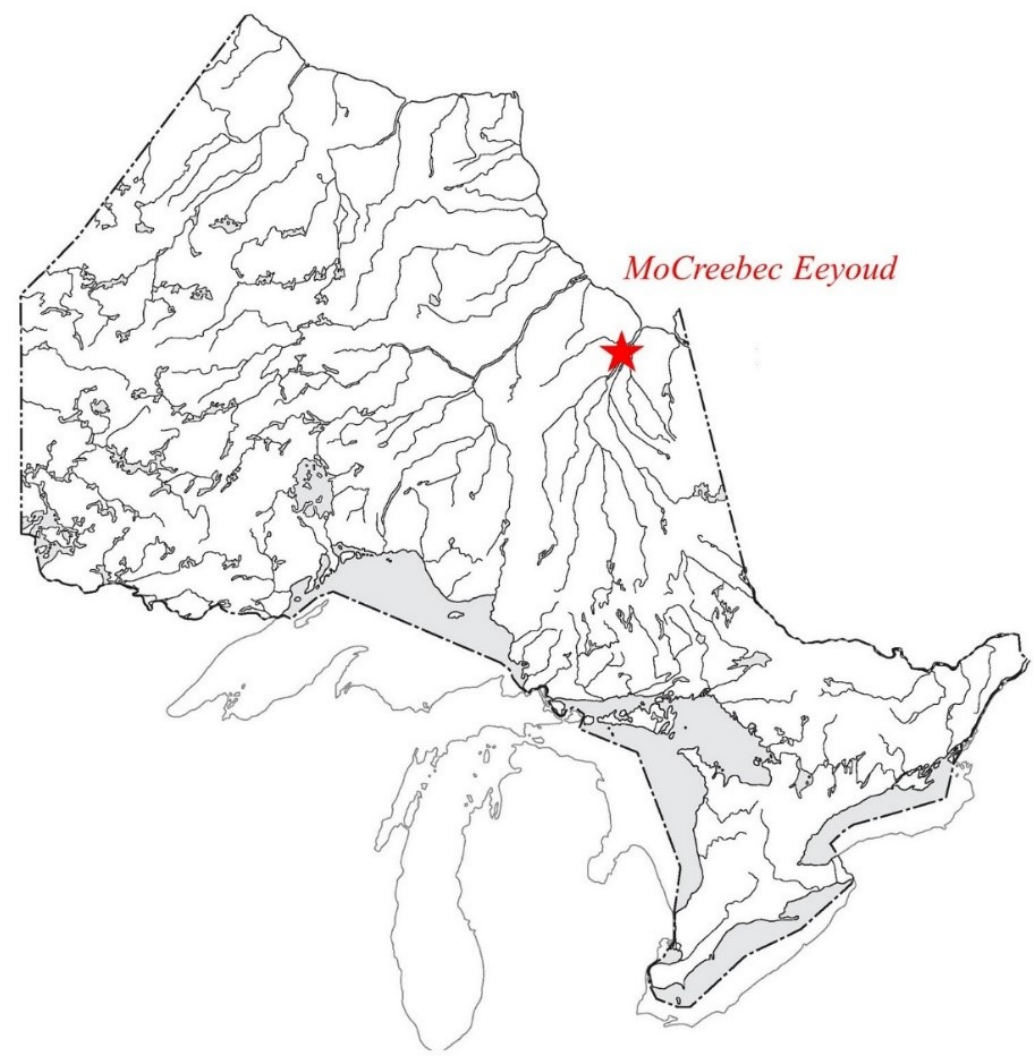

Figure 1-1: MoCreebec Eeyoud community. Image adapted from Ref [3].

The research team included three research assistants Keelia LaFreniere, Joshua Russell, and myself, as well as two Carleton University professors Dr. Jean Duquette and Dr. Stephan Schott. Each research assistant was tasked with their own unique project goals and objectives. Joshua conducted research on energy policy and occupancy behavior, Keelia focused on the integration of wind and solar based renewable energy technologies, while I was tasked with investigating the feasibility of implementing a biomass driven district heating grid as well as residential building-based energy retrofits.

As part of the research project, several site visits to the community by the project team were conducted in order to gather and collect data, build relationships with local residents, and present and share research findings with members of the community and to the MoCreebec Eeyoud Chief and Council. The research project successfully led to several 
contributions such as media interviews, technical reports, conference proceedings, and journal publications. These contributions are as follows:

Journal Publications:

- J. Coady*, and J. Duquette, "Quantifying the impacts of biomass driven combined heat and power grids in northern rural and remote communities," Renewable and Sustainable Energy Reviews [Under Review]

- J. Coady*, and J. Duquette, "Towards a cost-effective remote community energy system model: Evaluating tradeoffs between supply and demand-side interventions," Energy and Buildings [Complete - awaiting submission]

Conference proceedings:

- J. Coady*, and J. Duquette, “A techno-economic assessment of residential building energy retrofits in Canada's remote communities: A case study," in Proc. of IBPSA Canada's eSim 2021, Vancouver, Canada. [Accepted]

\section{Project reports:}

- J. Coady*, K. LaFreniere*, J. Russell*, J.P Chabot, J. Duquette, S. Schott, "Sustainable Energy Options for the Future of MoCreebec Eeyoud - November 2019," Toronto, Canada, Final project report presented at 2019 First Nations Energy Symposium by MoCreebec Eeyoud Chief and Council, 1 Nov. 2019. Available: https://ir.library.carleton.ca/pub/27090/. [Accessed Jul. 20, 2020]

\section{Media interviews:}

- (2018) Energy road map - MoCreebec Eeyoud enlists Carleton students, Carleton University Communications. (https://newsroom.carleton.ca/story/energy-roadmap-mocreebec-eeyoud/). A separate online article was written on the MoCreebec 
Eeyoud energy project in Alternatives Journal.

(https://www.alternativesjournal.ca/community/blogs/green-living/poweringnorth)

Conference presentations:

- J. Coady*, J. Duquette, "Quantifying barriers to district heating grid integration in Canadian rural and remote communities," presented at $8^{\text {th }}$ International Conference \& Exhibition on Clean Energy, Montreal, Canada, 2019. 


\section{Chapter 1: Introduction}

There are currently over 250 remote communities in Canada with a combined population of roughly 194,000 inhabitants [4], [5]. A remote community is defined as a long-term (five years or more) permanent settlement with at least 10 dwellings that has little or no road accessibility, and is not connected to the North American electrical grid, nor to a natural gas pipe network [2]. Historically, the need for energy and the lack of feasible alternatives in these locations forced residents to accept diesel generators as their primary means for delivering electricity and heat to its residents [5], [6]. Annually, the total amount of diesel consumed for electricity and heat generation in these communities amounts to approximately 90 million litres [1]. Although these diesel energy systems are desirable due to their low maintenance, flexibility, and stable operation in extreme climates, they are also the main cause of a number of environmental, social, and economic challenges such as high levels of air pollution and noise, energy insecurity, and high energy costs [5], [6]. The latter of these challenges is especially problematic as it can precipitate other undesirable impacts on communities such as debt accumulation, and local economic stagnation [6], [7]. Rural communities are similar to remote communities in many respects except that they are connected to the North American electrical grid [8]. Current estimates suggest that there are roughly 995 rural communities across Canada [4]. Although rural communities are not as impacted by the detrimental energy system related issues faced by remote communities, they also suffer from steep energy costs due to the exorbitant delivery and regulatory charges that are imposed by local utilities [9]. 
In recent years, significant progress has been made with regards to developing supply and demand-side technology-based interventions that allow remote and rural communities to address these challenges in a manner that is both economically and environmentally feasible. One supply-side intervention that holds considerable promise for a large number of these communities is biomass driven district heating (DH) grids [10]. These systems generate heat from a centralized plant using biomass fuel as the primary feedstock and distribute this heat to community buildings via a DH grid. This district heat is subsequently used for meeting space heating and domestic hot water (DHW) demands [11]. However, a considerable barrier to adopting this technology in isolated communities ${ }^{1}$ is the high capital cost associated with building a DH grid in an isolated setting. DH grid piping installation and trenching cost can average anywhere between $\$ 300$ and $\$ 800$ per meter installed, while building energy plant conversion and connection cost can range from $\$ 7,500$ to $\$ 15,000$ per building [10], [12]. This significant up-front cost can be a major deterrent for isolated community leaders and policymakers and is one of the main reasons why many communities are opting to invest in building-based demand-side interventions (DSI) instead [13]. These DSIs typically involve the implementation of energy efficiency measures that reduce a building's total annual energy consumption [6], [13]. Typical DSIs in this category include building envelope energy retrofits, upgraded energy-efficient electrical appliances, and improved hot water faucets. Apart from reducing total electricity and heating demands at the building level, implementing DSIs can also potentially

\footnotetext{
${ }^{1}$ For the remainder of this thesis, the term "isolated community" is used in reference to both remote and rural communities alike
} 
contribute to reducing the above-mentioned barriers to adopting biomass driven $\mathrm{DH}$ grids at the community level, since the up-front cost of these systems varies significantly as a function of the total community peak heating demand [14], [15]. Potential economic tradeoffs, therefore, exist as a result of integrating the above-mentioned supply and demandside interventions.

However, as of yet little research on the potential economic trade-offs between these two interventions has been studied in great detail in an isolated community energy system setting. Therefore, northern policymakers and community leaders have very little information and data to support their decisions regarding which intervention they should focus their capital investments towards. This could potentially lead to mismanagement or inefficient use of resources and perpetuate an isolated community's already dire financial situation.

\subsection{Research Objectives and Questions}

Given the detrimental energy system related challenges faced by many isolated communities and the lack of clear information and established best practices to tackle energy insecurity, autonomy, and inefficiency in the North, the quantitative evaluation of the impacts of supply and demand-side interventions in isolated community energy systems is the subject of this research. The indigenous community of MoCreebec Eeyoud is used as the case study in the analysis. The major research questions addressed in this integrated thesis are broken down by chapter as follows:

- Building-based demand-side interventions: a multi-objective techno-economic assessment of residential building envelope energy retrofits (Chapter 2): 
$\circ$ What are the most economically attractive building envelope energy retrofits in isolated communities?

- Which building envelope energy retrofit results in the highest annual energy savings and improvements in thermal comfort?

○ How do the techno-economic impacts of building envelope energy retrofits vary by building archetype?

○ Is it preferable to implement multiple building envelope energy retrofits simultaneously in order to optimize thermal comfort, annual energy savings, and project economics?

- Supply-side interventions: quantifying the impacts of biomass DH grids (Chapter 3):

○ Do biomass driven DH grids economically outperform conventional energy systems in isolated communities?

- Which are the most cost-effective biomass energy plant technologies for isolated communities? Are biomass combined heat and power plants preferred over biomass heat-only boilers?

- How do socio-economic factors related to the utilization of locally sourced biomass feedstock impact the economic attractiveness of biomass energy systems?

$\circ$ What are the potential greenhouse gas emission reductions from reconfiguring an isolated community's energy system to a biomass-based energy system? 
- Towards a cost-effective remote community energy system: the economic tradeoffs of building-based DSI implemented within a community-owned biomass driven DH grid (Chapter 4):

- Under which conditions is it preferable to invest in building-based DSIs as opposed to investing in these interventions within a newly built communityowned biomass driven $\mathrm{DH}$ grid?

○ In which ways are the design considerations and capital cost of a newly built community-owned biomass driven DH grid impacted by the implementation of building-based DSIs?

- How does the economic viability of a newly built community-owned biomass driven $\mathrm{DH}$ grid vary as a function of the annual energy savings associated with the implementation of building-based DSIs?

- How do community energy density and DH grid length affect the economic viability of a newly built community-owned biomass driven DH grid?

\subsection{Document structure}

The remainder of this integrated thesis consists of three main body chapters on (1) building-based demand-side interventions, (2) biomass driven DH grid supply-side interventions, and (3) pathways towards a cost-effective remote community energy system, followed by a summary of research contributions, a list of recommendations and areas of future work, and a conclusion. All three chapters utilize the MoCreebec Eeyoud community energy system as the case study in the analysis (a brief overview of the 
MoCreebec Eeyoud community energy system is provided in Chapter 1.3). Each chapter is outlined briefly below:

Chapter 2: This chapter presents a multi-objective techno-economic analysis of residential building-based DSIs in northern isolated communities. Three building energy models (BEM) are developed which correspond to a row, semi-detached, and detached building. The BEMs are created using existing MoCreebec Eeyoud community housing data. To assess the impacts of building-based DSIs, a wide range of packaged envelope energy retrofits (PER) are presented. Finally, a multi-objective techno-economic assessment is presented which describes the impacts of implementing building-based DSIs on occupant thermal comfort, and annual energy savings.

Chapter 3: This chapter evaluates the potential technical, economic, environmental, and socio-economic benefits of implementing biomass driven DH grids in two community energy system layouts commonly encountered in isolated communities in northern Canada. The plant technologies evaluated focus primarily on biomass combined heat and power (CHP) plant technologies. For each energy system, five district heating-based energy plant technologies are assessed which include: a propane boiler plant, a biomass boiler plant, a biomass gasification (BG) CHP plant, a biomass organic Rankine cycle (BORC) CHP plant, and a diesel CHP plant. Annual energy demand distribution data from MoCreebec Eeyoud is utilized in the analysis. Lastly, in order to evaluate the potential benefits of implementing these technologies within an isolated community, results are compared relative to conventional energy plant technologies such as a diesel generator plant, and an electrical transmission grid. 
Chapter 4: This chapter presents an economic evaluation of the impacts of implementing building-based DSIs in community-owned biomass driven DH grids in isolated energy system settings. The methodology presented in Chapter 4 is a continuation of the work described in the two previous chapters. The three residential BEMs developed in Chapter 2 are utilized to represent typical isolated community homes. For each BEM, a worst-case, base-case, and best-case housing efficiency scenario (HES) are presented. To assess the economic impacts of implementing DSIs on these HESs within an isolated utility-owned energy system, the PERs from Chapter 2 are utilized. To assess the economic impacts of implementing PERs within a community-owned centralized biomass energy system, the community-scale biomass driven DH grid model from Chapter 3 is employed. Three distinct biomass plant technologies are investigated: a heat-only biomass boiler, a BG CHP plant, and a BORC CHP plant. A simulation dispatch algorithm is developed to investigate the potential economic benefits of implementing PERs across these three biomass plant technologies. Lastly, several key policy questions are addressed and directed towards isolated community leaders and policymakers who are considering transitioning from a conventional utility-owned energy system to a community-owned biomass driven $\mathrm{DH}$ grid energy system.

Chapters 5-7: These chapters summarize and outline key research contributions, future research work and recommendations, and conclusions in the order stated.

\subsection{The MoCreebec Eeyoud community energy system}

The MoCreebec Eeyoud community is utilized as the case study throughout this thesis. Though the community is not powered via a diesel generator, and would technically be 
considered a rural community, its far northern location, limited road accessibility, and housing stock profile is representative of a typical remote Canadian diesel-powered community, and thus serves as an accurate case study of an isolated community for the aforementioned thesis chapters.

The following is a brief overview of the community's current energy system layout:

- Residential space heating loads in the community are primarily met using electric forced-air furnaces. Although electric baseboard heaters and wood stoves are also employed, their use is limited and thus not considered in the current study.

- Residential DHW heating loads are primarily met using electrically heated tanks.

- Space cooling is not considered in this study as most homes within the community are equipped with heat-only mechanical systems, which is typical of isolated communities in northern Canada.

- The community currently has no DH grid in place.

A breakdown of the total residential annual energy use by end-use for the MoCreebec Eeyoud community for the reference year 2016 is shown Table 1-1. Table 1-1 shows that heating loads account for roughly $61 \%$ of the total annual energy use by end-use.

Table 1-1: MoCreebec Eeyoud residential annual energy use by end-use [16]

\begin{tabular}{ccc} 
End-use (load type) & Energy use (MWh) & Share of total energy use (\%) \\
\hline Electrical plug-in & 1,484 & 39 \\
Space heating & 1,789 & 47 \\
DHW & 527 & 14 \\
Total & 3,800 & 100
\end{tabular}




\section{Chapter 2}

\section{This chapter has been submitted for publication as:}

J. Coady, and J. Duquette, "A techno-economic assessment of residential building energy retrofits in Canada's remote communities: A case study," in Proc. of IBPSA Canada's eSim 2021, Vancouver, Canada. [Accepted] 


\section{Chapter 2: Building-based demand-side interventions: a multi- objective techno-economic assessment of residential building envelope energy retrofits}

\subsection{Introduction}

As stated in Chapter 1, isolated communities face a number of energy system related concerns which often lead to exorbitant electricity rates. The true cost of electricity in many far northern isolated communities can be as high as $\$ 1.14 / \mathrm{kWh}$; this is nearly ten times greater than the average price paid by Canadians [17]. As a result, the cost of electricity in many of these communities is heavily subsidized to reduce the financial burden on the consumer. Electricity subsidies currently account for roughly $74 \%$ of a typical consumer's electricity bill [17]. If these subsidies were instead redirected towards improving a community's building stock, the net effect would potentially lead to a decrease in total annual consumer energy demand. Additional benefits would include an increase in occupant thermal comfort, and a decrease in annual diesel fuel consumption and associated fuel shipments to the community.

Canada has a long history regarding the implementation of residential energy retrofit (ER) incentive programs. One of the most noteworthy and successful of these programs is the home-as-a-system program launched by Natural Resources Canada (NRCan) in April of 1998 [18]. Although the program was marketed under several different names throughout its roughly 13 year duration such as EnerGuide for Houses, or ecoEnergy, the underlining structure of the program essentially remained the same. This program differs substantially from typical list-based incentive programs, in which fixed financial incentives 
are given to specific stand-alone retrofits regardless of building type and location. The home-as-a-system program is more detailed in scope and comprises a three-step process. The first step involves a personalized home energy audit conducted by a home energy advisor. Advisors then create an energy model of the building using building simulation software (often HOT2000 [19]). The second step involves creating a custom-tailored packaged list of recommended home ERs from the information gathered from the energy model. The homeowner, with the assistance of an advisor, is then able to act on any number of the ERs recommended within the package. The final step involves a follow-up evaluation to assess the effectiveness of the ERs, which is required to occur within 18 months of the ERs being implemented [20], [21].

The home-as-a-system program and other similar programs have been extensively studied by several researchers and were found to be highly effective at promoting customer participation and reducing annual energy use [20]-[22]. Hoicka \& Parker [21] wrote "when homeowners make decisions based on the home-as-a-system approach and act on the totality of advice given to them, it is more likely that greater energy and greenhouse gas savings will be achieved". Similarly, Gamtessa [20] wrote "high ratios of pre-retrofit to post-retrofit energy consumption and cost generally correspond to homeowners undertaking more upgrades". The conclusions of these studies are straightforward; the more custom-tailored ERs applied to a home, the more energy savings will be achieved. Unfortunately, for these programs to be implemented successfully they require a home energy advisor to complete personalized home energy evaluations for all participants. This can be both costly and time consuming, especially in an isolated community setting. 


\subsubsection{Literature Review}

A number of studies have investigated the cost and energy saving potential from implementing several individual and/or packaged residential building ERs. An early study by Cohen, Goldman, and Harris [23] assessed energy and cost savings from retrofitting a typical single-family home in northern USA. Both individual and packaged retrofit options were considered in the study, and the retrofit performance was assessed based on pre and post-construction cost and metered data. Increasing ceiling and wall insulation levels were found to be the most cost-effective envelope retrofit with energy savings ranging from 12$21 \%$. Upgrading windows was found to be the least cost-effective retrofit with energy savings ranging from 2-5\%. Another study by Guler et al. [24] compared the economic feasibility and annual energy savings of a wide range of ERs in the Canadian housing stock. The researchers modelled a number of homes with the modelling software HOT2000 using surveyed housing energy consumption data from 1993. They found that only minimal energy savings of approximately $0-8 \%$ were possible across the ERs considered. Upgraded basement wall insulation and windows were identified as being the most and least effective at reducing annual energy savings, respectively.

Oberegger, Pernetti, and Lollini [25] developed calibrated bottom-up building models to estimate the cost and energy savings from implementing individual and packaged ERs in several homes located in northern Italy. The researchers subdivided the homes in terms of size, age, and location, and used the modelling software PHPP [26] to estimate the energy savings incurred. They found that façade and roof insulation upgrades were the highest priority ERs with respect to both annual energy savings and project cost. Asadi et al. [27] conducted a study in which they developed a multi-objective optimization model 
to assess the feasibility of several residential building energy retrofits for a single-family home located in Portugal. The objective of the study was to identify the most optimal building energy retrofit packages which offered the highest energy savings at the lowest cost. They found that packages with high levels of added exterior wall insulation and minimal upgrades to both window and roof insulation led to the most economically feasible scenarios. Streicher et al. [28] completed a thorough analysis of over 6000 recently renovated homes in Switzerland to assess the techno-economic impact of implementing individual and combined ER packages. The retrofitted homes were part of an energy efficiency program in which households were given suggested retrofits by home energy advisors. Although the advisors prioritized upgrading exterior building façade insulation, results showed that these retrofits were not cost-effective over their projected lifetime. The most cost-effective retrofits included increased insulation on unheated slabs and upgraded windows. Hoicka \& Parker [22] conducted a survey-based study in which they asked several Canadian home energy advisors which residential building energy retrofits they recommended to the majority of clients. Their recommendations in order of decreasing importance were air sealing, increased attic/roof insulation, increased basement insulation, increased exterior wall insulation, upgraded windows, and installation of high-efficiency mechanical systems [22].

The studies discussed above, whether they are based on expert recommendations, modelling predictions, or post-retrofit data analysis, demonstrate that there are no clear building ERs that are consistently superior to others across different building types and climate regions. The techno-economic feasibility of the retrofits considered in these studies vary substantially based on building type, envelope construction, age, and location, as well 
as the cost and performance of the ERs themselves. Moreover, the majority of homes assessed in these studies utilize both heating and cooling systems and are located in relatively mild climates. To the authors' knowledge, no other studies have been conducted to assess the techno-economic impacts of residential home ERs in communities located in northern heating-only climates.

\subsubsection{Research objective}

The objective of this study is to conduct a multi-objective techno-economic assessment of a wide range of building ERs on a subset of building archetypes commonly found in northern Canadian isolated communities. The multi-objective techno-economic assessment will aim to identify the most economically feasible packaged energy retrofits (PER), with the largest increases in both annual energy savings and thermal comfort. Both remote (i.e. off-grid) and rural (i.e. grid-connected) community energy systems are investigated. The EnergyPlus $^{\mathrm{TM}}$ [29] building performance simulation tool is used to construct the building energy models. For each building archetype, optimal PERs are identified that maximize energy savings, thermal comfort, and project economics. These PERs are useful to policymakers and community leaders in isolated communities who can potentially use them for the planning of future residential housing stock and/or ER incentive programs.

\subsection{Methodology}

\subsubsection{MoCreebec Eeyoud residential building energy models}

A large number of MoCreebec Eeyoud community homes were built in the early 1990s, and consist primarily of detached, semi-detached, and row homes. Archived construction drawings for each of these building types were collected from the community 
and used to develop three building energy models (BEM) in EnergyPlus ${ }^{\mathrm{TM}}$ (see Figure 2-1 and Table 2-1 for building profile views and housing data). As all homes in this study were built roughly during the same period and by the same builder, there was little to no variation in the construction materials used. Envelope construction specifications are shown in Table 2-2. Construction specifications and envelope details are taken directly from archived constructions drawings of MoCreebec Eeyoud community buildings. Through several site visits to the community, it was determined that little to no retrofitting has been done since the time of construction, and therefore the original construction drawings serve as accurate documentation to build the building energy models. Based on blow-door test complete on several community buildings, air leakage rates and effective leakage areas are assumed to be 3.19 air-change/hour (at $50 \mathrm{~Pa}$ ) and $443.03 \mathrm{~cm}^{2}$, respectively. All material thermal properties are taken from the National Renewable Energy Laboratory - Building Component Library [30]. As the current study focuses exclusively on building envelope retrofits, improvements in air-tightness and building mechanical systems are neglected. The buildings' mechanical heating systems consist of a $15 \mathrm{~kW}$ electric forced-air furnace with an outdoor-air heat recovery ventilator. Occupant-based passive cooling control is employed in the cooling season: when zone temperatures exceed $24^{\circ} \mathrm{C}$, windows are opened and slated blinds are shut. Each building had a total of four occupants. Though the national building code suggest that the number of occupants within residential building energy models be equal to the number of bedrooms plus one [31]; through several interviews with members of the MoCreebec Eeyoud community, four occupants more appropriately matches their specific living standards . 

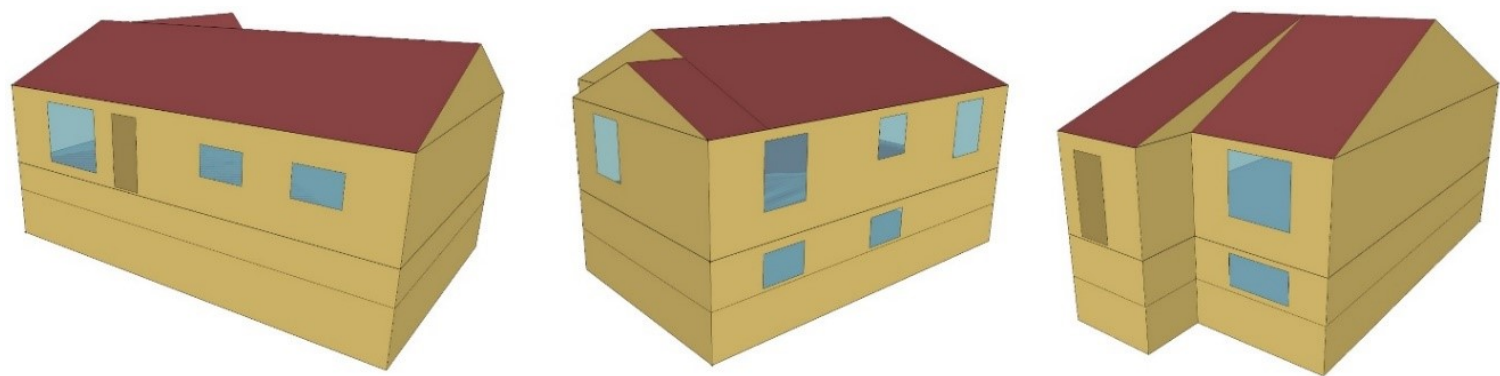

Figure 2-1: Building archetype profile views. From left to right: detached, semidetached, and row home

Table 2-1: Community housing data by building type

\begin{tabular}{cccccc} 
Building Type & $\begin{array}{c}\text { Floor } \\
\text { Area }\left(\mathbf{m}^{\mathbf{2}}\right)\end{array}$ & $\begin{array}{c}\text { Window } \\
\text { Area }\left(\mathbf{m}^{\mathbf{2}}\right)\end{array}$ & $\begin{array}{c}\text { No. of } \\
\text { Doors }\end{array}$ & $\begin{array}{c}\text { Year } \\
\text { Built }\end{array}$ & $\begin{array}{c}\text { Proportion within } \\
\text { the community* (\%) }\end{array}$ \\
\hline Detached & 206 & 9.5 & 2 & 1990 & 28 \\
Semi-detached & 175 & 12.4 & 1 & 1992 & 56 \\
Row & 143 & 8.8 & 1 & 1990 & 16 \\
\hline
\end{tabular}

* estimated based on MoCreebec Eeyoud housing energy audits

Table 2-2: Building component construction material details

\begin{tabular}{|c|c|c|}
\hline $\begin{array}{l}\text { Building } \\
\text { Component }\end{array}$ & $\begin{array}{l}\text { Material components (from exterior to } \\
\text { interior) }\end{array}$ & $\begin{array}{c}\text { Insulation } \\
\text { Value }\left(\mathbf{m}^{2} \mathbf{K} / \mathbf{W}\right)\end{array}$ \\
\hline Attic floor & Gypsum board, wood stud, batt insulation $(0.3 \mathrm{~m})$ & 6.10 \\
\hline Main level floor & $\begin{array}{l}\text { Gypsum board, wood stud, oriented strand board } \\
\text { (OSB) sheathing, vinyl flooring }\end{array}$ & 0.24 \\
\hline $\begin{array}{l}\text { Above-grade } \\
\text { exterior wall }\end{array}$ & $\begin{array}{l}\text { Vinyl siding, OSB sheathing, wood stud, batt } \\
\text { insulation }(0.152 \mathrm{~m}) \text {, gypsum board }\end{array}$ & 3.26 \\
\hline $\begin{array}{l}\text { Above-grade } \\
\text { portioning wall }\end{array}$ & $\begin{array}{l}\text { Gypsum board, wood stud, batt sound insulation } \\
(0.152 \mathrm{~m}) \text {, gypsum board }\end{array}$ & 3.25 \\
\hline $\begin{array}{l}\text { Below-grade } \\
\text { basement wall }\end{array}$ & $\begin{array}{l}\text { Reinforced concrete, wood stud, batt insulation } \\
(0.102 \mathrm{~m})\end{array}$ & 2.79 \\
\hline Basement floor & Reinforced concrete slab-on grade $(0.102 \mathrm{~m})$ & 0.34 \\
\hline Windows & Double glazed wood sliders & $0.41^{\mathrm{a}}$ \\
\hline Doors & Insulated steel door & $0.54^{\mathrm{a}}$ \\
\hline
\end{tabular}

${ }^{\text {a }}$ Insulation values are obtained from various MoCreebec Eeyoud community home energy audit reports 
All building models are subdivided into three zones: basement, main level, and attic. It is assumed that the thermal mass of internal objects (e.g. walls, furniture, etc.) and air transfer in-between zones is negligible. Latent and sensible loads of the casual internal gains (such as appliance and lighting loads, as well as occupant metabolic rates) are obtained from ASHRAE's Handbook of Fundamentals [32], and are scheduled based on typical residential schedules obtained from COMNET codes and standards [33]. Occupant metabolic rate is modelled to vary as a function of time from $70 \mathrm{~W}$ (in the morning and at night) to $160 \mathrm{~W}$ (in the afternoon). For specific details on both casual gains and schedules refer to Appendix A Table A-1. Although these assumptions oversimplify temporal heat and mass transfer processes during simulation, and as a result may lead to increased error in energy use and thermal comfort results, they are deemed warranted as 1) the assumptions are constant for all scenarios and thus relative changes from implementing ERs will be reflected accordingly, and 2) model complexity and corresponding simulation run-time are reduced considerably enabling a larger dataset to be assessed in the study.

\subsubsection{Building envelope energy retrofit scenarios}

The list of building envelope ERs considered in this study is shown in Table 2-3. The packaged energy retrofits (PER) comprise every single packaged combination of these retrofits implemented on the base case models of all three building types, amounting to a total of 324 PERs per building type. An iterative simulation process is conducted using the python v3.8.0 $i d f$ editing package Eppy [34]. EnergyPlus $i d f$ files are first edited by the Eppy script to implement the desired energy retrofit scenario. The newly edited idf file is then run in EnergyPlus and the results are stored in a separate folder. 
The ERs are based on the ENERGY STAR ${ }^{\circledR}$ for New Homes Standard program [35]. This program is a collaboration between NRCan and ENERGY STAR ${ }^{\circledR}$ that promotes energy efficiency of new homes built in Canada through an accreditation process that certifies homes that meet predetermined minimum standards. Minimum insulation envelope standards vary depending on the region. The program subdivides Canada into several climate zones based on their annual heating degree days (HDD) as shown in Figure 2-2. Annual HDDs (as defined by NRCan) represent the annual sum of all daily HDDs, which are equivalent to the number of degrees Celsius a given day's mean temperature is below $18^{\circ} \mathrm{C}$ [35]. The MoCreebec Eeyoud community is located in climate Zone 3 (equivalent to ASHRAE climate zone 7-8). For the purposes of this study, the authors only analyze the impact of upgrading envelope insulation to ENERY STAR ${ }^{\circledR}$ climate Zones 2 (equivalent to ASHRAE climate zone 6-7) and 3, as climate zone 1 is only applicable to a small region in southern British Columbia. Climate zones are indicated for each retrofit as a subscript of the retrofit labels (i.e. column 2) shown in Table 2-3. For example, the label exWall $z 2$ is representative of exterior walls that meet ENERGY STAR ${ }^{\circ}$ climate Zone 2 minimum insulation requirements. Building component labels that correspond to the base case (i.e. pre-retrofit) buildings are indicated with the subscript "BC" (not shown in Table 2-3)

Column 4 of Table 2-3 indicates the cost of the ER which has been extrapolated from the RSMeans construction database, and adjusted for northern Ontario prices using the RSMeans location factor correction data sheet [36]. The costs shown accounts for all phases of the construction process. For example, the cost associated with the exWallzz retrofit 
includes the removal of the existing vinyl siding, the installation of the added rigid board insulation, and the reinstallation of new vinyl siding.

Table 2-3: Building envelope energy retrofits

\begin{tabular}{|c|c|c|c|}
\hline $\begin{array}{c}\text { Building } \\
\text { Component }\end{array}$ & $\begin{array}{c}\text { Retrofit } \\
\text { label }\end{array}$ & Retrofit description & $\begin{array}{c}\text { Cost } \\
\left(\$ / \mathbf{m}^{2}\right)\end{array}$ \\
\hline \multirow{2}{*}{$\begin{array}{l}\text { Above-grade } \\
\text { exterior walls }\end{array}$} & exWall $\mathrm{Z2}$ & Add exterior wall rigid board insulation: $57.15 \mathrm{~mm}$ & 77.6 \\
\hline & exWallz3 & Add exterior wall rigid board insulation: $69.85 \mathrm{~mm}$ & 80.8 \\
\hline \multirow{2}{*}{$\begin{array}{l}\text { Below-grade } \\
\text { basement walls }\end{array}$} & bWall 22 & Add interior wall rigid board insulation: $12.7 \mathrm{~mm}$ & 42.3 \\
\hline & bWall $\mathrm{Z3}$ & Add interior wall rigid board insulation: $38.1 \mathrm{~mm}$ & 47.6 \\
\hline \multirow{2}{*}{ Basement floor } & bFloorz2 & Add floor rigid board insulation: $57.15 \mathrm{~mm}$ & 71.9 \\
\hline & bFloorz3 & Add floor rigid board insulation: $120.65 \mathrm{~mm}$ & 90.6 \\
\hline \multirow{2}{*}{ Attic floor } & aFloorz2 & Increase batt insulation: $431.8 \mathrm{~mm}$ & 26.0 \\
\hline & aFloorz3 & Increase batt insulation: $433.4 \mathrm{~mm}$ & 28.6 \\
\hline Door & door $_{Z 3}$ & $\begin{array}{l}\text { Replace door(s) with high-efficiency door(s): U- } \\
\text { factor: } 1.2 \mathrm{~W} / \mathrm{m}^{2} \mathrm{~K}\end{array}$ & $\$ 531 /$ unit \\
\hline Window & windowz3 & $\begin{array}{l}\text { Replace window(s) with high-efficiency window(s): } \\
\text { U-factor: } 1.2 \mathrm{~W} / \mathrm{m}^{2} \mathrm{~K}\end{array}$ & $\$ 515 /$ unit \\
\hline
\end{tabular}




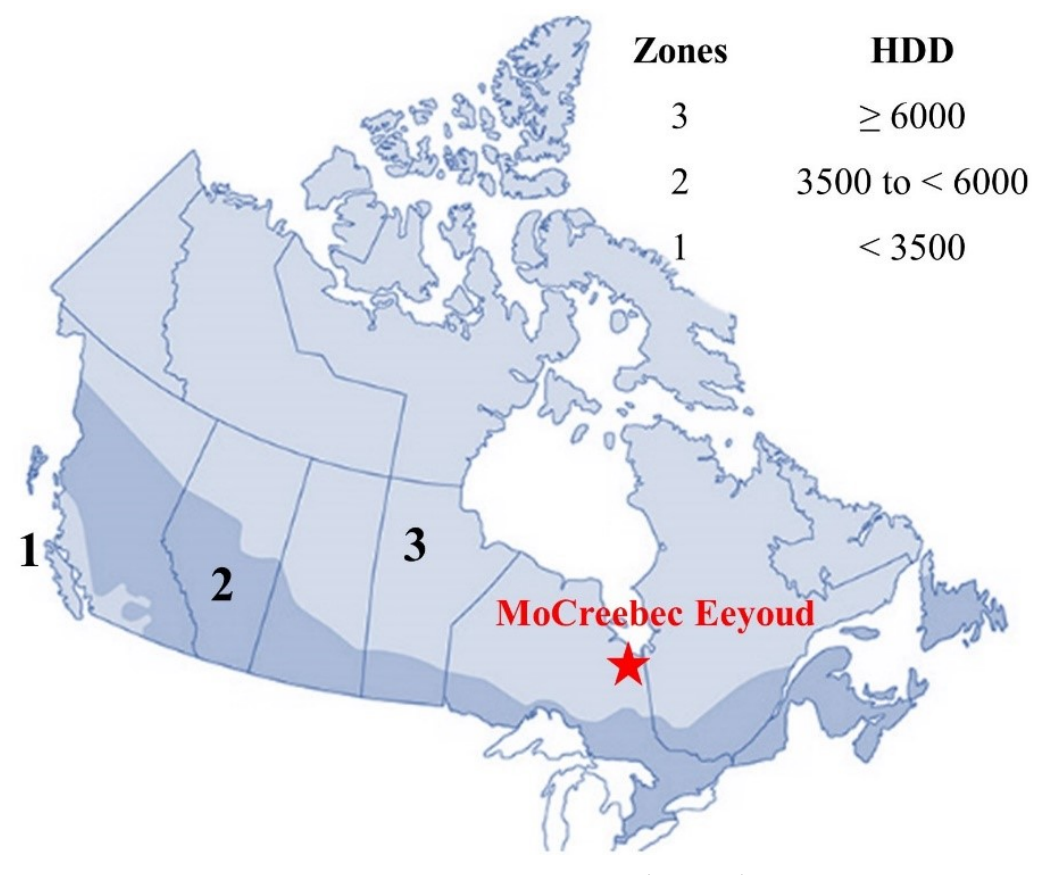

Figure 2-2: ENERGY STAR® Canadian climate zones [37]

\subsubsection{Technical Metrics}

Annual energy savings (AES) and thermal comfort (TC) are used as the metrics to assess the technical performance of each PER in this study. The annual energy savings by PER is calculated using the following equation:

$$
A E S_{i}=A E_{\text {pre-retrofit }}-A E_{\text {post-retrofit }, i}
$$

where, $A E S_{i}$ is the annual energy saved by PER $i, A E_{\text {pre-retrofit }}$ and $A E_{\text {post-retrofit }}$ are the annual energy (AE) consumptions for the base case and post-retrofit PER $i$, respectively.

Thermal comfort is measured using the Fanger comfort model [38]. This model is widely used amongst practitioners and has been adopted by ASHRAE 55 [39]. The Fanger comfort model uses the occupants predicted mean vote (PMV) to quantify the level of discomfort experienced. PMV scores TC on a scale from -3 (too cold) to 3 (too hot); with a score of 0 being ideal TC. The score is generated by the EnergyPlus People object. The 
object requires many user inputs from the modeller such as occupant presence, metabolic rate, and zone air velocity. Occupant presence and metabolic rate are input as fixed schedules (as discussed in Chapter 2.2.1) and zone air velocity is assumed to be constant at $0.1 \mathrm{~m} / \mathrm{s}$. The latter assumption is supported through a sensitivity analysis conducted by the author with a range of published residential indoor air velocities [40] and found very little deviation in TC. A notable difficulty in comparing the TC across PMV scores, is that the PMV scale views a score of -1 and +1 to be as equally uncomfortable. To overcome this issue, the annual mean squared PMV score $\left(\overline{P M V}_{i}^{2}\right)$ is used as the TC indicator for each PER in this study.

\subsubsection{Economic Metrics}

The net present value (NPV) is used as the metric to assess the economic performance of each PER in this study. The NPV is a measure of the current value of a project over its expected lifetime considering all project cash flows and the time value of money. A positive NPV implies that a project is economically feasible, whereas a negative NPV implies that a project is not economically feasible. The NPV is expressed as

$$
N P V_{i}=\sum_{j=0}^{n} \frac{\left(\text { Benefit }_{i}-\text { Cost }_{i}\right)_{j}}{\left(1+i_{d}\right)^{j}}
$$

where $i, j, n(\mathrm{yr})$, and $i_{d}(\%)$ represent the PER $i$, the year, the total lifetime of the project, and the discount rate, respectively. $\operatorname{Cost}_{i}(\$)$ and Benefit $(\$)$ represent the total PER capital cost (only applied at year 0), and the annual cost savings, respectively. The latter term is expressed as

$$
\text { Benefit }_{i}=A E S_{i} \cdot\left(C f+c T a x \cdot \frac{c E m m}{\eta_{e s}}\right)
$$


Table 2-4: Economic parameters used in energy retrofit scenarios

Economic cost parameters

$\begin{array}{cc}C f_{\text {remote }} & 32 \$ / \mathrm{kWh}^{\mathrm{a}} \\ C f_{\text {rural }} & 14 \$ / \mathrm{kWh}^{\mathrm{b}} \\ c E m m_{\text {remote }} & 255 \mathrm{~kg} / \mathrm{MWh}^{\mathrm{c}} \\ c E m m_{\text {rural }} & 31 \mathrm{~kg} / \mathrm{MWh}^{\mathrm{d}} \\ \text { cTax } & 20 \$ / \mathrm{tCO}_{2}^{\mathrm{e}} \\ \eta_{\text {es,remote }} & 27 \%^{\mathrm{c}} \\ \eta_{\text {es }, \text { rural }} & 100 \%{ }^{\mathrm{f}}\end{array}$

a The average unsubsidized energy rate paid in northern remote communities in Canada [5]

$\mathrm{b}$ The weighted average energy rate (including regulatory and delivery charges) paid in northern rural communities in Ontario, Canada [41]

c The average $\mathrm{CO}_{2}$ emission intensity and efficiency of a typical diesel generator plant [42], [7]

$\mathrm{d}$ The average $\mathrm{CO}_{2}$ emission intensity of the Ontario electrical grid [43]

e The current Canadian federal government carbon tax [44]

f Transmission and distribution line losses of the electrical grid are neglected

where $C f(\$ / \mathrm{MWh})$ and $c E m m\left(\mathrm{tCO}_{2} / \mathrm{MWh}\right)$ represent the community energy rate, and the $\mathrm{CO}_{2}$ emission intensity of the community's energy system, respectively. cTax $\left(\$ / \mathrm{tCO}_{2}\right)$ and $A E S_{i}(\mathrm{MWh})$ represent the regional carbon tax rate, and the annual energy savings from implementing the PER, respectively. Lastly, $\eta_{e s}(\%)$ is the electrical efficiency of the energy system. Assumed values for all economic parameters are shown in Table 2-4.

\subsubsection{Multi-objective optimization analysis}

The technical and economic metrics noted in chapters 2.2.3 and 2.2.4 are used to develop the following multi-objective problem statement:

- Maximize $\{A E S\}$

- Maximize $\{N P V\}$, while ensuring $N P V>0$

- Minimize $\left\{\overline{P M V}^{2}\right\}$

Although meeting all three objectives would, in theory, lead to optimal PERs, these objectives often conflict with one another (i.e. higher NPVs do not necessarily correlate to higher AES and/or lower $\overline{P M V}^{2}$ values). Building upon previous work conducted by Asadi 
et al. (2012), the Tchebycheff method (otherwise known as the weighted min-max method) is used to solve the multi-objective problem stated above. The method is programmed in the python environment and formulated using the following set of equations:

$$
\begin{gathered}
\operatorname{Min}\left\{\alpha_{i}\right\} \\
\alpha_{i} \geq\left(A E S_{\text {max }}-A E S_{i}\right) \cdot\left(\sigma_{\text {aes }} / A E S_{\text {max }}\right) \\
\alpha_{i} \geq\left(\overline{P M V}^{2}-{\overline{P M V_{\text {min }}}}^{2}\right) \cdot\left(\sigma_{p m v} / \overline{P M V}_{\text {min }}^{2}\right) \\
\alpha_{i} \geq\left(N P V_{\text {max }}-N P V_{i}\right) \cdot\left(\sigma_{\text {npv }} / N P V_{\text {max }}\right) \\
\alpha_{i} \geq 0 \\
\sigma_{\text {aes }}+\sigma_{p m v}+\sigma_{\text {npv }}=1
\end{gathered}
$$

where $A E S_{\max }$, and $N P V_{\max }$ represent the maximum AES and NPV, respectively, and $\overline{P M V}_{\min }^{2}$ represents the minimum $\overline{P M V}^{2}$ value across all PERs. Parameters $\sigma_{a e s}, \sigma_{p m v}$ and $\sigma_{n p v}$ are the weights of each objective. These weights can be adjusted depending on the relative importance of each objective. $\alpha$ is calculated for each PER $i$, and the PER with the lowest $\alpha_{i}$ value is considered to be the 'non-dominant' solution to the multi-objective problem. That is, there exists no other PER that can optimize any one objective (e.g. maximize AES, maximize NPV and/or minimize $\overline{P M V}^{2}$ ) without negatively impacting another objective [27].

\subsection{Results}

Figures 2-3 through 2-5 show the impact of individual ERs on TC, AES, and NPV, respectively, across all PERs comprising each stated ER. Each box plot shown in these figures represents a statistical distribution of results obtained across a given PER and 
indicates the minimum, lower quartile, median, upper quartile, and maximum values obtained, from bottom to top, respectively.

a) Row

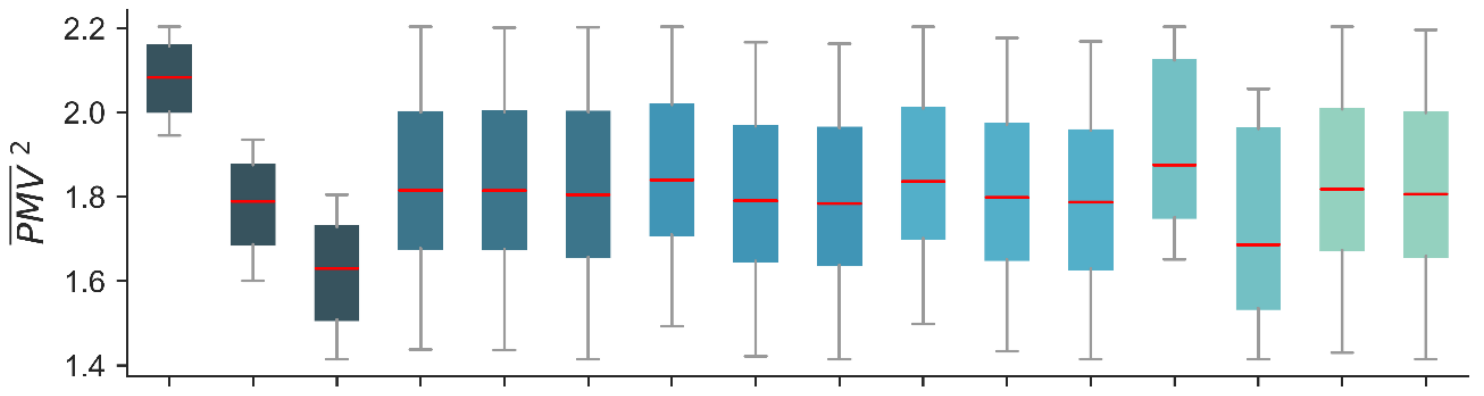

a) Semi-detached

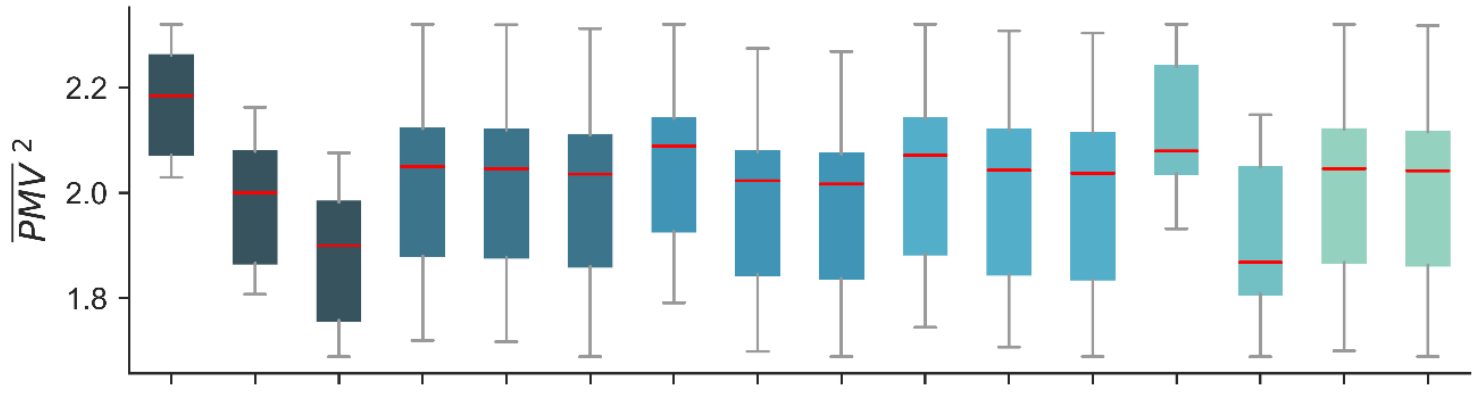

a) Detached

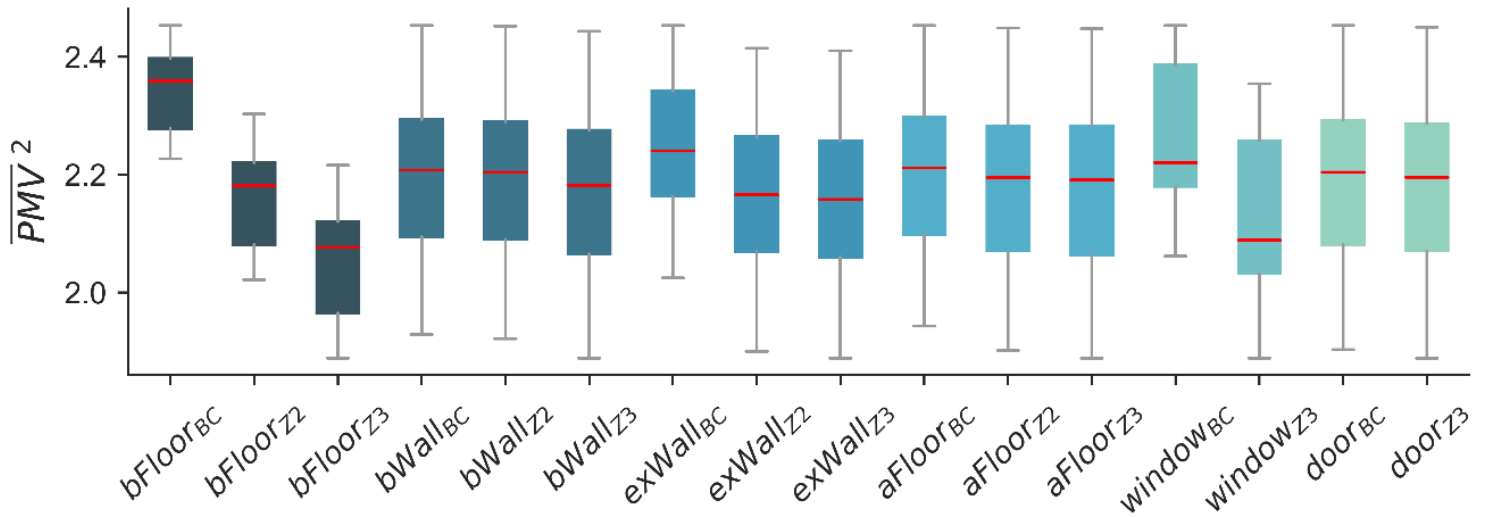

Figure 2-3: Impact of individual ERs on TC across all PERs comprising the stated ER for a) row homes, b) semi-detached homes, and c) detached homes 
a) Row

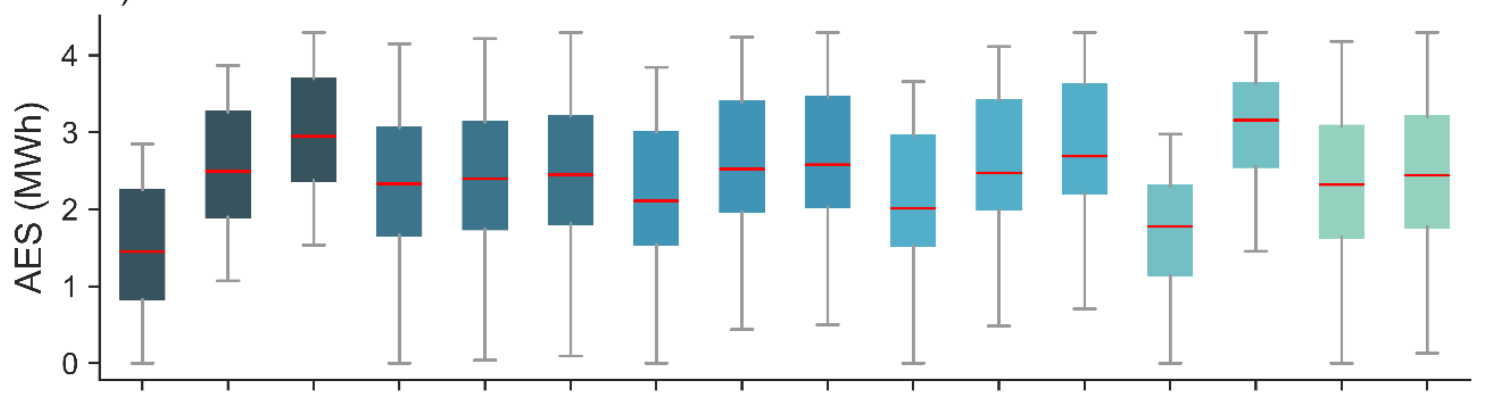

a) Semi-detached

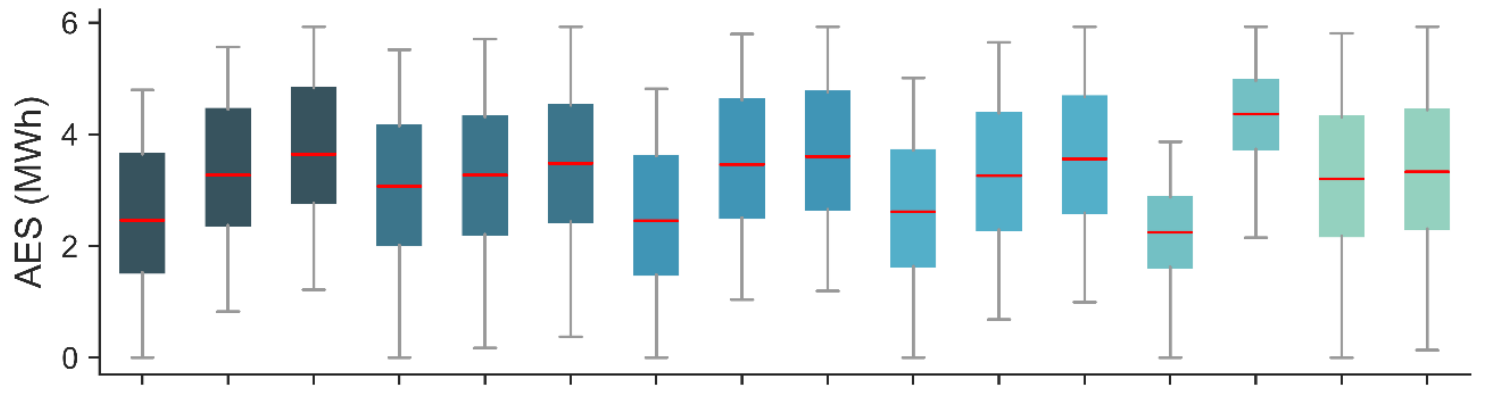

a) Detached

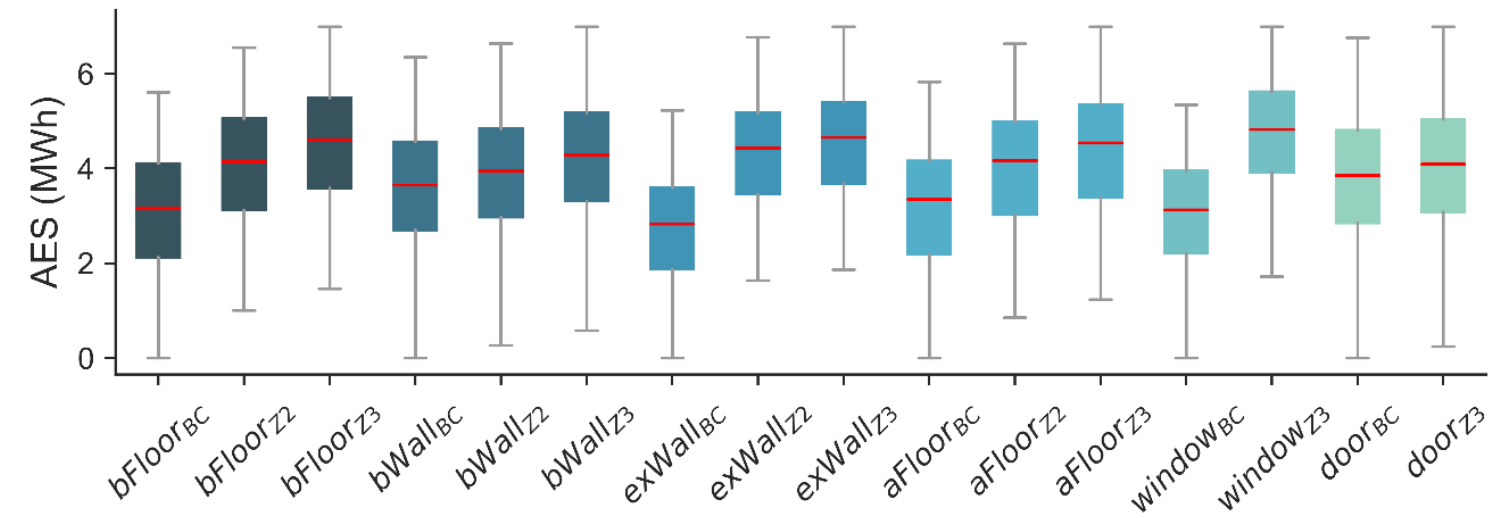

Figure 2-4: Impact of individual ERs on AES across all PERs comprising the stated ER for a) row homes, b) semi-detached homes and c) detached homes

Figure 2-3 shows that increased insulation to basement floors and upgraded windows have the largest impact on $\overline{P M V}^{2}$. A reduction of $0.43(21 \%)$ in the median $\overline{P M V}^{2}$ of the row home is observed for $b F$ loor $_{Z 3}$ relative to $b F$ loor $_{B C}$, whereas an $11 \%$ reduction in the median $\overline{P M V}^{2}$ of the row home is observed for window $w_{Z 3}$ relative to window $_{B C}$. Similar however much less pronounced reductions are also observed across the semi-detached and detached homes. Therefore, increased basement floor insulation and upgraded windows 
have a considerable impact on the building's TC. ER $b F l o o r_{Z 3}$ has the smallest median $\overline{P M V}^{2}$ across all building archetypes followed closely by ER window $w_{Z 3}$. The median $\overline{P M V}^{2}$ for ER bFloor $_{Z 3}$ is $1.63,1.89$, and 2.07 for the row, semi-detached, and detached homes, respectively. It is important to note that overall, the row and detached homes have the highest and the lowest $\overline{P M V}^{2}$ values, respectively. The higher $\overline{P M V}^{2}$ values for the detached home is most likely attributed to the fact that the detached home has the largest floor area yet still equipped with the same sized furnace as both the semi-detached and row homes.

Figure 2-4 shows that AES are most sensitive to upgrades in basement floor insulation and windows. An increase from 1.46 to $2.94 \mathrm{MWh}(102 \%)$ in median AES of the row home is observed for $b_{F l o o r}$ r relative to $b_{F l o o r}$, , whereas a $77 \%$ increase in median AES of the row home is observed for window $w_{Z 3}$ relative to window $_{B C}$. More modest increases in median AES of the row home are observed for aFloor $_{Z 3}$ relative to aFloor $_{B C}(33 \%)$, and for exWall Zn $_{3}$ relative to exWall ${ }_{B C}(22 \%)$. Similar however less pronounced increases across the aforementioned ERs are also noticed for both the semi-detached and detached homes. ER window $w_{Z 3}$ demonstrates the largest median AES of 3.6, 4.37, and 4.76 MWh for the row, semi-detached and detached homes, respectively.

Overall, the implementation of upgraded doors has very little impact on either $\overline{P M V}^{2}$ or AES. Though all building archetypes share very similar results in both Figure 2-3 and Figure 2-4, there are a few notable differences. Insulation improvements to both basement and exterior walls are more effective at decreasing $\overline{P M V}^{2}$ and increasing AES in the semidetached and detached homes as compared to the row home. The reason for this is likely due to the exterior walls (both below and above grade) of both the semi-detached and 
detached homes having considerably more exposure to the outdoor environment. This results in a decrease in $\overline{P M V}^{2}$ and an increase in AES from improvements in exterior wall insulation.

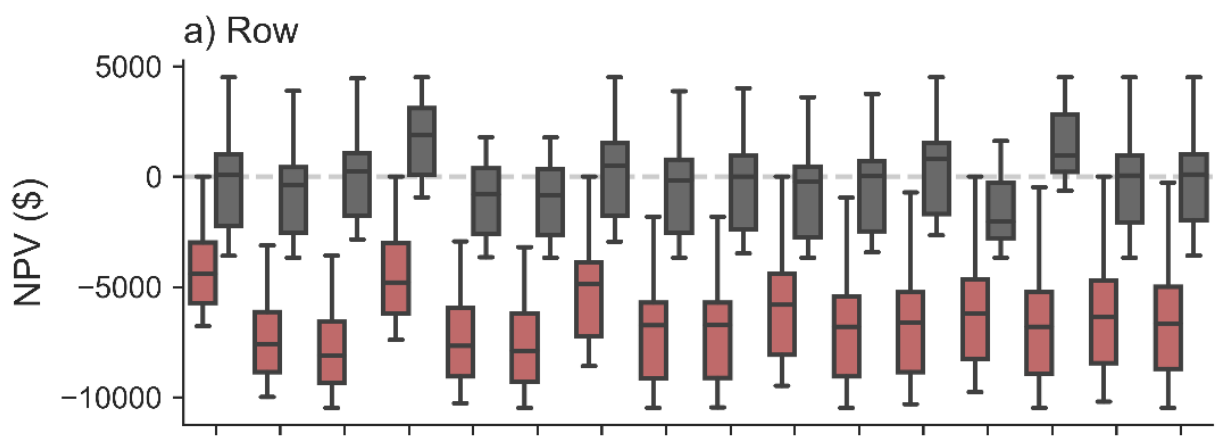

a) Semi-detached

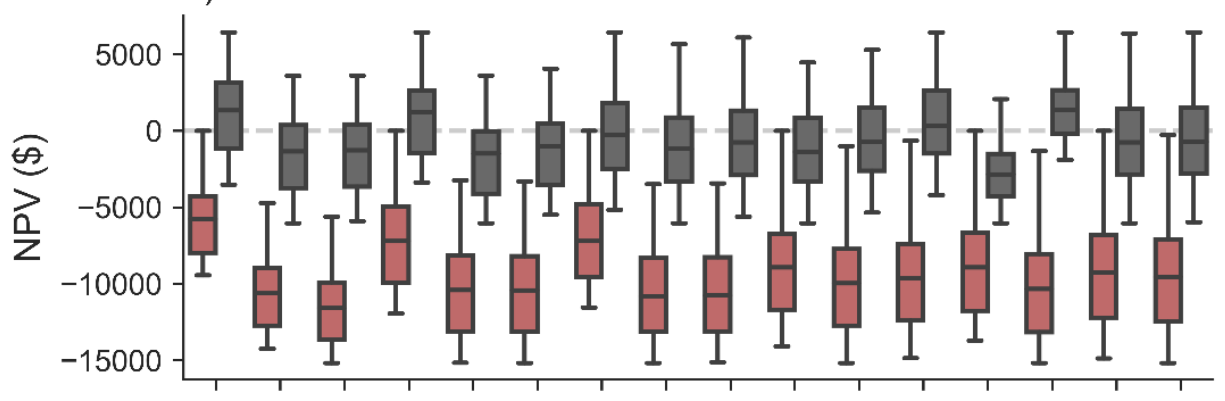

a) Detached

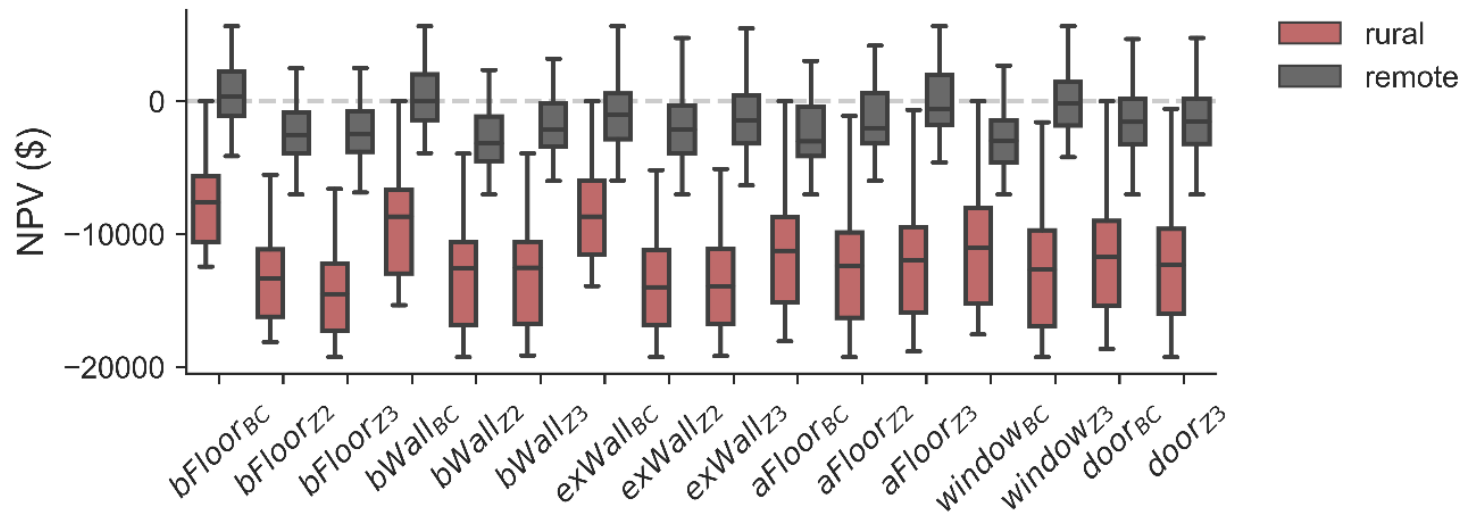

Figure 2-5: Impact of individual ERs on NPV across all PERs comprising the stated ER for a) row homes, b) semi-detached homes, and c) detached homes

Figure 2-5 shows the impact of individual ERs on NPV, across all PERs comprising each stated ER for both remote and rural communities. The results show that the cost- 
effectiveness of ERs vary greatly depending on both community electricity rates and the building's archetype. Regarding the remote community row home, the results show that the only ERs (excluding base case insulation levels $b W a l l_{B C}$ and $e x W a l l_{B C}$ ) that resulted in a positive median NPV across all PERs are the window ${ }_{Z 3}$, door $_{Z 3}$, bFloor $_{Z 3}$, and $a{ }^{\prime} l o o r_{Z 3}$ retrofits. The remote community row home ERs that include the $b W a l l_{B C}$ have the highest median NPV at $\$ 1730$. This suggests that in most cases increasing basement wall insulation is not a cost-effective measure. Similar results are also observed for both the remote community detached and semi-detached homes. With exceptions being that ERs bFloor $_{Z 3}$ and door $_{Z 3}$ do not result in a positive median NPV across both remote community semi-detached and detached homes, and ER aFloor $r_{Z 3}$ does not result in a positive median NPV in the remote community detached home. Overall, the median NPVs across all ERs is much lower for the semi-detached and detached homes, relative to the row home. The PERs under the rural community energy system electricity pricing, on the other hand, result in a negative NPV across all building archetypes.

Table 2-5 shows the results of the multi-objective analysis. Only remote community results are shown as all rural community results have a negative NPV. The table shows the PERs selected by building type for three different multi-objective weighting schemes. Each multi-objective weighting scheme prioritizes one techno-economic metric (AES, TC, or $\mathrm{NPV}$ ). Metrics that are prioritized have their objective weights set at 0.6 , whereas the remaining objective weights are set at 0.2 . Across all building types and weighting schemes, the solutions (i.e. the selected PERs) all consist of both window $w_{Z 3}$ and aFloor $_{Z 3}$. Upgraded doors are included in all but one PER; i.e. the semi-detached home under the TC prioritized weighting scheme. Under the NPV prioritized weighting scheme, the basement 
walls are left unchanged across all building types. The AES prioritized weighting scheme favours exWall $\mathrm{Zz}_{3}$ as it is selected across all building types. Although improvements to the basement floor have mixed success across the weighting schemes, these retrofits are preferred under the TC prioritized weighting scheme as bFloor $_{Z 3}$ and bFloor $_{Z 2}$ are selected for the row and semi homes, respectively.

Table 2-5: Remote community building retrofit multi-objective optimization results

\begin{tabular}{|c|c|c|c|c|c|c|c|c|c|}
\hline $\begin{array}{l}\text { Building } \\
\text { Archetype }\end{array}$ & $\begin{array}{c}\text { Basement } \\
\text { Floor }\end{array}$ & $\begin{array}{l}\text { Basement } \\
\text { Walls }\end{array}$ & $\begin{array}{c}\text { Exterior } \\
\text { Walls }\end{array}$ & $\begin{array}{l}\text { Attic } \\
\text { Floor }\end{array}$ & Windows & Doors & $\begin{array}{c}\text { NPV } \\
(\$)\end{array}$ & $\begin{array}{c}\text { AES } \\
(\mathbf{M W h})\end{array}$ & $\overline{\mathrm{PMV}}^{2}$ \\
\hline \multicolumn{10}{|c|}{ AES prioritized solution: $\sigma_{a e s}=0.6, \sigma_{n p v}=0.2$, and $\sigma_{p m v}=0.2$} \\
\hline Row & bFloorz3 & $\mathrm{bWall}_{\mathrm{BC}}$ & exWallz3 & aFloorz3 & windowz3 & doorz3 & 3207 & 4.15 & 1.44 \\
\hline $\begin{array}{c}\text { Semi- } \\
\text { detached }\end{array}$ & bFloor ${ }_{B C}$ & bWallz3 & exWallz3 & aFloorz3 & windowz3 & doorz3 & 2990 & 4.80 & 2.03 \\
\hline Detached & bFloor ${ }_{B C}$ & bWallz3 & exWallz3 & aFloorz3 & windowz3 & doorz3 & 2201 & 5.61 & 2.23 \\
\hline \multicolumn{10}{|c|}{ NPV prioritized solution : $\sigma_{a e s}=0.2, \sigma_{n p v}=0.6$, and $\sigma_{p m v}=0.2$} \\
\hline Row & bFloorz3 & bWall $\mathrm{BC}$ & exWall ${ }_{\mathrm{BC}}$ & aFloorz3 & windowz3 & doorz3 & 3935 & 3.68 & 1.52 \\
\hline $\begin{array}{c}\text { Semi- } \\
\text { detached }\end{array}$ & bFloor ${ }_{B C}$ & bWall ${ }_{B C}$ & exWallz3 & aFloor $\mathrm{Z3}$ & windowz3 & doorz3 & 5458 & 4.45 & 2.04 \\
\hline Detached & bFloor $_{\mathrm{BC}}$ & $\mathrm{bWall}_{\mathrm{BC}}$ & exWallz3 & aFloorz3 & windowz3 & doorz3 & 4750 & 5.05 & 2.25 \\
\hline \multicolumn{10}{|c|}{ Thermal Comfort prioritized solution : $\sigma_{a e s}=0.2, \sigma_{n p v}=0.2$, and $\sigma_{p m v}=0.6$} \\
\hline Row & bFloorz3 & bWall $\mathrm{BC}$ & exWallz3 & aFloorz3 & windowz3 & doorz3 & 3207 & 4.15 & 1.44 \\
\hline $\begin{array}{c}\text { Semi- } \\
\text { detached }\end{array}$ & bFloorz2 & bWall $\mathrm{BC}$ & exWall $_{\mathrm{BC}}$ & aFloorz3 & windowz3 & door $_{B C}$ & 3025 & 3.91 & 1.93 \\
\hline Detached & bFloor $_{\mathrm{BC}}$ & bWallz3 & exWallz3 & aFloorz3 & windowz3 & doorz3 & 2201 & 5.61 & 2.23 \\
\hline
\end{tabular}




\subsection{Discussion}

A number of insights are drawn from the current study, which can be used to inform economic and policy decisions regarding the implementation of residential ERs in isolated communities. These insights are described as follows:

Insight 1: With respect to remote community homes, regardless of building archetype, improving attic insulation, and upgrading windows and doors are cost-effective retrofits that will increase both TC and AES.

The solutions (i.e. the selected PERs) from the multi-object analysis (see Table 2-5) consistently include improvements in attic insulation and upgrades to windows and doors across all building archetypes (row, semi-detached, and detached) and prioritized weighting schemes. The only exception is the semi-detached home under the TC prioritized weighting scheme where the door was left unchanged from the base case. These ERs are thus cost-effective measures that will lead to superior TC and increased AES. These claims are further supported by Figures 2-3 through 2-5 which demonstrate that increased attic insulation and upgraded windows are superior to all other ERs with respect to increases in AES and NPV, and improvements in TC. The fact that ER door ${ }_{Z 3}$ is consistently selected in the multi-objective analysis comes as a surprise as upgraded doors are shown to have minimal impact on either TC, AES, or NPV (see Figures 2-3 through 2-5). This result is likely due to the low installation cost to upgrade doors relative to all other ERs.

Insight 2: Upgraded windows and improvements in insulation to the basement floor lead to the highest AES regardless of building archetype.

If policymakers and northern community leaders sought to prioritize AES above all else, for reasons such as reducing diesel fuel use or decreasing regional air pollutants, the 
following ERs should be prioritized in order of decreasing importance: windows, basement floor insulation, attic floor insulation, above-grade exterior walls, below-grade exterior walls, and doors. This recommendation is supported by comparing the median AES for each ER in Figure 2-4. However, in the semi-detached and detached homes, where a larger portion of the exterior walls are exposed to the outdoor environment, increased insulation to exterior walls should be prioritized above increased attic insulation as the former leads to higher AES in these homes.

Insight 3: Only modest NPV is observed for even the most economical remote community PER, while no PER was found to be economically feasible in a rural community setting.

The maximum NPV corresponding to a remote community PER for the row, semidetached, and detached homes are $\$ 4,507, \$ 6,433$, and $\$ 5,624$, respectively which equates to a modest return for a project with a 30-year lifetime. On the other hand, all rural community PERs result in negative NPVs. These results are expected given the considerable lack of government backed monetary incentive programs in Canada which promote the adoption of economically viable residential energy efficiency measures [21].

Insight 4: In the remote community BEMs, building components such as the basement floor and the exterior and basement walls require a minimum thickness of insulation in order to lead to an increase in project economics (i.e. net present value).

Adding insulation thicknesses to the bFloor, bWall, and exWall at or above Zone 3 insulation levels (i.e. $120.65 \mathrm{~mm}, 38.1$, and $69.85 \mathrm{~mm}$, respectively) leads to an increase in NPV, however, below these levels of insulation a decrease in NPV is observed. This trend in NPV amongst the remote community BEMs is observed in the row home for 
building components bFloor and exWall, while in the semi-detached and detached homes it is observed for building components $b W$ all and exWall. This can be visualized in Figure 2-5 and is especially apparent when observing the change in NPV between ER bFloor ${ }_{B C}$ through bFloor $_{Z 3}$ for the remote community row home. The remote community row home equipped with the base case basement floor insulation thicknesses has a median NPV of effectively zero. When basement floor insulation thicknesses are increased to Zone 2 levels, the median NPV decreases to $-\$ 364$. However, when basement floor insulation thicknesses are further increased to Zone 3 levels, the median NPV surpasses both the base case and the Zone 2 levels to $\$ 230$. Even though these shifts in NPV are minimal, it is noteworthy to point out that some envelope energy retrofits (bFloor, bWall, and exWall) require a minimum level of insulation to be installed in order for project economics to trend upwards. A similar trend in NPV across the rural community BEMs (the row, semidetached, and detached ) is also observed in increases in attic floor insulation levels from ER aFloor ${ }_{B C}$ through aFloor $_{Z 3}$.

Insight 5: The combined implementation of several envelope energy retrofits is preferred over the installment of any single envelope energy retrofit.

Across all selected PERs from the multi-objective analysis shown in Table 2-5, at least three of the six PER building components are retrofits from the base case. This finding indicates that a combination of building envelope energy retrofits is preferred in order to maximize TC, AES, and NPV. 


\subsection{Closing remarks}

Three BEMs were developed corresponding to a row, semi-detached, and detached home. In order to investigate the impacts of implementing building-based DSIs, several PERs were considered. PERs included any combination of the following ERs: upgraded doors and windows, improvements in insulation to the exterior and basement walls, as well as to the basement and attic floors. Finally, a multi-objective analysis was presented to maximize NPV, TC, and AES. Results show that the investigated PERs can be an attractive solution for policymakers and community leaders in remote community settings to reinvest energy subsidies towards PERs that are not only economically feasible but will lead to reductions in energy consumption and improvements in TC. However, rural communities do not experience the same economic benefits, as no singular ER or PER was shown to be economically feasible under rural electricity consumer rates.

While this chapter has shown the benefits of residential building-based DSIs in the form of PERs implemented in isolated communities, there are still several research questions and issues to be resolved, namely:

- How will the investigated energy retrofits perform in far northern arctic communities? There are over 1000 rural and remote communities across Canada, in which many are situated in northern parts of the Arctic. Though MoCreebec Eeyoud is considered to be in a subarctic region of Canada, it would be prudent to investigate the impact of residential building envelope energy retrofits in communities located further north, as they would most likely experience much higher annual energy savings (albeit with potentially much higher construction costs due to the increased cost of labour and construction materials). 
- How will the modelling results of this study compare with experimental data taken from the implementation of the PERs on an actual isolated community home? Several assumptions and simplifications were taken when developing the residential building energy models such as the thermal properties of the building materials (e.g. thermal mass, conductivity, solar absorptance and reflectivity, etc.) and the weekly occupancy schedules were assumed based on published databases, internal rooms and spaces were simplified into three zones (basement, main level, and attic), and air transfer between zones was neglected. Therefore, it is important to reinforce the findings from this modelling study with experimental data from homes in northern isolated communities that have undergone envelope energy retrofits.

- How do electrical energy saving measures compare relative to building envelope ERs? The current study has focused exclusively on building envelope ERs. Electrical energy saving measures such as high-efficiency appliances, LED lighting, low flow faucets were not considered. The literature suggests that electrical energy saving measures are more cost-effective, yet result in lower energy savings relative to building envelope ERs [45]. Therefore, it is prudent to study these measures in further detail and compare them against the building envelope ERs investigated in the current study.

It is important to note that the recommendations presented in this study should only be considered for buildings of similar archetype, age, and location. When comparing these recommendations to those suggested by advisors in previous studies [22], there are noticeable differences. Although both prioritize attic insulation, the advisors recommend 
prioritizing increased basement and exterior wall insulation over upgraded windows. To the advisors' credit, it is difficult to determine what exactly the homeowner's priorities are when these recommendations are given. However, regardless of the building's archetype or the homeowner's priorities, what is evident from these findings and those from the literature is that a simple 'one size fits all' ER recommendation for residential buildings is ill-advised. 


\section{Chapter 3}

This chapter has been submitted for publication as:

J. Coady, and J. Duquette, "Quantifying the impacts of biomass driven combined heat and power grids in northern rural and remote communities," Renewable and Sustainable Energy Reviews [Under Review] 


\section{Chapter 3: Supply-side interventions: quantifying the impacts of biomass driven district heating grids}

\subsection{Introduction}

Many of the detrimental energy systems issues described in Chapter 1 that isolated communities face (e.g. high levels of air pollution and noise, energy insecurity, and high energy costs) can largely be addressed by restructuring the community's supply-side energy mix and introducing local community-owned sustainable energy generation technologies. One of the more promising options in this regard is biomass driven combined heat and power (CHP) grids [46]. Further to meeting community electricity demands, these systems are able to recover heat, otherwise exhausted to the environment, from a centralized plant location and distribute it via a district heating (DH) grid to community buildings for meeting space heating and domestic hot water (DHW) demands.

There is a growing body of research that demonstrates the ability of biomass CHP generation to replace conventional fossil fuel based heat and power generation in isolated regions. Loeser \& Redfern [47] developed and studied a small-scale biomass CHP plant suitable for remote communities, industrial customers, or agricultural farms. The plant under review was sized at $100 \mathrm{~kW}$ and was modelled to service a typical community in the UK of 120 dwellings. Void of any economic analysis, the researchers demonstrated the system's ability to reliably supply power to small-scale variable load residential dwellings. Thompson \& Duggirala [48] conducted a techno-economic review of the implementation of a biomass CHP plant with diesel backup in a small off-grid research facility in northern Canada. The biomass CHP plant was modelled to supply both heat and electricity to a select 
few buildings within the small research facility. They compared the plant with two other competing renewable energy technologies: a wind-diesel hybrid plant, and a solar PVdiesel hybrid plant; and found that the biomass CHP plant was the most attractive option as annual energy costs and $\mathrm{CO}_{2}$ emissions were reduced by $92 \%$ and $98 \%$ relative to the existing diesel generators, respectively. Zhu et al. [49] analyzed a small-scale biomass fired organic Rankine cycle CHP plant integrated with $\mathrm{CO}_{2}$ capture technology from a technoeconomic standpoint. They found that superior economic and thermodynamic performance is observed when both electricity and domestic hot water are produced simultaneously. Amirante et al. [50] conducted an experimental study of a novel biomass fired organic Rankine cycle CHP plant designed specifically for low variable load rural applications. Their findings showed that the plant could produce heat and power from local wood residue (olive oil) at rates that are $38-46 \%$ cheaper than conventional diesel powered CHP units.

Although few community-based biomass driven CHP grids have actually been installed in Canada in recent years, mainly due to the high up-front costs associated with installing a DH grid [51], this technology is beneficial on a number of fronts. For example, overall energy system efficiency is increased relative to conventional power and heating systems, leading to lower fuel costs; and $\mathrm{CO}_{2}$ emissions are negligible, as biomass generation is considered to be carbon neutral in many jurisdictions [52]. Other typical benefits include improved energy system reliability and dispatchability. Often overlooked, however, are the socio-economic benefits associated with biomass utilization such as avoided $\mathrm{CO}_{2}$ emission related costs and increased local job creation. In many cases, biomass can be harvested locally through community organized efforts [53]. Using local labour to harvest biomass feedstocks has been shown to significantly reduce a community's 
dependence on imported energy, create local employment, and retain energy related expenditures in the local economy [46]. A number of studies have shown the potential benefits of coupling biomass CHP plants with locally sourced biomass feedstock. Yablecki et al. [54] developed a model that combines a community-based pre-emptive forestry management plan with a biomass CHP plant to reduce the risk of wildfires in a remote Canadian community. They found that by implementing this plan, which consists of harvesting small diameter trees and forest debris, $\mathrm{CO}_{2}$ emissions could potentially be reduced by roughly 1,000 tonnes annually relative to the current energy system. Forbes et al. [55] investigated the performance of a combined renewable energy and biomass CHP plant located at a farming research center in Northern Ireland to replace a fuel-oil based heating system. The plant's biomass feedstock consisted of a mixture of local sources including biogas from an anaerobic digester run on dairy cow slurry, and woodchips sourced from local and farmed forest residue. Results showed that annual fuel oil consumption and carbon emissions decreased by roughly $37 \%$ and $40 \%$, respectively. Mertzis et al. [56] studied the performance of a small-scale biomass CHP plant across several different regions in Greece. At each location the researchers varied the feedstock to match the local agricultural residue of the region. Feedstocks consisted of olive and peach kernels, as well as grape seeds. Researchers found that the plants ran reliably regardless of region and feedstock, and total plant efficiency across all regions ranged from $48-52 \%$.

As shown above, the majority of the studies found in the literature on the topic of biomass CHP generation in isolated regions are centered on small-scale systems. Despite being beneficial on a number of fronts, these systems are not suitable for meeting the 
heating needs of communities comprising multiple residential buildings. Providing heat in such a way can only be achieved via the implementation of a community-scale DH grid. Furthermore, although many of these studies focus on the environmental impacts associated with biomass $\mathrm{CHP}$ generation, these impacts are solely related to global $\mathrm{CO}_{2}$ emissions, meaning that local air quality impacts are largely ignored. Moreover, the socioeconomic impacts associated with biomass CHP generation are entirely disregarded, and no distinction is made between remote and rural community energy systems.

\subsubsection{Research objectives}

The objective of the current study is to compare the technical, economic, socioeconomic, and environmental impacts of implementing biomass driven CHP grids in the two main community energy system layouts commonly encountered in Canada's far north: remote, and rural communities. Models corresponding to both remote and rural community energy systems are constructed using the Matlab ${ }^{\circledR} /$ Simulink ${ }^{\circledR}$ software tool [57]. For each of these energy system layouts, five energy plant technology scenarios are considered which are divided into the following two energy system model configurations: energy systems comprising a DH grid, and energy systems comprising a CHP plant and a DH grid. The energy plant technologies utilized in these scenarios include a propane boiler plant, a biomass boiler plant, a biomass gasification (BG) CHP plant, a biomass organic Rankine cycle (ORC) CHP plant, and a diesel CHP plant. An additional reference scenario is constructed for each energy system layout as a means to compare the proposed scenarios with one that consists of conventional energy plant technologies (i.e. a diesel generator plant, and the electrical grid for remote and rural energy systems, respectively). The indigenous community of MoCreebec Eeyoud is used as the case study in the analysis. 
Data from 2016 (the reference year) is used to formulate the reference scenarios primarily because this is the most recent year for which community data is available. The proposed scenarios are compared with the reference scenario on the basis of the following technical, economic, socio-economic, and environmental factors, in the order given:

- the total annual primary energy requirement;

- the levelized energy cost (LEC), with and without consideration for electrical transmission line extension costs for the rural energy system layout;

- the LEC as a result of implementing a carbon tax, and increasing local biomass fuel production;

- total annual carbon dioxide $\left(\mathrm{CO}_{2}\right)$ emissions, and emissions from the following key criteria pollutants which greatly affect local air quality: sulphur dioxide $\left(\mathrm{SO}_{2}\right)$, nitrogen oxide $\left(\mathrm{NO}_{\mathrm{x}}\right)$, and particulate matter with a diameter of less than $10 \mu \mathrm{m}$ $\left(\mathrm{PM}_{10}\right)$.

\subsection{Methodology}

\subsubsection{Energy system model configurations}

Two energy models are developed that are representative of two distinct community energy system layouts: a remote energy system (M1) and a rural energy system (M2). The rural energy system is connected to the provincial electrical grid, whereas the remote energy system is isolated and thus electricity is generated on-site. For each energy model, the following three heating system configurations are analyzed: C1) electrical heating, C2) district heating (DH), and C3) DH and combined heat and power (CHP). Figure 3-1 shows the energy balances that correspond to each of the six energy system model configurations 
described above. Each energy balance includes a control volume (dotted line) drawn around the technologies of interest, as well as a number of curved arrows that represent energy losses associated with these technologies. The variables $L_{E l e c}$, and $L_{\text {Heating }}$ represent the MoCreebec Eeyoud community electrical and heating load, respectively, whereas the variables $E_{\text {Diesel }}, E_{\text {Boiler }}, E_{C H P}$, and $E_{\text {Grid }}$ represent the primary energy requirement from the diesel generator (DG) plant, boiler plant, CHP plant, and the electrical grid (i.e. the Ontario power plant fleet), respectively. $E_{C T}$ represents the excess energy that is dissipated using the cooling tower (CT). Losses in both the Ontario power plant fleet and electrical transmission grid, and the community electrical distribution grid are ignored as they are minimal relative to the other losses considered.

Figure 3-1a (M1C1) represents a remote community energy system in which electricity is produced on-site using a DG plant and the heating load is met using building based electrical heaters. Figure 3-1c (M1C2) is similar to M1C1 except instead of meeting the heating load electrically, it is met via a district heating grid that is powered from a centralized boiler plant. Figure 3-1e (M1C3) is distinct from $\mathrm{M} 1 \mathrm{C} 2$ in that a CHP plant is used instead of a DG plant. Since the community energy system is isolated, the CHP plant operates to follow the electrical load. Heat that is produced by the CHP plant is sent to the DH grid when a heating load is present. Any excess heat that is produced by the CHP plant is sent to a cooling tower. 


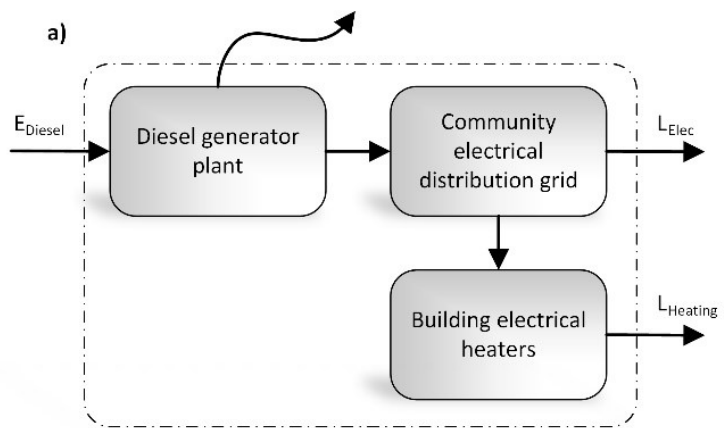

b)

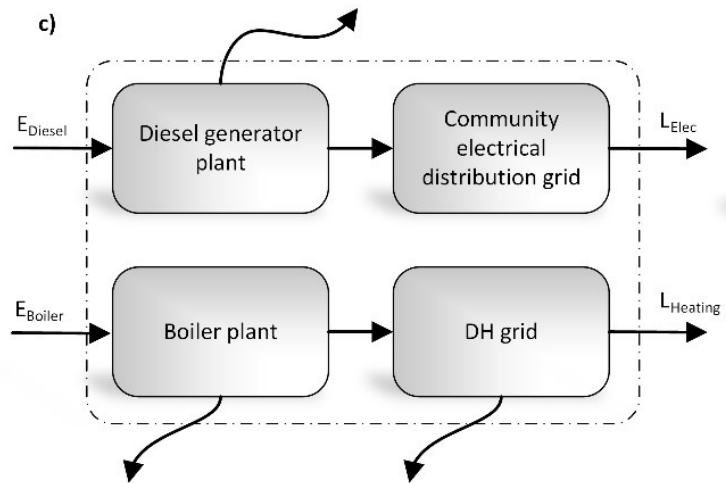

d)
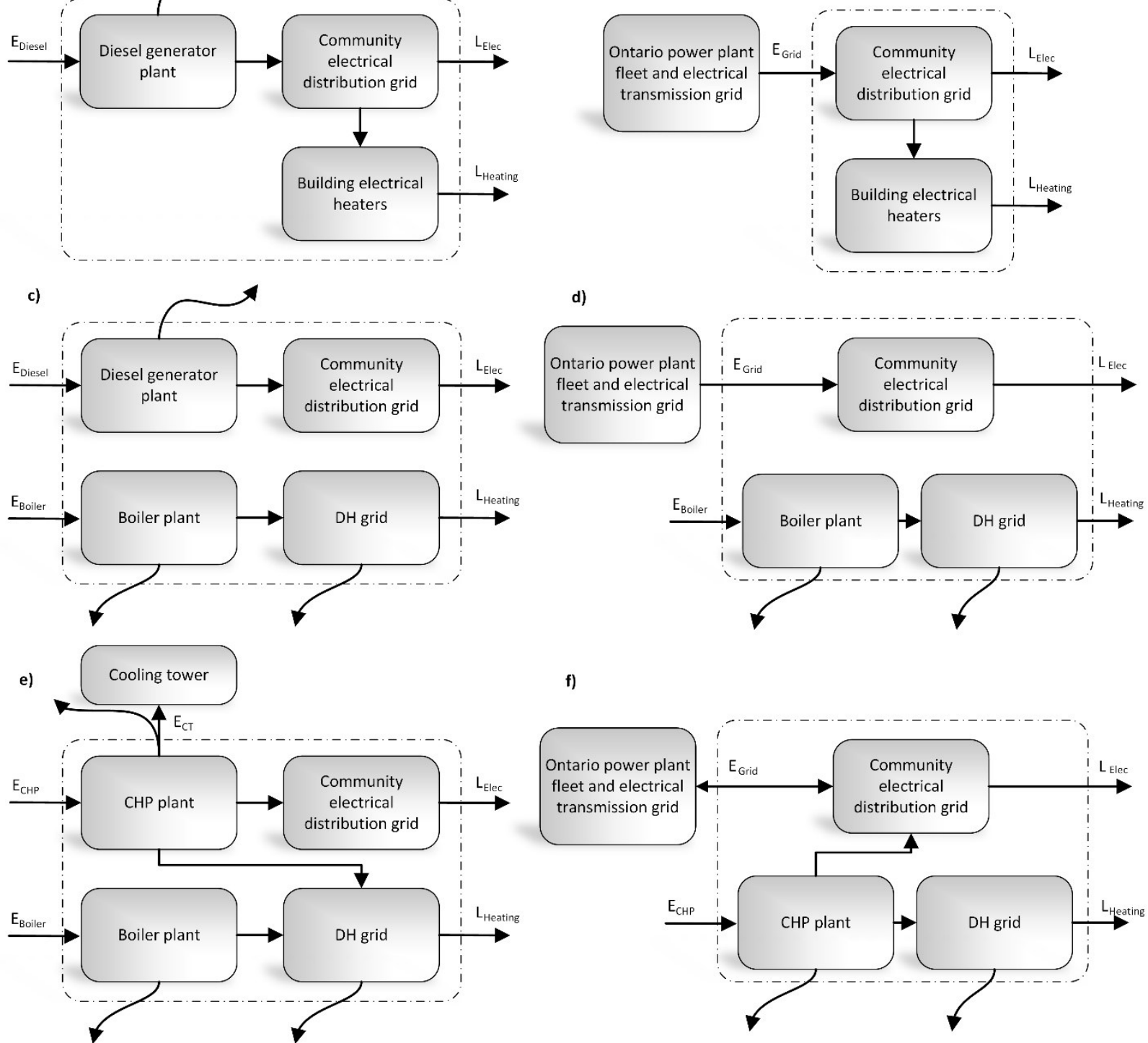

f)

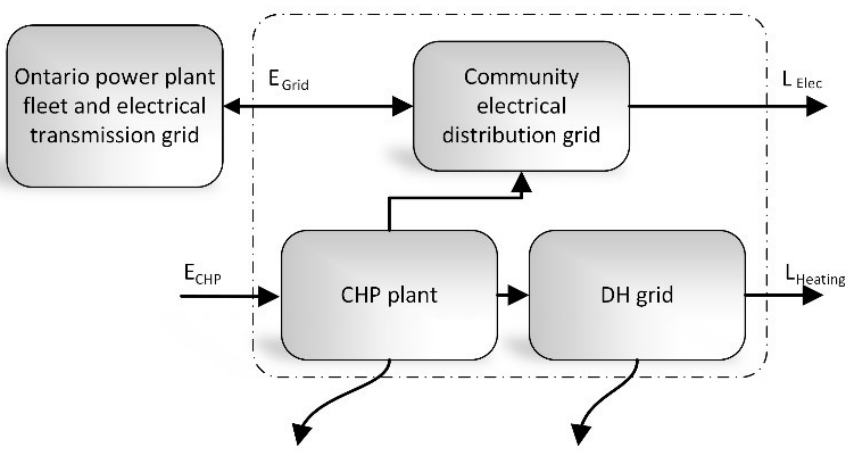

Figure 3-1: Energy balance schematic of six distinct energy system model configurations: a) Remote community energy system with electrical heating (M1C1), b) Rural community energy system with electrical heating (M2C1), c) Remote community energy system with DH (M1C2), d) Rural community energy system with DH (M2C2), e) Remote community energy system with DH and CHP (M1C3), f) Rural community energy system with DH and CHP (M2C3). The dotted line and curved arrows in each configuration represent the control volume and energy losses, respectively.

Figure 3-1b (M2C1), on the other hand, represents a rural community energy system in which electricity is produced a great distance away and imported into the community. Like M1C1, the heating load is met using building based electrical heaters. Figure 3-1d 
(M2C2) is similar to $\mathrm{M} 2 \mathrm{C} 1$ except a district heating grid that is powered from a centralized boiler plant is used to meet the heating load. Figure 3-1f(M2C3) is similar to M2C2 except that a CHP plant replaces the boiler plant. As the community energy system is gridconnected, the CHP plant operates to follow the heating load. Electricity that is produced by the CHP plant is used to meet the electrical load. Any excess electricity that is produced by the CHP plant is supplied to the Ontario electrical grid.

\subsubsection{Energy plant technology scenarios}

A number of energy plant technology scenarios are considered for each of the community energy system model configurations developed in this study. Energy plant technologies include a DG plant, the Ontario electrical grid, a propane boiler plant, a biomass boiler plant, a biomass gasification (BG) CHP plant, a biomass organic Rankine cycle (BORC) CHP plant, and a diesel CHP plant. Table 3-1 provides a description of the technology scenarios considered by scenario name and energy system model configuration. Model configurations $\mathrm{M} 1 \mathrm{C} 1$ and $\mathrm{M} 2 \mathrm{C} 1$ are representative of typical northern remote and rural communities, respectively, and as such are used as the reference scenarios in the current study. Model configurations M1C2 and M2C2 are analyzed using the two following technology scenarios: a propane boiler plant, and a biomass boiler plant. Model configurations $\mathrm{M} 1 \mathrm{C} 3$ and $\mathrm{M} 2 \mathrm{C} 3$ are analyzed using the following three technology scenarios: a BG CHP plant, a BORC CHP plant, and a diesel CHP plant.

Table 3-2 shows the average electrical efficiencies, thermal efficiencies, and CHP heat-to-power ratios that are assumed for each of the energy plant technologies considered in the current study. 
Table 3-1: Summary of energy plant technology scenarios. BG and BORC represent biomass gasification and biomass organic Rankine cycle, respectively

Energy

$$
\text { system model Scenario name Description }
$$

configuration

\begin{tabular}{lll}
\hline M1C1 & $M 1 C 1_{D G}$ & Remote community with diesel generator plant \\
\hline M1C2 & $M 1 C 2_{f f B o i l e r}$ & $\begin{array}{l}\text { Remote community with diesel generator plant, propane } \\
\text { boiler plant, and DH grid } \\
\text { Remote community with diesel generator plant, biomass } \\
\text { boiler plant, and DH grid }\end{array}$ \\
\hline$M 1 C 2_{\text {bioBoiler }}$ & $M 1 C 3_{B G}$ & $\begin{array}{l}\text { Remote community with BG CHP plant, propane boiler } \\
\text { plant, and DH grid } \\
\text { Remote community with BORC CHP plant, propane } \\
\text { boiler plant, and DH grid } \\
\text { Remote community with diesel CHP plant, propane } \\
\text { boiler plant, and DH grid }\end{array}$ \\
$M 1 C 3_{B O R C}$ & $M 1 C 3_{D C H P}$ & $\begin{array}{l}\text { Rural community with connection to Ontario electrical } \\
\text { grid }\end{array}$ \\
\hline M2C1 & $M 2 C 1_{\text {Grid }}$ & $\begin{array}{l}\text { Rural community with propane boiler plant, DH grid, and } \\
\text { connection to Ontario electrical grid } \\
\text { Rural community with biomass boiler plant, DH grid, } \\
\text { and connection to Ontario electrical grid }\end{array}$ \\
\hline$M 2 C 2_{f f B o i l e r}$ & $M 2 C 2_{\text {bioBoiler }}$ & $\begin{array}{l}\text { Rural community with BG CHP plant, DH grid, and } \\
\text { connection to Ontario electrical grid } \\
\text { Rural community with BORC CHP plant, DH grid, and } \\
\text { connection to Ontario electrical grid } \\
\text { Rural community with diesel CHP plant, DH grid, and } \\
\text { connection to Ontario electrical grid }\end{array}$ \\
\hline$M 2 C 3_{B G}$ & $M 2 C 3_{B O R C}$ \\
$M 2 C 3_{D C H P}$ &
\end{tabular}


Table 3-2: Average electrical efficiencies, thermal efficiencies, and CHP heat-to-power ratios for energy plant technologies considered in the current study.

\begin{tabular}{cccc} 
Energy plant technology & Technical parameter & Symbol & Value \\
\hline Diesel generator plant [58] & Electrical efficiency & $\eta_{\text {Diesel }}$ & $31 \%$ \\
\hline Propane boiler plant [59] & Thermal efficiency & $\eta_{\text {Boiler }}$ & $82 \%$ \\
\hline Biomass boiler plant [60] & Thermal efficiency & $\eta_{\text {Boiler }}$ & $75 \%$ \\
\hline \multirow{2}{*}{ Gasification CHP plant [52], [61] } & Electrical efficiency & $\eta_{C H P e}$ & $27 \%$ \\
\cline { 2 - 4 } & Thermal efficiency & $\eta_{C H P t}$ & $50 \%$ \\
\cline { 2 - 4 } & Heat-to-power ratio & $r_{h t p}$ & 1.6 \\
\hline \multirow{3}{*}{ ORC CHP plant [52], [61] } & Electrical efficiency & $\eta_{C H P e}$ & $17 \%$ \\
\cline { 2 - 4 } & Thermal efficiency & $\eta_{C H P t}$ & $75 \%$ \\
\cline { 2 - 4 } & Heat-to-power ratio & $r_{h t p}$ & 4.2 \\
\hline \multirow{2}{*}{ Diesel CHP Plant [7] } & Electrical efficiency & $\eta_{C H P e}$ & $27 \%$ \\
\cline { 2 - 4 } & Thermal efficiency & $\eta_{C H P t}$ & $53 \%$ \\
\cline { 2 - 4 } & Heat-to-power ratio & $r_{h t p}$ & 2.0 \\
\hline
\end{tabular}

\subsubsection{Scenario Dispatch}

Time-series simulations are conducted for each of the scenarios listed in Table 3-1 over the course of one year. The Matlab ${ }^{\circledR} / \operatorname{Simulink}{ }^{\circledR}$ environment is used to conduct the simulations using a fixed step continuous solver based on Euler's method. Hourly time steps are used in the analysis. The scenario dispatch algorithm used to conduct the simulations is shown in Figure 3-2. Figure 3-2 shows that a number of time step inputs are initially loaded at the start of each simulation. Fixed inputs represent technical parameters that remain constant as the simulation proceeds. These parameters are the electrical and thermal efficiencies $\left(\eta_{\text {Diesel }}, \eta_{\text {Boiler }}, \eta_{C H P e}, \eta_{C H P t}\right)$ and heat-to-power ratios $\left(r_{h t p}\right)$ of the various components listed in Table 3-2. Variable inputs, on the other hand, represent parameters that change as a function of time as the simulation proceeds. These parameters are the community electrical and heating load $\left(L_{\text {Elec }}, L_{\text {Heating }}\right)$, as well as the pumping 
energy requirement $\left(L_{P u m p}\right)$ and heat loss $\left(L_{D H}\right)$ from the community district heating (DH) grid.

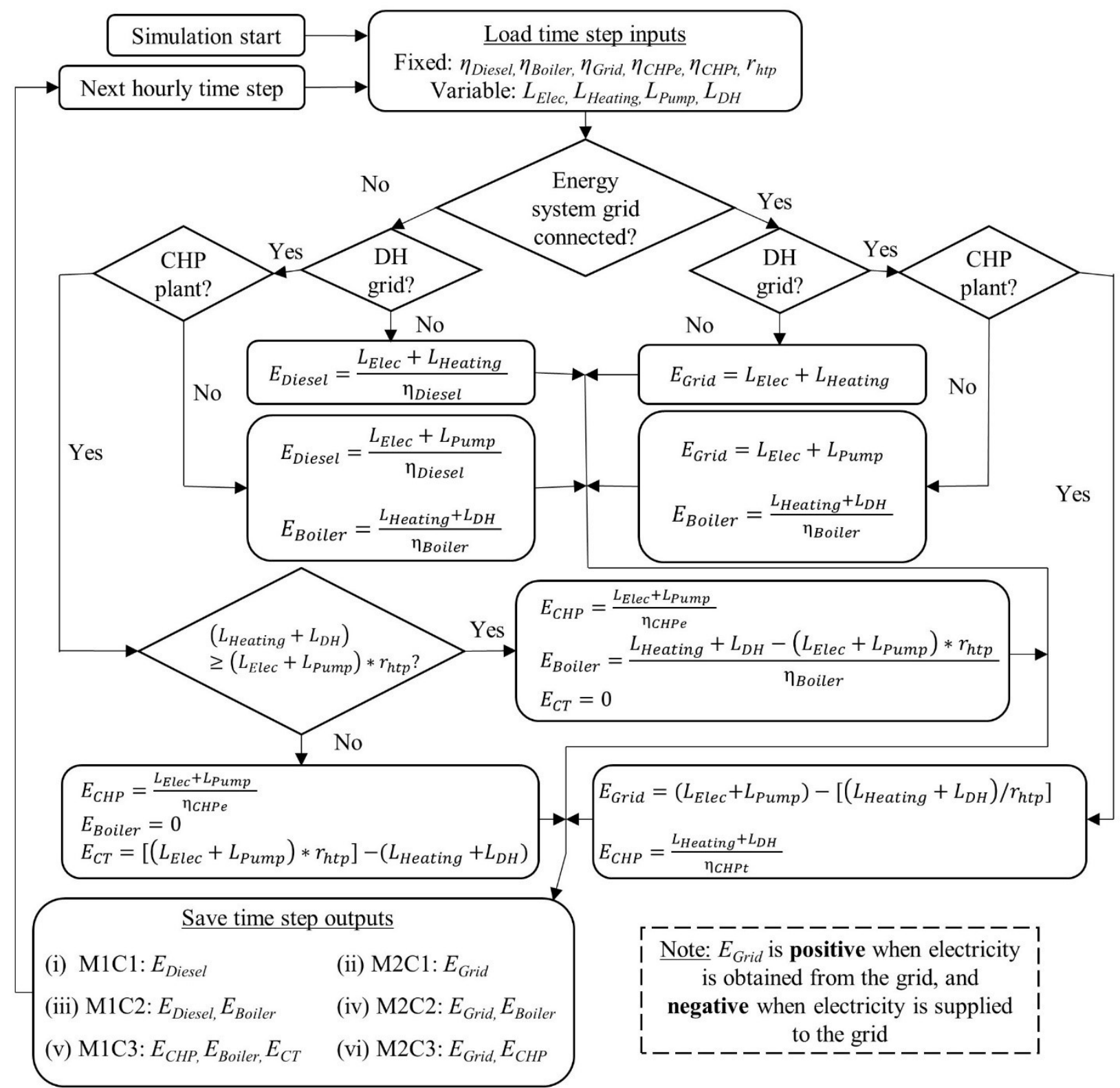

Figure 3-2: Scenario dispatch algorithm used for energy system simulation. Labels (i) (vi) correspond to energy system model configurations M1C1-M2C3 in Table 2 in the order stated, respectively. 
The community electrical and heating load distributions are obtained from a study conducted by LaFreniere [16] focused on assessing the feasibility of implementing renewable energy generation sources in the MoCreebec Eeyoud energy system. The distributions comprise hourly electrical, space heating, and DHW heating loads for the reference year 2016, and are based on a combination of measured and estimated data. The $L_{P u m p}$ and $L_{D H}$ distributions are calculated from a district heating grid model of the MoCreebec Eeyoud community (see Chapter 3.2.4 for details).

The scenario dispatch algorithm shown in Figure 3-2 is used to calculate the total primary energy requirement that corresponds to each scenario assessed in the current study. Boxes labelled $(i)-(v i)$ list the equations used to calculate the relevant energy terms by source (i.e. $E_{\text {Diesel }}, E_{\text {Grid }}, E_{\text {Boiler }}, E_{C H P}$, and $E_{C T}$ ) for the energy system model configurations shown in Table 3-1, in the order specified. For the M1C1 (i) and M2C1 (ii) scenarios, the total energy required to meet both electrical and heating loads is equivalent to the diesel fuel consumed by the DG plant, $E_{\text {Diesel }}$, and the electricity obtained from the electrical grid, $E_{\text {Grid }}$, respectively. For the $\mathrm{M} 1 \mathrm{C} 2$ (iii) scenarios, diesel fuel is used to meet the electrical load and DH grid pumping energy requirement via the DG plant, whereas boiler fuel, $E_{\text {Boiler }}$, (either propane or biomass) is used to meet the heating load and DH grid heat loss via the boiler plant. The $\mathrm{M} 2 \mathrm{C} 2$ (iv) scenarios are identical to the $\mathrm{M} 1 \mathrm{C} 2$ scenarios with the exception that the electrical load and DH grid pumping energy requirements are met using electricity from the electrical grid. For the M1C3 (v) scenarios, the CHP plant is used to meet the electrical load and DH grid pumping energy requirement. Depending on the scenario, either the BG, BORC or diesel CHP plant is used. For all cases, if the combined heating load and $\mathrm{DH}$ grid heat loss is greater than the total heat provided 
by the CHP plant, then the remaining heat requirement is met using the propane boiler plant. As there is no heat excess in the system, the CT is left unutilized. However, if on the other hand, the total heat provided by the CHP plant is greater than the combined heating load and $\mathrm{DH}$ grid heat loss, then the heat surplus is dissipated to the environment using the CT. As there is no additional heat requirement in the system, the propane boiler plant is left unutilized. For the M2C3 (vi) scenarios, the CHP plant is used to meet the combined heating load and $\mathrm{DH}$ grid heat loss. As in the $\mathrm{M} 1 \mathrm{C} 3$ scenarios, either the $\mathrm{BG}, \mathrm{BORC}$, or diesel CHP plant are used in any given scenario. For all cases, if the electrical load and DH grid pumping energy requirement is greater than the total electricity provided by the CHP plant, then the remaining electricity requirement is met using the electrical grid. However, if on the other hand, the total electricity provided by the CHP plant is greater than the electrical load and DH grid pumping energy requirement, then the excess electricity is supplied to the electrical grid.

\subsubsection{Estimation of community DH grid heat loss and pumping energy requirement}

The community DH grid heat loss, $L_{D H}$, and pumping energy requirement, $L_{P u m p}$, hourly distributions shown in Figure 3-2 are calculated using a DH grid time series simulation model developed for the MoCreebec Eeyoud community. The DH grid model emulates a variable flow, medium temperature, direct-return system that uses water as the working fluid. Figure 3-3 shows the general layout of the DH grid as well as the main components that make up the system. The DH grid main circuit and branches are laid out spatially to overlap with existing community roadways. The DH grid connects the energy plant to the residential buildings in the community and consists of a network of insulated steel pipes 
buried at a depth of $1.1 \mathrm{~m}$. Both supply and return pipes are shown in Figure 3-3. Fluid flow in the main circuit and branches is driven via the main variable speed pump (VSP). The total length of the DH grid's main circuit is approximately $1,000 \mathrm{~m}$. The DH grid branches are roughly 1,015 $\mathrm{m}$ in length and are connected to the main circuit using a set of T-junctions. Likewise, a set of T-junctions is used to connect each branch to a building energy transfer station (BETS). The BETS is the main interface between the building and the DH grid and contains both a heat exchanger (HEX) and a VSP. Additional DH grid components depicted in Figure 3-3 include a modulating control valve (MCV) located at the furthest extremity of the main circuit and a number of control valves (CV) located at the end of each branch. Pipe diameters are sized to deliver the required flow rate to community buildings at the peak heating load condition subject to the following constraints: pressure due to friction cannot exceed 200 Pa per meter of pipe, and the fluid velocity cannot exceed $3 \mathrm{~m} / \mathrm{s}$ [12]. Table 3-8 provides a detailed breakdown of the various nominal pipe diameters and corresponding lengths required to assemble the DH grid piping network.

The CVs shown at the end of each branch in Figure 3-3 are used to ensure that a minimum amount of flow is available in the system at all times. When a call for heat occurs in any given building, the VSP located in the BETS responds by providing the mass flow rate required to meet this load. Any change in pressure in the system is sensed at the MCV. Therefore, when one or more VSPs in the system increase or decrease their respective flow rate, a pressure drop or rise is sensed on the supply side of the MCV, respectively. This change in pressure causes the differential pressure across the MCV to change. As the MCV is designed to operate at a setpoint pressure differential, any pressure differential that is 
above or below this value causes the main VSP to decrease or increase its flow rate, respectively, until the MCV setpoint value is reestablished. Controlling the main VSP (MVSP) in this way ensures that heat is supplied to the DH grid in the most efficient manner.

The formulation of the DH grid simulation model is based on a physical pipe network model developed by Duquette et. al. [62] for simulating district heating grids with variable flow. However, rather than utilizing a variable transport delay to track the progress of the fluid in time as the flow rate varies, a steady state approach is employed. Furthermore, to reduce the computational intensity of the model, heating loads from buildings in the community that are in close physical proximity are grouped together into clusters, as depicted in Figure 3-3. In this way, the original building heating load points located across the community are reduced from 144 to 24 . A full description of the building clustering method can be obtained from Ref. [12]. The following additional assumptions are used in formulating the DH grid model:

1) Water is the working fluid

2) The working fluid is incompressible

3) Fluid flow is fully developed

4) Convective heat transfer from the working fluid to the surroundings is in the radial direction only

5) Conduction heat transfer is considered through the pipe assembly (i.e. pipe, insulation, and casing), and the soil

6) Material properties of the pipe assembly and soil are fixed

7) Thermal interaction between supply and return pipes is not considered 
8) Hydraulic balance is maintained at all times in the system

9) Electricity consumption from VSPs located in building energy transfer stations is not included as consumption is negligible relative to the main VSP

DH grid model simulations are conducted in Simulink ${ }^{\circledR}$ using time steps of 1 hour for 1 year. To conduct the simulations, a number of variable and fixed inputs are required. Variable model inputs include hourly heating load distributions for each building cluster and hourly outdoor air temperature. The various fixed model inputs are summarized in Table 3-3 and are based on typical DH grid operation in the province of Ontario.

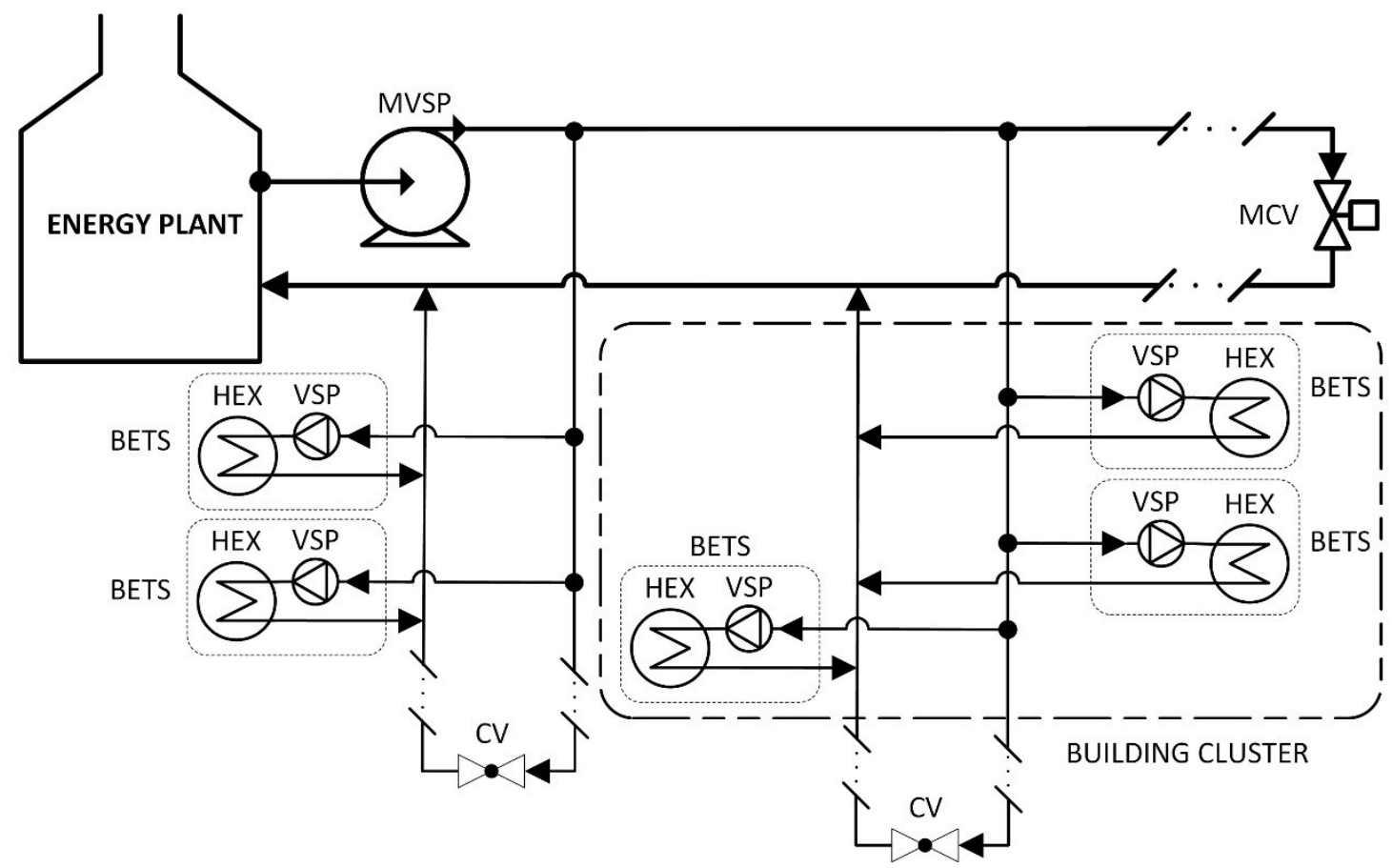

Figure 3-3: Schematic representation of MoCreebec Eeyoud district heating grid layout. $M C V, C V, V S P, M V S P, H E X$, and BETS represent modulating control valve, control valve, variable speed pump, main variable speed pump, heat exchanger, and building energy transfer station, respectively 
Table 3-3: Fixed inputs to the DH grid model. Parameters are obtained from a typical North American DH grid installation [62], as well as standard specifications for commercially available insulated steel pipes [63].

\begin{tabular}{lc} 
DH grid model parameter & Value \\
\hline Pipe centreline burial depth relative to the soil surface & $1.1 \mathrm{~m}$ \\
Pipe insulation thickness & $5 \mathrm{~cm}$ \\
Pipe casing thickness & $0.4 \mathrm{~cm}$ \\
Pipe roughness & $4.5 \mathrm{e}-5 \mathrm{~m}$ \\
Pipe thermal conductivity (steel) & $43 \mathrm{~W} / \mathrm{mK}$ \\
Insulation thermal conductivity (Rigid polyurethane foam) & $0.025 \mathrm{~W} / \mathrm{mK}$ \\
Casing thermal conductivity (Polyethylene) & $0.027 \mathrm{~W} / \mathrm{mK}$ \\
Soil thermal conductivity & $0.6 \mathrm{~W} / \mathrm{mK}$ \\
DH grid supply temperature & $70^{\circ} \mathrm{C}$ \\
Flow rate at no-load condition (as \% of peak load flow) & $15 \%$ \\
Temperature differential across DH side of BETS HEX & $30^{\circ} \mathrm{C}$ \\
BETS HEX effectiveness & $100 \%$ \\
Main VSP efficiency & $85 \%$
\end{tabular}

\subsubsection{Economic Model}

The levelized energy cost $(L E C)$ is used to compare the cost of energy generation for each model scenario. In the current study, energy generation comprises both heating energy and electricity. The $L E C$ is defined as the cost per unit of energy produced in a given energy system over a year [30] and is expressed as

$$
L E C=\frac{C R F \cdot N P V_{c} \cdot\left(1+i_{d}\right)^{t_{\text {delay }}}}{A E O}
$$

where $N P V_{c}$ is the net present value of energy system costs, $C R F$ is the capital recovery factor, $i_{d}$ is the discount rate, $t_{\text {delay }}$ is the energy system build time, and $A E O$ is the annual energy output (in units of MWh). In terms of cost-benefit analysis a discount rate, given as a percentage, is used to account for the time value of money: money is worth more today and it is in the future. For government backed projects it is recommended to utilize a 
discount rate between $6-8 \%$ [64]. The $C R F$ and $N P V_{c}$ are given by Eq. (3.2) and (3.3), respectively, where $j$ denotes the year, and $n$ represents the energy system lifetime.

$$
\begin{gathered}
C R F=\frac{i_{d} \cdot\left(1+i_{d}\right)^{n}}{(1+i)^{n}-1} \\
N P V_{c}=\sum_{j=1}^{n} \frac{\text { Annual cost }}{\left(1+i_{d}\right)^{j}}
\end{gathered}
$$

The annual cost of the energy system in Eq. (3.3) is expressed as

$$
\text { Annual cost }_{j}=C C+C_{O \& M}+C_{f u e l}+C_{P u m p}
$$

where $C C, C_{f u e l}, C_{O \& M}$, and $C_{P u m p}$ represent the energy system capital cost, fuel cost, operation, and maintenance cost, and pumping electricity cost, respectively. The energy system capital cost includes the cost of the energy plant equipment and facilities, and DH and/or electrical transmission grid if applicable.

Tables 3-4 through 3-8 provide a breakdown of the economic data used in the current analysis. These data include energy plant capital costs, fuel costs, DH grid steel piping costs, and economic parameters used to determine the levelized energy cost for each model scenario. The grid electricity cost is found by taking the weighted average Ontario timeof-use electricity price and including the corresponding delivery and regulatory charges for a rural medium density community. Transmission line construction costs are adapted from a detailed report examining the cost of transmission line installations in Northern Ontario [65]. Transmission line and facilities costs are separately grouped by line voltage and length in Table 3-6, as voltage requirements of transmission lines increase with increasing line length. All costs associated with the local community electrical distribution grid are ignored in the study as the existing grid infrastructure is assumed to be utilized. The DH 
grid steel piping costs include the cost of insulation and fittings, as well as associated planning, design, and installation costs.

Table 3-4: Economic parameters used to compare the levelized cost of energy generation for each model scenario considered in the current study.

\begin{tabular}{ccc} 
Economic Parameter & Symbol & Value \\
\hline $\begin{array}{c}\text { Discount rate } \\
\text { Lifetime of energy plants }\end{array}$ & $i_{d}$ & $6 \%$ \\
Lifetime of electrical transmission grid and DH & $n$ & 20 years \\
grid & $n$ & 60 years \\
Build time & $t_{\text {delay }}$ & 1 year \\
O\&M cost (as $\%$ of $\left.C_{C}\right)$ & $C_{O \& M}$ & $2 \%[66]$
\end{tabular}

Table 3-5: Capital cost of energy plant by type.

\begin{tabular}{cc} 
Plant Type & $\begin{array}{c}\text { Capital cost } \\
\mathbf{( \$ M / M W ) ~}\end{array}$ \\
\hline Propane boiler & $0.9[66]$ \\
Biomass boiler & $1.1[61],[10]$ \\
Diesel generator & $1.4[67],[68]$ \\
Biomass gasification CHP & $3.3[61]$ \\
Biomass ORC CHP & $5.9[61]$ \\
Diesel CHP & $2.9[68]$ \\
Cooling tower & $0.40[69]$ \\
Main variable speed pump & $0.47[10]$ \\
* Price taken from a natural gas boiler, as natural gas to propane \\
conversion costs are assumed to be negligible [70]
\end{tabular}

Table 3-6: Capital cost of transmission lines by length and voltage [65]

\begin{tabular}{ccccc}
$\begin{array}{c}\text { Transmission } \\
\text { line length } \\
(\mathbf{k m})\end{array}$ & $\begin{array}{c}\text { Voltage } \\
\mathbf{( k V )}\end{array}$ & $\begin{array}{c}\text { Facilities } \\
\text { cost } \\
\mathbf{( \$ K )}\end{array}$ & $\begin{array}{c}\text { Transmission } \\
\text { line cost } \\
\mathbf{( \$ K / k m )}\end{array}$ & $\begin{array}{c}\text { Total } \\
\text { cost } \\
\mathbf{( \$ K )}\end{array}$ \\
\hline 200 & 230 & 2,467 & 581 & 118,667 \\
100 & 115 & 1,202 & 549 & 56,102 \\
50 & 44 & 316 & 214 & 11,016 \\
25 & 25 & 316 & 198 & 5,266
\end{tabular}


Table 3-7: Variable cost of fuel by type.

\begin{tabular}{cc} 
Fuel Type & Fuel cost (\$/MWh) \\
\hline Propane & $169[1]$ \\
Diesel & $209[5]$ \\
Biomass (50\% moisture content, LHV) & $23[1]$ \\
Grid Electricity & $135[41]$
\end{tabular}

Table 3-8: District heating grid steel piping cost by pipe nominal diameter and length

\begin{tabular}{cccc}
$\begin{array}{c}\text { Nominal pipe } \\
\text { diameter (inches) }\end{array}$ & $\begin{array}{c}\text { Cost per meter } \\
\text { of pipe (\$/m) }\end{array}$ & $\begin{array}{c}\text { Length of pipe } \\
(\mathbf{m})\end{array}$ & $\begin{array}{c}\text { Cost per length of } \\
\text { pipe (\$K) }\end{array}$ \\
\hline 1 & 300 & 232 & 70 \\
$11 / 4$ & 325 & 464 & 151 \\
$11 / 2$ & 350 & 464 & 162 \\
2 & 375 & 1624 & 609 \\
$21 / 2$ & 420 & 2088 & 877 \\
3 & 450 & 3748 & 1,687 \\
4 & 520 & 500 & 260 \\
5 & 590 & 1000 & 590 \\
\hline
\end{tabular}

\subsubsection{Socio-economic Model}

Although $L E C$ is one of the most widely used metrics for assessing the economic feasibility of energy projects, it is often used without consideration of socio-economic benefits. A study conducted by Frank [71] shows several limitations to the use of $L E C$ for comparing typical fossil fuel technologies with a number of renewable energy alternatives. One such limitation is the habitual disregard for the impacts of carbon taxation in calculating $L E C$. To address this issue, they propose quantifying the $L E C$ of $\mathrm{CO}_{2}$ emissions for fossil fuel projects under a given carbon tax scheme as follows:

$$
L E C_{\mathrm{CO}_{2}}=\frac{A E * c \operatorname{Tax}}{A E O}
$$

where $A E$ represents the annual amount of $\mathrm{CO}_{2}$ emissions released (in units of tonnes), and cTax represents the value at which carbon is taxed (in units of $\$$ tonne of $\mathrm{CO}_{2}$ ). In the 
current study, a carbon tax of $\$ 10 /$ tonne of $\mathrm{CO}_{2}$ is assumed. The value of $L E C_{\mathrm{CO}_{2}}$ is added to the $L E C$ value calculated in Chapter 3.2.5 to account for the socio-economic impact of $\mathrm{CO}_{2}$ emissions on the overall cost of the energy plant.

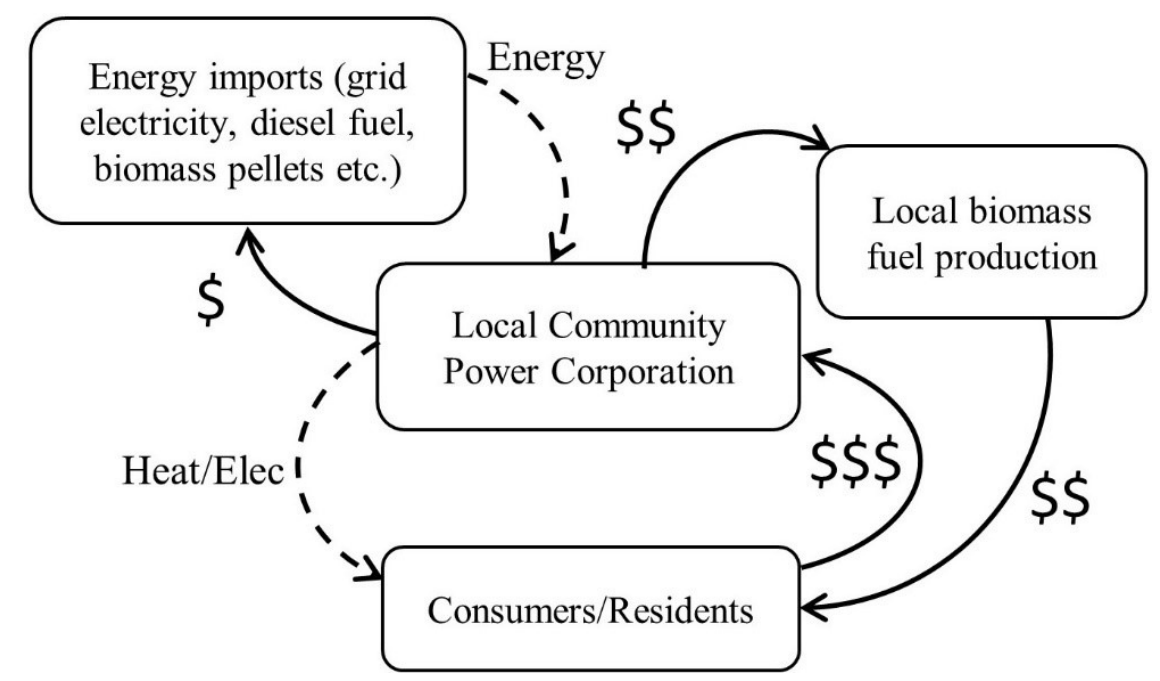

Figure 3-4: Benefits of local biomass fuel production relative to energy imports.

Another limitation to the conventional use of $L E C$ for comparing energy project options is that no consideration is given to the advantages of sourcing fuel locally. This consideration is especially relevant for biomass energy generation projects. One of the main benefits of implementing biomass energy generation in remote and rural communities is the ability to keep cash otherwise spent on energy imports circulating within the local economy, as depicted in Figure 3-4. This is achieved by utilizing biomass fuel that is harvested locally through local community employment [46].

Communities with biomass energy generation often rely on a fixed percentage of imported biomass to keep their plants operational [72]. The following expression is used to quantify the levelized energy benefit (LEB) associated with local biomass fuel production: 


$$
L E B_{\text {localbio }}=\frac{C_{b i o} * p_{\text {local }}}{A E O}
$$

where $C_{\text {bio }}$ and $p_{\text {local }}$ represent the annual cost of biomass, and the proportion of total biomass that is sourced locally (in \%), respectively. In the current study, a $p_{\text {local }}$ value of $50 \%$ is assumed. Contrary to $L E C_{C_{2}}, L E B_{\text {localbio }}$ is subtracted from the $L E C$ value calculated in Chapter 3.2.5 as all annual expenditures that go towards local jobs (such as biomass harvesting) can be viewed as an overall benefit to the community rather than a cost.

\subsubsection{Environmental Model}

The environmental impact of each scenario in the current study is based on both $\mathrm{CO}_{2}$ emissions, as well as other emissions which primarily affect local air quality. Local air quality greatly decreases as emissions of criteria pollutants such as $\mathrm{SO}_{2}, \mathrm{NO}_{\mathrm{x}}$, and $\mathrm{PM}_{10}$ increase. The U.S. Environmental Protection Agency (EPA) defines a criteria pollutant to be a "pollutant determined to be hazardous to human health and regulated under EPA's National Ambient Air Quality Standards" [73]. The three criteria pollutants mentioned above have been selected as they are known to have the most harmful impact on human health [74], [75]. Table 3-9 shows relative emissions per unit energy output of each of these pollutants for a number of fuel types. Since biomass is considered to be a carbon neutral fuel source, $\mathrm{CO}_{2}$ emissions from its combustion are assumed to be zero in this study [42]. Moreover, criteria pollutants from grid electricity are assumed to be zero as these emissions are not released to the atmosphere locally. 
Table 3-9: Emissions per unit energy output for a variety of fuel types.

$\begin{array}{llll}\mathrm{CO}_{2} & \mathrm{SO}_{2} & \mathrm{NO}_{2} & \mathrm{PM}_{10}\end{array}$

Fuel Type emissions emissions emissions emissions

\begin{tabular}{ccccc} 
& $\mathbf{( k g / \mathbf { M W h } )}$ & $\mathbf{( k g / \mathbf { M W h } )}$ & $\mathbf{( k g / \mathbf { M W h } )}$ & $\mathbf{( k g / \mathbf { M W h } )}$ \\
\hline Propane [42] & 211 & 0.001 & 0.22 & 0.01 \\
Diesel [42] & 255 & 1.58 & 2.97 & 0.09 \\
Grid electricity [43] & 31 & 0 & 0 & 0 \\
$\begin{array}{c}\text { Biomass (50\% moisture } \\
\text { content) [42] }\end{array}$ & 0 & 0.04 & 0.56 & 0.43
\end{tabular}

\subsection{Results \& Discussion}

A number of insights are drawn from the current study, which can be used to inform economic and policy decisions regarding the implementation of biomass driven CHP grids in remote and rural communities located in Canada and abroad. These insights are described as follows:

Insight 1: Biomass driven CHP grids are an economically attractive alternative for remote community energy systems however, this is not the case for rural community energy systems. In both systems, BG CHP plants are preferable to BORC CHP plants from an economic standpoint.

The $L E C$ values corresponding to each energy plant technology scenario, described in Table 3-1, are shown in Figure 3-5. These scenarios are categorized by the two main energy system layouts considered in this study: remote (M1) and rural (M2) community energy systems. Regarding the remote layout, all five proposed scenarios have a lower $L E C$ than that of the base case scenario, $\mathrm{M} 1 \mathrm{C} 1_{\mathrm{DG}}$, despite the fact that these scenarios contain a $\mathrm{DH}$ grid. Of these cases, the biomass $\mathrm{CHP}$ scenarios, $\mathrm{M} 1 \mathrm{C} 3_{\mathrm{BG}}$, and $\mathrm{M} 1 \mathrm{C} 3_{\mathrm{BORC}}$ have the lowest and highest $L E C$ values at $\$ 448 / \mathrm{MWh}$ and $\$ 784 / \mathrm{MWh}$, respectively. These values in the order given correspond to reductions in $L E C$ of approximately $45 \%$ and $4 \%$ relative to the

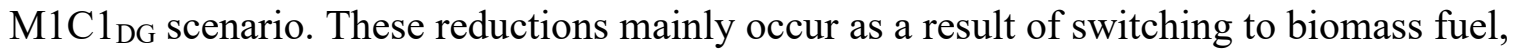


as well as from increasing overall system efficiency by generating heat and power simultaneously. The rural layout, on the other hand, shows the $L E C$ increasing for all five proposed scenarios relative to the base case scenario, $\mathrm{M} 2 \mathrm{C} 1_{\text {Grid. }}$ Of the proposed cases, the two biomass $\mathrm{CHP}$ scenarios (i.e. $\mathrm{M} 1 \mathrm{C} 3_{\mathrm{BG}}$, and $\mathrm{M} 1 \mathrm{C} 3_{\mathrm{BORC}}$ ) have the second lowest and second highest $L E C$ values at $\$ 358 / \mathrm{MWh}$ and $\$ 419 / \mathrm{MWh}$, respectively. These values in the order given correspond to increases in $L E C$ of approximately $165 \%$ and $209 \%$ relative to the $\mathrm{M} 2 \mathrm{C}_{\text {Grid }}$ scenario. The highest $L E C$, however, corresponds to the $\mathrm{M} 2 \mathrm{C} 3{ }_{\mathrm{DCHP}}$ scenario at $\$ 616 / \mathrm{MWh}$.

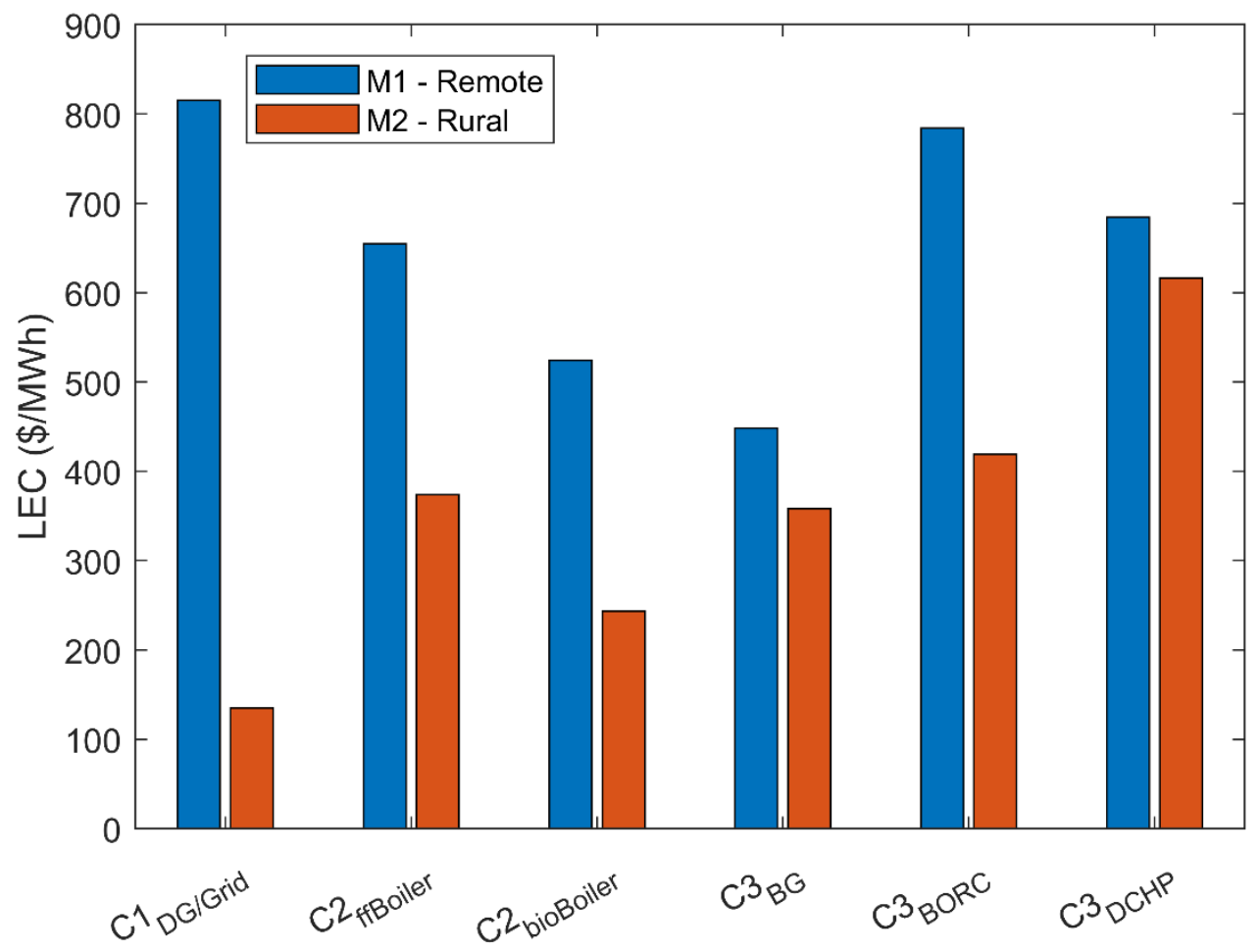

Energy plant technology scenario

Figure 3-5: Levelized energy cost corresponding to energy plant technology scenarios. M1 and M2 represent remote and rural community energy system layouts, respectively. 
The relative difference between remote and rural $L E C$ values varies considerably between each energy plant technology scenario shown in Figure 3-5. For the scenarios that include CHP generation, this variation is primarily due to the remote CHP plants operating to follow the community electrical load and not the heating load as is the case for rural CHP plants. As a result, greater fuel consumption and greater costs are incurred since all CHP technologies considered have low electrical to thermal efficiency ratios (see Table 3-2). For the heat-only scenarios, on the other hand, this variation is mainly due to the higher cost of diesel fuel relative to grid electricity, and also the additional capital cost associated with the construction of a diesel generator plant.

Insight 2: Remote biomass driven CHP grids are largely preferable to rural energy systems when electrical transmission grid extension costs are considered.

For all scenarios depicted in Figure 3-5, the $L E C$ values corresponding to the remote energy system layout exceed those of the rural system layout by a significant amount. It should be noted that this trend assumes that capital and operating costs associated with installing and maintaining the portion of the electrical transmission grid that extends into the community from the closest connection point are not considered. Therefore, the results of Figure 3-5 are only appropriate for existing rural or remote communities that are interested in switching energy plant technologies. However, for existing remote communities that are interested in connecting to the electrical transmission grid, the aforementioned costs need to be considered. Figure 3-6 shows the impact of increasing the length of the grid extension on $L E C$ for each rural scenario considered. $L E C S$ corresponding to the three remote biomass scenarios are also depicted in the figure for comparison. As these scenarios do not include an electrical grid connection, $L E C$ values remain unchanged 
as a function of the electrical transmission grid extension length. For the rural scenarios, on the other hand, $L E C$ values increase progressively by a fixed amount relative to each other as the grid extension length increases. The remote biomass CHP scenarios, $\mathrm{M} 1 \mathrm{C} 3_{\mathrm{BORC}}$, and $\mathrm{M} 1 \mathrm{C} 3_{\mathrm{Bg}}$ start to become more economical than the lowest $L E C$ rural scenario, $\mathrm{M} 2 \mathrm{C} 1_{\text {Grid, }}$, as the electrical grid extends beyond $54 \mathrm{~km}$ and $69 \mathrm{~km}$ in length, respectively. These distances decrease considerably when this comparison is made relative to all other proposed rural scenarios. At grid extension lengths of $100 \mathrm{~km}$ and $200 \mathrm{~km}, L E C$ values corresponding to scenario $\mathrm{M} 1 \mathrm{C} 3_{\mathrm{BG}}$ are roughly $67 \%$ and $83 \%$ lower than that of scenario $\mathrm{M} 2 \mathrm{C} 1_{\text {Grid, }}$, respectively. This finding supports the case for implementing biomass driven CHP grids as opposed to extending the electrical grid in remote communities located at a distance from the nearest grid connection point. This finding is also of particular relevance in the province of Ontario today as a major project is currently being built that involves the construction of a billion-dollar electrical transmission line spanning 2,000 km to interconnect 32 remote communities [76]. 


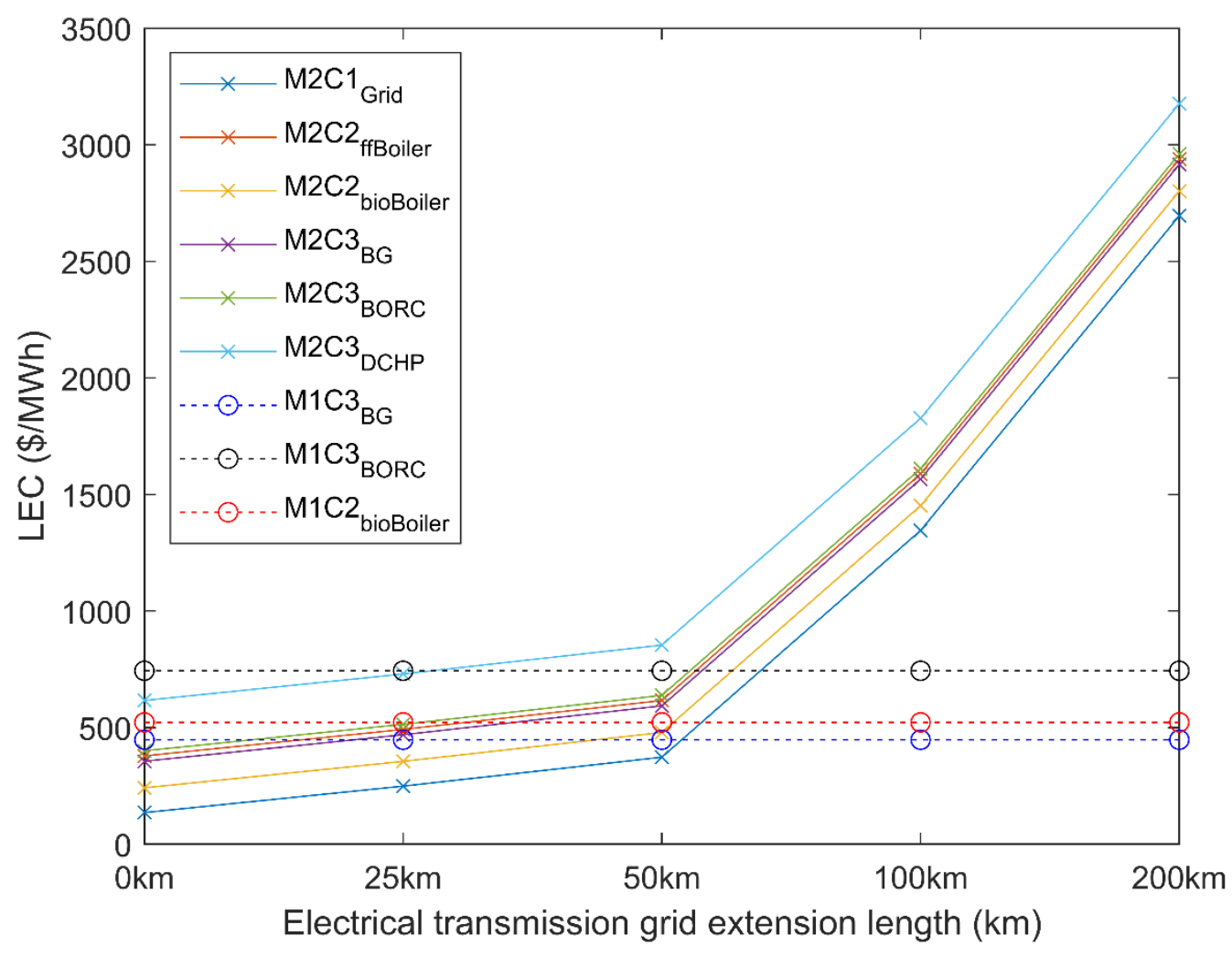

Figure 3-6: LEC corresponding to proposed rural energy plant technology scenarios as a function of electrical transmission grid extension length. In the current study, construction and maintenance costs associated with the transmission grid extension are not considered.

Insight 3: Energy systems comprising biomass driven CHP grids experience only $\underline{\text { marginal socio-economic benefits when highly conservative values of cTax and plocal are }}$ considered.

Figure 3-7 shows the percent change in $L E C$ for all scenarios as a result of including the levelized energy cost of $\mathrm{CO}_{2}$ emissions, $L E C_{\mathrm{CO}_{2}}$, in the $L E C$ calculation. This figure also shows, for the biomass scenarios only, the percent change in $L E C$ as a result of including the levelized energy benefit associated with local biomass fuel production, $L E B_{\text {localbio. }}$. The formula used to represent the percent change in $L E C$ in the current study is expressed as: 


$$
\text { Percent change in } \operatorname{LEC}(\%)=\frac{\left(L E C_{\text {new }}-L E C_{\text {original }}\right)}{\left|L E C_{\text {original }}\right|}
$$

where $L E C_{\text {original }}$ is the original $L E C$ value before any change is implemented, and $L E C_{\text {new }}$ is the new $L E C$ value after a change has been implemented. For all scenarios, an increase in $L E C$ occurs as a result of including the $L E C_{\mathrm{CO}_{2}}$ in the $L E C$ calculation. The largest increases are shown for the non-CHP biomass scenarios, as these scenarios include fossil fuel driven energy plant technologies. Overall, the percent change values associated to each scenario are relatively small, with the largest value $(\sim 1 \%)$ corresponding to the $\mathrm{M} 1 \mathrm{C} 1_{\mathrm{DG}}$ scenario. With regards to including the $L E B_{\text {localbio }}$ in the $L E C$ calculation, a decrease in $L E C$ is shown for all biomass scenarios. As in the previous case, the percent change values are relatively small, with the largest value $(\sim 6 \%)$ corresponding to the $\mathrm{M} 2 \mathrm{C} 2_{\text {bioBoiler }}$ Scenario. Although the socio-economic impact on $L E C$ as a result of including these parameters may appear to be trivial relative to the other costs considered in this study, it should be noted that these results are based on highly conservative values of $c$ Tax and $p_{\text {local }}$, equivalent to $\$ 10 /$ tonne of $\mathrm{CO}_{2}$, and $50 \%$, respectively. As these parameters are highly jurisdiction dependent, a sensitivity analysis is conducted to gauge the impacts of increasing both $c$ Tax and $p_{\text {local }}$ on LEC. 


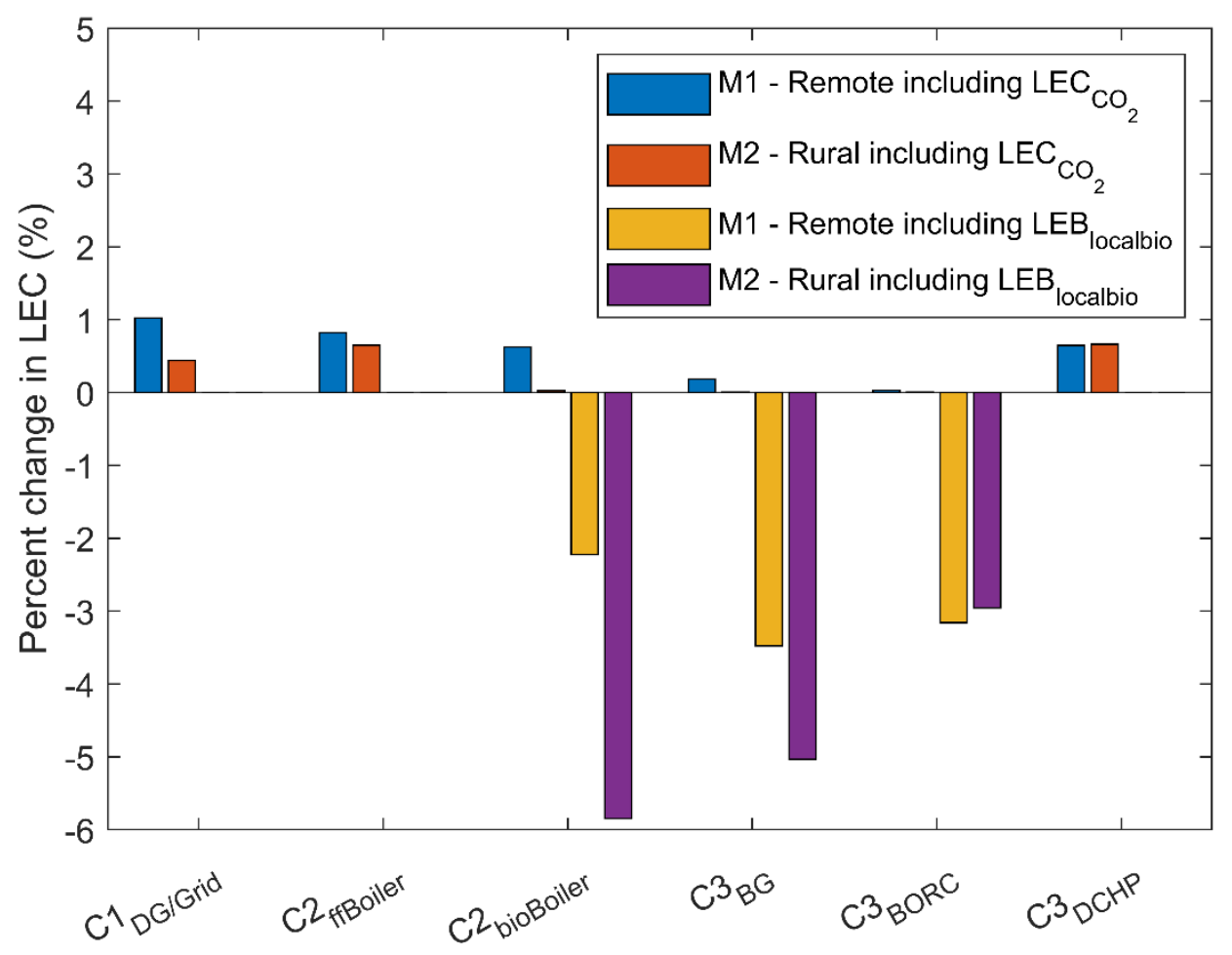

Energy plant technology scenario

Figure 3-7: Percent change in LEC by energy plant technology scenario as a result of including the levelized energy cost of $\mathrm{CO}_{2}$ emissions, $L E C_{C O}$, and the levelized energy benefit associated with local biomass fuel production, $L E B_{\text {localbio, }}$ in the LEC calculation.

Insight 4: Energy systems comprising biomass driven CHP grids experience significant socio-economic benefits when cTax and plocal values are increased, whereas, the opposite holds true for fossil fuel-based energy systems.

Figure 3-8a shows the percent change in $L E C$ for all scenarios as $c T a x$ increases from $\$ 10$ to $\$ 100 /$ tonne of $\mathrm{CO}_{2}$. All fossil fuel-based scenarios for both remote and rural energy system layouts are highly sensitive to variations in $c \operatorname{Tax}$. Scenario $\mathrm{M} 1 \mathrm{C} 1_{\mathrm{DG}}$ is the second most sensitive to this value, with corresponding increases in $L E C$ of $4 \%$ and $8 \%$ at $c T a x$ values of $\$ 50$ and $\$ 100 /$ tonne of $\mathrm{CO}_{2}$, respectively. Scenario $\mathrm{M} 2 \mathrm{C}_{\text {Grid, }}$ on the other hand, is highly insensitive in this regard, with corresponding increases in $L E C$ in the order given 
of $2.2 \%$ and $4.4 \%$. Although this is the case for the province of Ontario, these values can change considerably based on the carbon intensity of the local electrical transmission grid. For example, the electrical grid in the province of Alberta has a carbon intensity that is approximately 20 times greater than that of Ontario [77], and thus is much more sensitive to increases in cTax. The biomass CHP scenarios for both remote and rural energy system layouts are also highly insensitive in this regard, with corresponding increases in $L E C$ remaining below $2 \%$ at a cTax value of $\$ 100 /$ tonne of $\mathrm{CO}_{2}$. The aforementioned cTax value of $\$ 50 /$ tonne is significant in the current jurisdiction as it represents the current carbon taxation goal set by the Federal government for the year 2022 [44]. For both the remote and rural configurations, the biomass CHP scenarios exhibit the least sensitivity to changes in $c$ Tax. Figure $3-8 \mathrm{~b}$ shows the percent change in $L E C$ for all biomass scenarios as $p_{\text {local }}$ increases from 10 to $100 \%$. Scenarios $\mathrm{M} 2 \mathrm{C} 3_{\mathrm{BG}}$ and $\mathrm{M} 2 \mathrm{C} 2_{\text {bioBoiler }}$ have the highest sensitivity to changes in local biomass supply, as they are the scenarios that have the largest biomass feedstock requirements. The percent change corresponding to the latter of these scenarios (i.e. $\mathrm{M} 2 \mathrm{C} 2_{\text {bioBoiler }}$ ) is slightly greater and reaches a maximum value of roughly $11.7 \%$ when $100 \%$ of the biomass feedstock is supplied locally. Scenario M1C 2 bioBoiler, on the other hand, has the lowest sensitivity to changes in local biomass supply and only reaches a maximum value of $-4.4 \%$ at this same level of local biomass supply. 

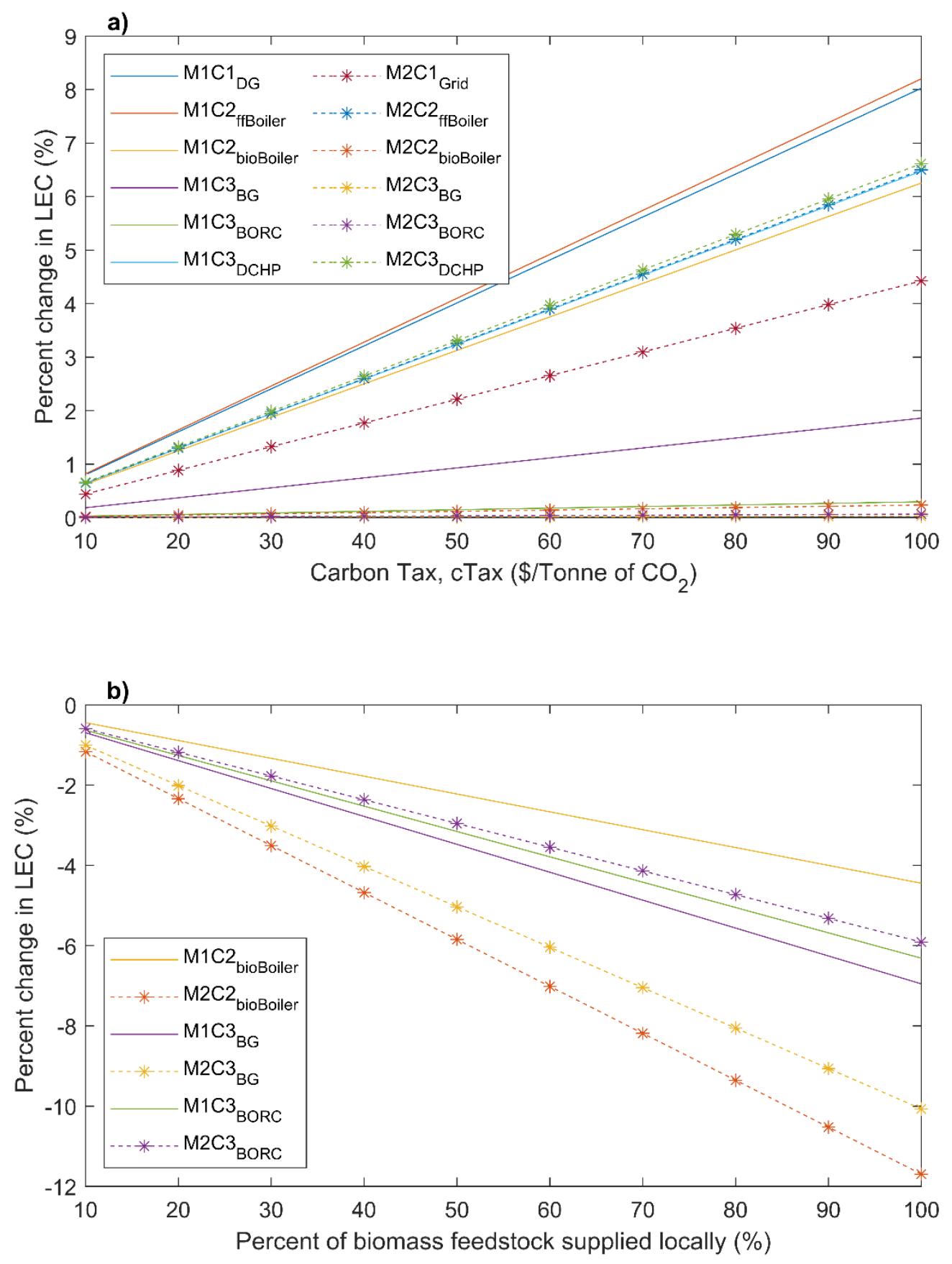

Figure 3-8: Percent change in LEC by energy plant technology scenario as a function of a) carbon tax, cTax, and b) percent of biomass feedstock supplied locally, $p_{\text {local. }}$ 
Insight 5: Energy systems comprising biomass driven CHP grids are relatively insensitive to varying fossil fuel and electricity costs from an economic standpoint.

To further assess the sensitivity of $L E C$ to changing system conditions, an analysis is conducted that consists of varying a number of parameters over an arbitrary range of plus or minus $80 \%$ relative to their assumed values. Figure 3-9 shows the percent change in $L E C$ for all scenarios as the following four parameters are varied: a) the discount rate, b) the biomass fuel cost, c) the diesel fuel cost, and d) the grid electricity cost. These parameters are selected as they are considered to be the most influential with regards to LEC sensitivity. Figure 3-9a shows that varying the discount rate has more of an impact on $L E C$ for the biomass $\mathrm{CHP}$ scenarios (i.e. $\mathrm{M} 1 \mathrm{C} 3_{\mathrm{BG}}, \mathrm{M} 2 \mathrm{C} 3_{\mathrm{BG}}, \mathrm{M} 1 \mathrm{C} 3_{\mathrm{BORC}}$, and $\mathrm{M} 2 \mathrm{C} 3_{\mathrm{BORC}}$ ) than the base case scenarios (i.e. $\mathrm{M} 1 \mathrm{C} 1_{\mathrm{DG}}$, and $\mathrm{M} 2 \mathrm{C} 1_{\mathrm{Grid}}$ ). This disparity is mainly due to the biomass CHP scenarios requiring a significantly greater capital investment. In all cases, however, the absolute percent change in $L E C$ remains below $40 \%$ as the discount rate is either increased or decreased by $80 \%$. Varying the biomass fuel cost, on the other hand, has a much lesser impact on $L E C$ for all scenarios considered, as shown by Figure 3-9b, with an absolute percent change in $L E C$ below $8 \%$ as the biomass fuel cost is either increased or decreased by $80 \%$. Figure $3-9 \mathrm{c}$ and $9 \mathrm{~d}$ show that varying diesel fuel and grid electricity costs have a significant impact on $L E C$ for the base case scenarios, $\mathrm{M} 1 \mathrm{C} 1_{\mathrm{DG}}$, and $\mathrm{M} 2 \mathrm{C} 1_{\text {Grid, }}$ respectively. For each of these scenarios in the order given, the corresponding absolute percent change in $L E C$ is approximately $66 \%$ and $80 \%$ as diesel and grid electricity costs are either increased or decreased by $80 \%$. Of much lesser magnitude, however, is the absolute percent change in $L E C$ corresponding to the biomass CHP scenarios as these parameters are varied over the same range. For the remote layout 
(Figure 3-9c), the biomass CHP scenarios (i.e. $\mathrm{M} 1 \mathrm{C} 3_{\mathrm{BG}}$, and $\mathrm{M} 1 \mathrm{C} 3_{\mathrm{BORC}}$ ) are not shown as diesel fuel is not utilized. As such, the $L E C$ for these scenarios is insensitive to changes in diesel fuel cost. For the rural layout (Figure 3-9d), the absolute percent change in $L E C$ remains below approximately $6 \%$ for the biomass $\mathrm{CHP}$ scenarios (i.e. $\mathrm{M} 2 \mathrm{C} 3_{\mathrm{BG}}$, and $\left.\mathrm{M} 2 \mathrm{C} 3_{\mathrm{BORC}}\right)$ as grid electricity costs are either increased or decreased by $80 \%$.

An important benefit that arises from this low sensitivity to changing fuel costs for communities comprising biomass driven CHP grids is enhanced energy security. The addition of biomass energy production in a community's energy supply can significantly increase a community's energy security and protect against fossil fuel and grid electricity pricing volatilities on the international market. This can be achieved by developing local supply infrastructure to harvest, collect, and store locally produced biomass. Apart from creating local employment opportunities, which are currently in short supply in small northern communities [78], sourcing biomass locally can reduce a community's dependence on conventional imported energy sources thereby increasing energy autonomy. 

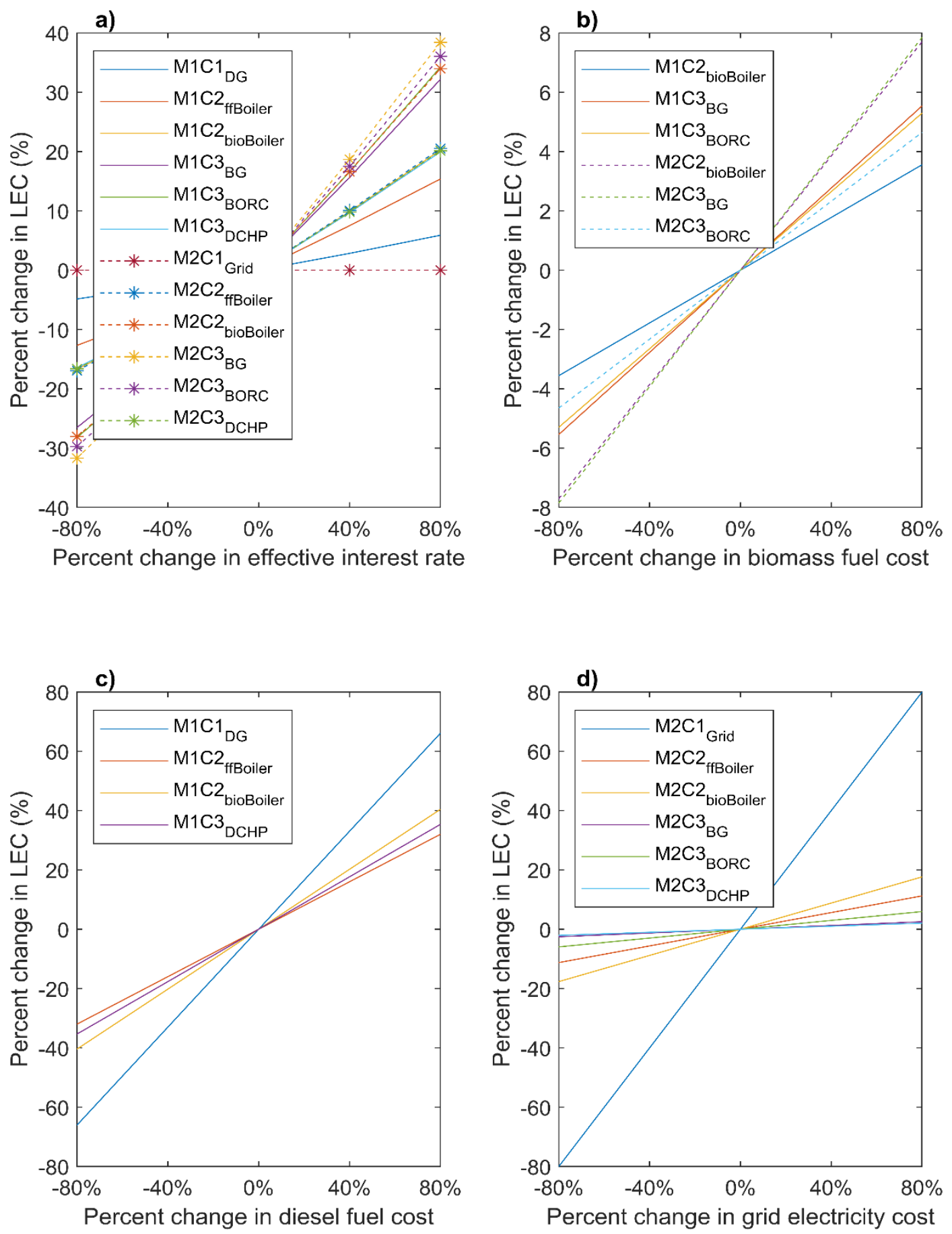

Figure 3-9: Percent change in LEC by energy plant technology scenario as a function of a) the discount rate, b) the biomass fuel cost, c) the diesel fuel cost, and d) the grid electricity cost. 
Insight 6: Despite generating low annual levels of $\mathrm{CO}_{2}, \mathrm{SO}_{2}$, and $\mathrm{NO}_{x}$ emissions, energy systems comprising biomass driven CHP grids are significant contributors of $\mathrm{PM}_{10}$ emissions.

Figure 3-10 shows the annual emissions (in tonnes) of a) $\mathrm{CO}_{2}$, b) $\mathrm{SO}_{2}$, c) $\mathrm{NO}_{\mathrm{x}}$, and d) $\mathrm{PM}_{10}$ for all scenarios. As shown in Figure 3-10a, annual $\mathrm{CO}_{2}$ emissions for all scenarios corresponding to the remote layout are much greater than those corresponding to the rural layout. The base case scenario $\mathrm{M} 1 \mathrm{C} 1_{\mathrm{DG}}$ shows the highest amount at 3164 tonnes per year. The biomass CHP scenarios for the rural layout (i.e. $\mathrm{M} 2 \mathrm{C} 3_{\mathrm{BG}}$ and $\mathrm{M} 2 \mathrm{C} 3_{\mathrm{BORC}}$ ), on the other hand, show the lowest amounts of annual $\mathrm{CO}_{2}$ emissions at 10 and 26 tonnes per year, respectively. These same biomass $\mathrm{CHP}$ scenarios for the remote layout (i.e. $\mathrm{M} 1 \mathrm{C} 3_{\mathrm{BG}}$ and M1C3 $3_{\text {BORC) }}$ show $\mathrm{CO}_{2}$ emissions that are slightly greater at 314 and 88 tonnes per year, respectively. Similar trends as those described above are also shown for annual $\mathrm{SO}_{2}$ and $\mathrm{NO}_{\mathrm{x}}$ emissions. Reductions as high as $98 \%$ of these criteria pollutants are shown in Figure 3-10b and 10c, respectively, for the biomass CHP scenarios relative to the highest emitting scenario (i.e. $\mathrm{M} 1 \mathrm{C} 1_{\mathrm{DG}}$ ). Despite these promising results, the opposite trend is shown in Figure 3-10d with regards to annual $\mathrm{PM}_{10}$ emissions. These emissions are shown to be the highest of all for the biomass CHP scenarios. This result is consistent with what is found in the literature and as such presents a significant drawback of implementing biomass driven CHP grids [61]. It should be noted, however, that with recent advancements in biomass CHP plant filter and scrubber technologies, the level of particulate matter emissions has been consistently diminishing year after year, and this trend is expected to continue as we move forward into the future [46]. 
a)

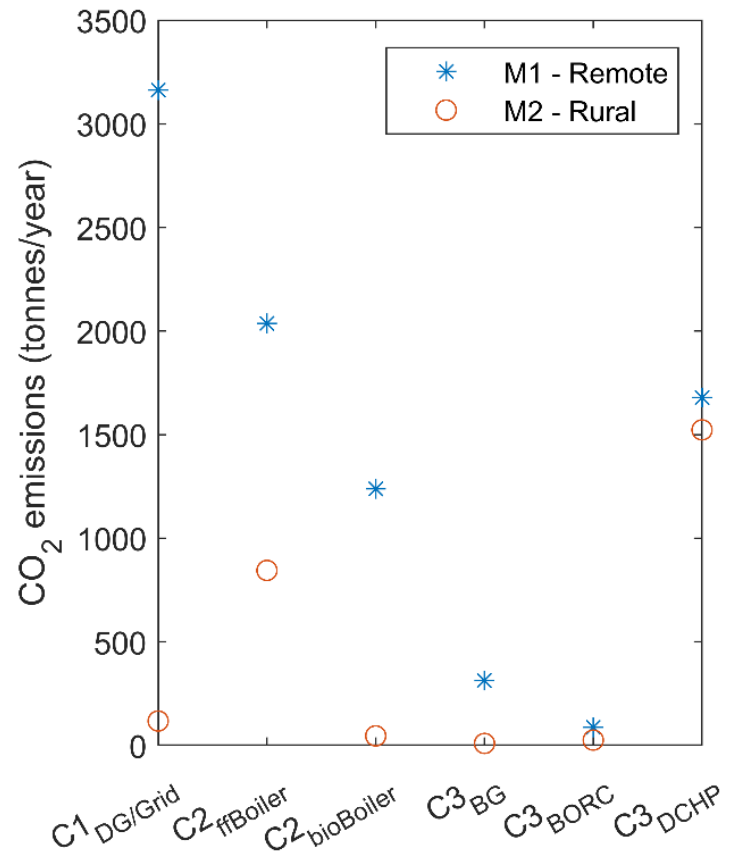

Energy plant technology scenario

c)

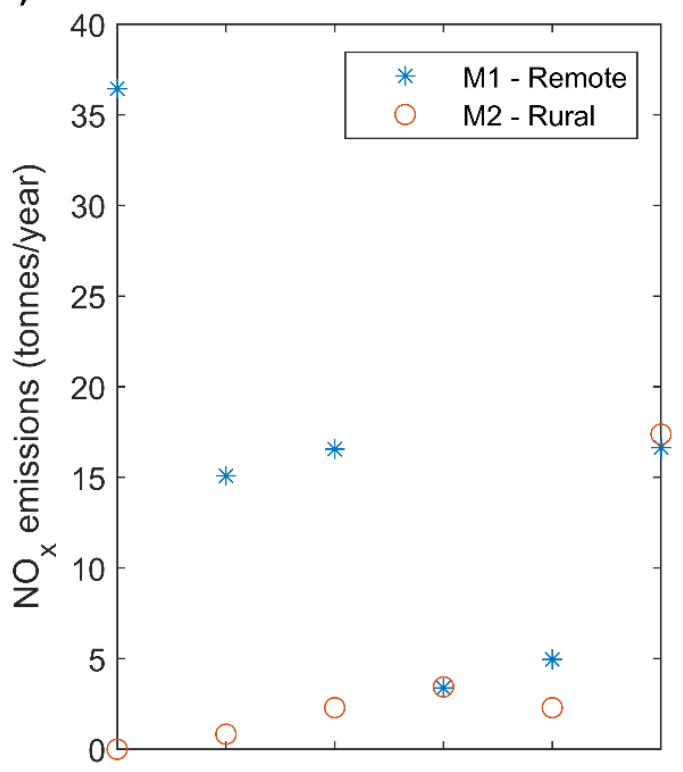

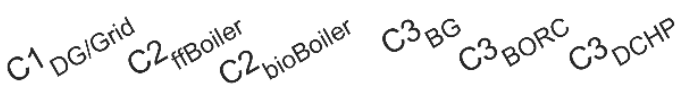

Energy plant technology scenario b)

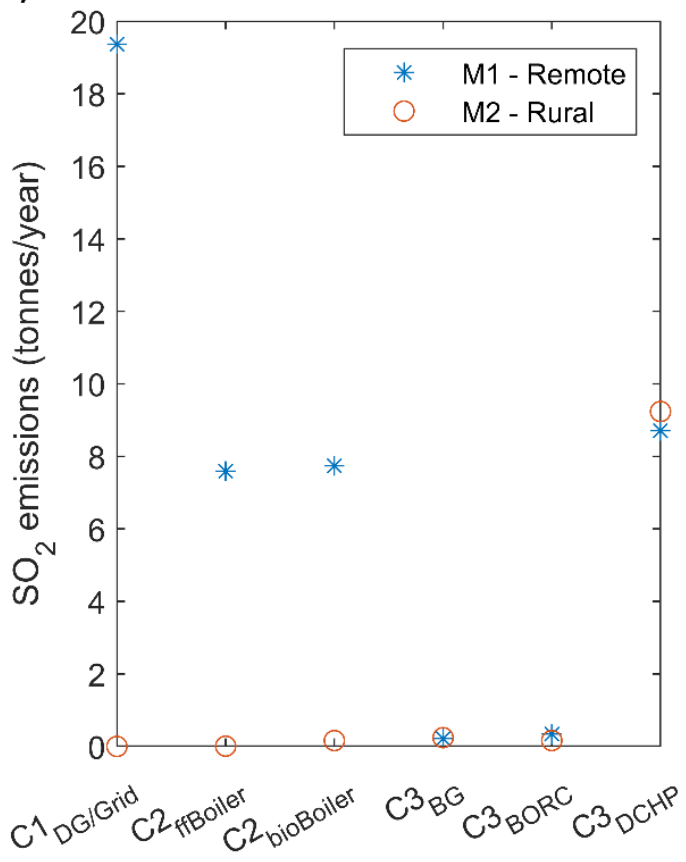

Energy plant technology scenario

d)

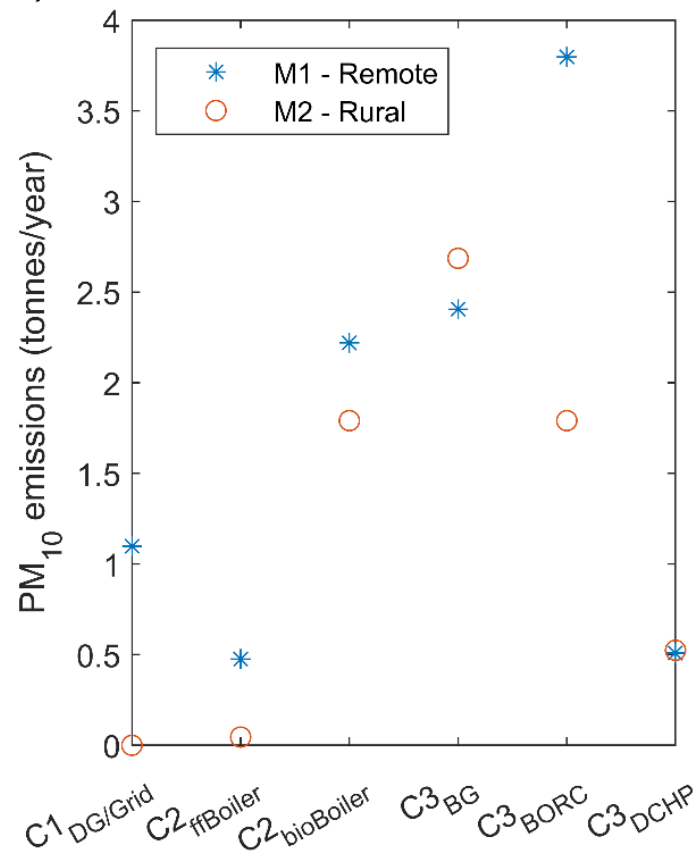

Energy plant technology scenario

Figure 3-10: Annual emissions (in tonnes) by energy plant technology scenario of a) $\mathrm{CO}_{2}$, b) $\mathrm{SO}_{2}$, c) $\mathrm{NO}_{x}$, and d) $\mathrm{PM}_{10}$ 


\subsection{Closing remarks}

Two distinct energy system models were developed in the current study that are representative of typical northern remote and rural communities. The MoCreebec Eeyoud community located in Northern Ontario, Canada, was used as the case study in the analysis. For each model, five district heating based energy plant technologies (i.e. a propane boiler plant, a biomass boiler plant, a biomass gasification CHP plant, a biomass ORC CHP plant, and a diesel CHP plant) were assessed. To gauge the potential benefits of implementing these technologies, results were compared relative to conventional energy plant technologies such as a diesel generator plant, and the electrical grid for remote and rural communities, respectively. Results show that biomass driven CHP grids are an economically attractive alternative for both remote and rural energy systems when electrical transmission grid costs are considered. In both remote and rural systems, biomass gasification CHP plants are preferable to biomass organic Ranking CHP plants from an economic standpoint. Socio-economic benefits were found to be negligible at low carbon tax rates and low levels of local biomass production. However, these benefits increased considerably as carbon tax rates and local biomass production increased. Furthermore, energy systems comprising biomass driven CHP grids were observed to be less sensitive to varying fossil fuel and electricity costs. Regarding the environmental impacts of biomass driven CHP grids, even though these systems generate significantly lower annual levels of $\mathrm{CO}_{2}, \mathrm{SO}_{2}$, and $\mathrm{NO}_{\mathrm{x}}$ emissions relative to fossil-fuel based energy plants, they contribute greater amounts of $\mathrm{PM}_{10}$ emissions. The insights gathered from this study are useful to similar northern remote and rural communities who are faced with disadvantageous energy 
systems and are seeking to transition to inexpensive, renewable, reliable, and locally sourced biomass energy options.

While this chapter has shown the benefits of the implementation of biomass driven district heating grids in isolated communities, there are several research questions and issues to be resolved, namely:

- How much biomass can communities feasibly produce locally? Though not a novel idea, the creation of a local biomass feedstock economy in an isolated community is a challenging task to undertake. Wood (in large volumes) needs to be gathered, prepped, stored, dried, then manually fed into the biomass energy plant. This may not be feasible for a number of communities for a variety of reasons, such as limited access to equipment or manpower, or low levels of biomass resource endowments. However, there are a growing number of communities (e.g. the indigenous community of Kwadacha located in northern remote British Columbia [79], or the Fort McPherson community located in remote Northwest Territories [72]) that have successfully implemented biomass driven DH energy systems sourced with locally harvested woody biomass to reduce their reliance on diesel generators and create local employment opportunities. Data on the volumes of wood these communities are able to gather are not publicly available however, it is prudent to investigate these communities in greater detail so similar isolated communities across Canada can learn from their challenges and successes.

- How closely do the findings from the current study apply to other isolated communities located across Canada? They are several isolated communities scattered across Canada in various climate zones. Many of whom are situated in 
northern arctic regions. Longer and more severe arctic weather could impact the performance of a DH grid in many aspects such as higher thermal losses through the DH pipes, and increases in community space heating demands which can potentially result in larger and more costly DH energy systems. Therefore, the impacts of biomass driven DH grids implemented across other Canadian climate zones and arctic regions should be studied in further detail.

- How do additional renewable energy sources such as wind or solar perform relative to biomass energy in isolated communities? Many northern communities are seeking supply-side interventions outside of biomass DH grids such as wind turbines, solar photovoltaic panels, or solar thermal heating systems [16], [72], [80]. Investigating and comparing the economic, environmental, and socio-economic benefits of these alternative supply-side interventions with those of the current study should be examined in further detail. Such information would be beneficial for northern community leaders and policymakers who are seeking to incorporate renewable energy sources into their current energy system configuration.

- Can alternative DH grid construction methods such as the use of utilidors or directional drilling increase the economic viability of DH energy systems relative to conventional DH grid construction methods? The current study assumes the DH grid pipes are built using conventional trenching methods, in which insulated pipes are buried in previously undisturbed soil. However, there exist several other construction methods such as exterior utility service corridors (i.e. utilidors) where pipes are built above grade, or the use of directional drilling construction methods [80]. In practice, these alternative construction methods have been shown to lead 
to reductions in $\mathrm{DH}$ grid construction costs of up to $17 \%$ [81]. However, these construction methods have not been studied in detail in isolated settings and warrants further research. 


\section{Chapter 4}

\section{This chapter has been submitted for publication as:}

J. Coady, and J. Duquette, "Towards a cost-effective remote community energy system model: Evaluating tradeoffs between supply and demand-side interventions," Energy and Buildings [Complete - awaiting submission] 


\section{Chapter 4: Towards a cost-effective remote community energy system: the economic trade-offs of building-based demand-side interventions implemented within a community-owned biomass driven DH grid}

\subsection{Introduction}

In recent years, significant progress has been made with regards to developing supply and demand-side technology-based interventions that allow isolated communities to address their energy system related challenges in a manner that is both economically viable and environmentally sound. As is shown in Chapter 3, one supply-side intervention that holds considerable promise for a large number of these communities is biomass driven $\mathrm{DH}$ grids [10]. However, a considerable barrier to adopting this technology in isolated communities, is the high capital cost associated with building a DH grid in far northern locations, which can cost as much as $\$ 800$ per meter installed [10], [12]. This significant up-front cost can be a major deterrent for northern community leaders and policymakers and is one of the main reasons why many communities are opting to invest in buildingbased demand-side interventions (DSI) instead [13]. Building-based demand-side interventions not only reduce total community energy demand, they can also increase occupant thermal comfort within residential community buildings. Furthermore, implementing DSIs can potentially contribute to reducing the above-mentioned barriers to adopting biomass driven DH grids at the community level, since the up-front cost of these systems varies significantly as a function of the total community peak heating demand [14], [15]. Therefore, potential economic trade-offs exist as a result of integrating the aforementioned supply and demand-side interventions. 


\subsubsection{Literature review}

A number of studies have been conducted to analyze the technical, and environmental impacts of implementing building-based DSIs in DH grid-based energy systems. Le Truong et al. [82] investigated the impacts of implementing a range of DSIs on the potential primary energy savings of a DH grid-connected multi-apartment building located in Sweden. They developed several hypothetical scenarios in which both the scale of the DH grid and the energy plant generation type was varied. They concluded that improved building envelope interventions have the greatest impact on primary energy savings in all cases considered. Similar findings were established by Joelsson \& Gustavsson [83] in a study in which they compared annual reductions in energy and $\mathrm{CO}_{2}$ emissions in residential Swedish households from the implementation of multiple envelope energy retrofits and heating plant conversions. Envelope energy retrofits included upgraded windows and increased envelope insulation to the attic floors, foundation, and walls. Heating plant conversions included switching from electric baseboard space heaters to a residential heat pump, a decentralized biomass pellet boiler, or connecting to a local DH grid under varying energy supply configurations. The researchers demonstrated that scenarios consisting of both a biomass DH grid connection and housing envelope retrofits showed the largest reduction in primary energy and $\mathrm{CO}_{2}$ emissions, equivalent to $88 \%$ and $96 \%$, respectively.

In addition to analyzing the potential technical and environmental benefits from implementing building-based DSIs on DH grids, several studies have also been conducted to assess the economic impacts of implementing these measures. Zvingilaite \& Balyk [84] studied the cost-effectiveness of implementing a range of DSIs including envelope energy retrofits and the installation of heat recovery ventilators in the Danish housing stock under 
the current state of the DH grid as well as under a number of future hypothetical scenarios for the year 2050 that assume a diverse energy mix, and the expansion of the existing DH grid to nearby homes and communities. They found that although it is possible to reduce the total heating demand by up to $40 \%$ via the implementation of DSIs, it is only economical to do so when these reductions do not exceed roughly $17 \%$. Difs et al. [85] studied the techno-economic impacts of implementing a variety of DSIs on a large subset of buildings connected to a regional DH grid in Sweden. The DSIs investigated include improved attic insulation, multiple electricity savings measures, and the implementation of a sophisticated heating demand control software. While the electricity savings measures were found to be the most economical option, and the improved attic insulation the least economical, the latter option provided much greater benefits to the consumers, as attic insulation was found to have the largest effect in colder months, and therefore significantly reduced demand on the building-based peak boilers. Sperling \& Möller [14] developed a numerical model to study the potential impacts of both expanding an existing DH grid as well as implementing building-based electrical and envelope retrofits in the city of Frederikshavn, Denmark. They found that scenarios comprising both a DH grid expansion and envelope energy retrofits resulted in the highest levels of both annual energy savings and $\mathrm{CO}_{2}$ reductions. However, they also found that $\mathrm{DH}$ grid costs increased as the annual heating demand decreased. Despite this economic setback, the researchers recommend that communities should first seek to retrofit neighborhood buildings prior to designing and building DH grid infrastructure. Similar recommendations were reached by Gustavsson, Dodoo, and Danielski [15] who assessed via numerical simulation the impacts of implementing building energy retrofit DSIs on a DH grid connected to a Swedish multi- 
story apartment building. They found that implementing DSIs caused the share of the heat production serviced by the baseload DH energy plant to drop by as much as $24 \%$; hence reinforcing the need to design the $\mathrm{DH}$ grid based on long-term energy demands, that take into account the possibility of future DSIs, to avoid oversizing of the baseload energy plant at great expense.

\subsubsection{Research gaps identified in the literature}

As described above, the majority of the studies found in the literature show promising results regarding the ability of building-based DSIs to drastically reduce greenhouse gas emissions and increase energy savings in $\mathrm{DH}$ grids. However, the potential economic benefits resulting from such interventions are still conflicting as they depend heavily on factors like system location, energy mix, and heating plant technology type. The following research gaps have been identified with regards to the above-mentioned studies:

1- The focus is predominantly on DH grids located in densely populated northern European cities where all residential buildings are connected to the electrical grid, and heating load densities are high. Only a limited number of studies have been conducted that focus on smaller scale off-grid locations such as isolated communities.

2- The energy systems considered are large and complex, and comprise a variety of energy sources and conversion technologies. The impacts of implementing building-based DSIs in DH grid based energy systems driven by biomass have not been investigated.

3- Only a limited number of building envelope energy retrofits are assessed, which are normally analyzed independently from one another. No studies have been 
conducted that investigate the impacts of implementing unique combinations of multiple building envelope energy retrofits in communities whose energy systems are biomass driven.

\subsubsection{Research objectives}

The objective of this study is to assess the impacts of implementing a wide range of building-based DSIs in the form of packaged envelope energy retrofits (PER) on the economic viability of biomass driven DH grids in isolated communities. A secondary objective is to address the following key questions faced by isolated community leaders and policymakers who are considering transitioning from a utility-owned diesel-based energy system (i.e. a system in which residents pay a specified rate to a third party utility for every unit of energy consumed) to a community-owned centralized biomass energy supply system:

1- Under which conditions is it preferable to invest in building-based DSIs within an existing utility-owned energy system as opposed to investing in these interventions within a newly built community-owned biomass driven DH grid?

2- In which ways are the design considerations and capital cost of a newly built community-owned biomass driven DH grid impacted by the implementation of building-based DSIs?

3- How does the economic viability of a newly built community-owned biomass driven DH grid vary as a function of the annual energy savings associated with the implementation of building-based DSIs?

4- How do community energy density and DH grid length affect the economic viability of a newly built community-owned biomass driven DH grid? 


\subsubsection{Organization of this chapter}

Three residential building energy models (BEM) corresponding to detached, semidetached, and row home buildings typically encountered in isolated communities are developed using the EnergyPlus ${ }^{\mathrm{TM}}$ [29] building energy modeling software. For each BEM, a worst-case, base-case, and best-case housing efficiency scenario (HES) is presented. To assess the economic impacts of implementing DSIs on these HESs within a utility-owned energy system, a wide range of PERs are developed which represent multiple unique combinations of building envelope energy retrofits. To assess the economic impacts of implementing PERs within a community-owned energy system, a community scale biomass driven DH grid model is also developed in Matlab ${ }^{\circledR} /$ Simulink ${ }^{\circledR}[57]$ and used to calculate annual energy plant fuel consumption, as well as DH grid pumping energy requirements and heat losses. Three distinct biomass plant technologies are investigated: a heat-only biomass boiler, a gasification combined heat and power (CHP) plant, and an organic Rankine cycle CHP plant. A simulation dispatch algorithm is developed to investigate the potential economic benefits of implementing PERs across these biomass plant technologies. The economic viability of implementing PERs in both of the energy systems described (i.e. utility-owned and community-owned) are compared using the net present value over the project lifetime. Ordinary least square regression models are developed for each BEM and HES using the Python v3.8.0 statistical modeling package statsmodels.

The methodology presented in the current study is a continuation of that described in the two previous chapters (i.e. Chapters 2 and 3) which focus on 1) assessing the impacts of building-based DSIs on annual energy savings and occupant thermal comfort in isolated 
communities [86], and 2) comparing the technical, economic, socio-economic, and environmental impacts of implementing biomass driven CHP grids in isolated communities [87]. The MoCreebec Eeyoud community is used as the case study in the analysis.

\subsection{Methodology}

\subsubsection{Residential building energy models}

The three residential building energy models (BEM) developed in Chapter 2 are used in the current study to represent typical housing archetypes found in northern isolated communities. These archetypes include detached, semi-detached, and row home buildings, as shown in Figure 2-1. For each BEM, a worst-case, base-case, and best-case housing efficiency scenario (HES) is developed (see Table 4-1) to assess a wider range of potential housing conditions encountered in isolated communities. These scenarios, in the order given, are based on the lowest, average, and highest component-specific envelope insulation values obtained from the housing energy audits.

Table 4-1: Envelope insulation value by building component and housing efficiency scenario. Data is obtained from multiple MoCreebec Eeyoud community housing energy audits.

\begin{tabular}{cccc}
$\begin{array}{c}\text { Building } \\
\text { Component }\end{array}$ & Worst-case & $\begin{array}{c}\text { Insulation value }\left(\mathbf{m}^{2} \mathbf{K} / \mathbf{W}\right) \\
\text { Base-case }\end{array}$ & Best-case \\
\hline $\begin{array}{c}\text { Attic Insulation } \\
\text { Above-grade ext. }\end{array}$ & 5.34 & 6.5 & 6.9 \\
wall insulation & 3.0 & 3.2 & 3.8 \\
$\begin{array}{c}\text { Below-grade ext. } \\
\text { wall insulation }\end{array}$ & 1.58 & 1.95 & 3.17 \\
$\quad$ Window & 0.34 & 0.41 & 0.46 \\
$\quad \begin{array}{c}\text { Ext. door } \\
\text { Effective leakage }\end{array}$ & 0.28 & 0.96 & 1.14 \\
area $\left(\mathrm{cm}^{2}\right)$ & 847 & 443 & 306 \\
\hline
\end{tabular}




\subsubsection{Demand-side interventions within utility-owned energy system - packaged envelope energy retrofits}

The PERs developed in Chapter 2 are utilized in the current study to assess the economic impacts of implementing DSIs on the HESs described in Chapter 4.2.1. Each PER represents a unique combination of the building envelope energy retrofits listed in Table 2-3 and can comprise any number of retrofits, however, no more than one retrofit can be selected for each building component. Initially, 324 PERs are developed. As shown in Table 2-3, retrofits include improvements to the above and below grade exterior walls, the basement, and attic floors, as well as the exterior doors and windows.

The net present value (NPV) is used to compare the economic viability of implementing any given PER on all community buildings simultaneously within a utilityowned energy system. As such, all building level energy costs (i.e. heating and electricity costs) are assumed to be valued at the local community energy rate (i.e. the rate paid for energy by homeowners). The NPV (\$) of PER $i$ under HES $k$ is expressed as

$$
N P V_{i, k}=\sum_{j=0}^{n} \frac{\left(\text { Benefit }_{i, k}-\text { Cost }_{i, k}\right)_{j}}{\left(1+i_{d}\right)^{j}}
$$

where $j, n(\mathrm{yr})$, and $i_{d}(\%)$ represent the year, project lifetime, and the discount rate, respectively. $\operatorname{Cost}_{i, k}(\$)$ and Benefit $_{i, k}(\$)$ represent the total PER capital cost (only applied at year 0), and the annual cost savings, respectively. The latter term is expressed as

$$
\text { Benefit }_{i, k}=A E S_{i, k} \cdot\left(C f+c T a x \cdot \frac{c E m m}{\eta_{\text {diesel }}}\right)
$$

where $C f(\$ / \mathrm{MWh}), c E m m\left(\mathrm{tCO}_{2} / \mathrm{MWh}\right)$, and $\eta_{\text {diesel }}(\%)$ represent the community energy rate, the $\mathrm{CO}_{2}$ emission intensity and electrical efficiency of the community diesel powered 
energy system ${ }^{2}$, respectively. A fixed value of $0.26 \mathrm{tCO}_{2} / \mathrm{MWh}$ [42] and $27 \%$ [7] are assumed for the latter term (see Table 3-9). cTax $\left(\$ / \mathrm{tCO}_{2}\right)$ and $A E S_{i, k}(\mathrm{MWh})$ represent the regional carbon tax rate, and the annual energy savings from implementing the PER, respectively. Assumed values for all other economic parameters are shown in Table 4-2.

Table 4-2: Economic parameters used to compare the NPV from the implementation of building-based DSIs within a utility-owned energy system.

\begin{tabular}{cc} 
Economic Parameter & Value \\
\hline Discount rate & $6 \%$ \\
Project lifetime & 30 years \\
Regional carbon tax rate & $(0-\$ 100 / \mathrm{tCO})$ \\
Community energy rate & $*(0.14-\$ 0.4 / \mathrm{kWh})$ \\
\hline
\end{tabular}

* The average unsubsidized energy rate paid in northern remote communities in Canada is $\$ 0.32 / \mathrm{kWh}[5]$

As the NPV of a large number of PERs is assessed under varying conditions, ordinary least square (OLS) regression models are developed for each BEM and HES. The Python v3.8.0 statistical modeling package statsmodels [88] is utilized to develop the OLS models. The coefficient of determination $\left(R^{2}\right)$ is utilized to compare the statistical significance of each model. $R^{2}$ is a statistical term that represents the 'goodness-of-fit' of any given model. An $R^{2}$ value of 1 indicates a perfect fit, whereas a value of 0 indicates that no relationship exists between the independent and dependent variables [89].

\subsubsection{DH grid energy model}

\footnotetext{
${ }^{2}$ For the current study only remote energy systems (i.e. off-grid) are considered. This is done as in Chapter 3 biomass based energy systems were not shown to be economically viable in rural energy systems (i.e. gridconnected), unless electrical grid transmission cost were considered.
} 
The community scale biomass driven DH grid model developed in Chapter 3 is employed to calculate annual energy plant fuel consumption, as well as DH grid pumping energy requirements and heat losses within the community-owned energy system. Two biomass driven DH grid energy plant configurations are investigated: a heat-only boiler plant configuration, and a CHP plant configuration. The heat-only biomass boiler (BB) plant configuration consists of a heat-only boiler connected to a DH grid and a diesel generator. The heat-only boiler and the diesel generator service the community's heating (i.e. space heating and domestic hot water) and electricity load, respectively. The CHP plant configuration consists of a CHP plant, a cooling tower, and a back-up propane boiler connected to a DH grid. The CHP plant operates to meet the community's electricity load, and all waste heat generated from the CHP plant is delivered to the DH grid to service the community's heating load. If at any given time the available waste heat from the CHP plant is less than the community's heating load, the back-up propane boiler is dispatched to make up the difference in heating energy. If, on the other hand, the available waste heat is greater than the community's heating load, this excess heat is released to the environment via the cooling tower. Two distinct CHP plant technologies are considered in the analysis: a biomass gasification (BG) CHP plant, and a biomass organic Rankine cycle (BORC) CHP plant. Efficiency values and heat-to-power ratios corresponding to each of the energy plant technologies considered in the analysis are given in Table 3-2.

The DH grid model is a physical model that emulates a variable flow, medium temperature, direct-return system that uses water as the working fluid. The general layout and main components of the system are depicted in Figure 3-3. All pipes and associated building connections are sized according to local professional design practices to 
accommodate the current MoCreebec Eeyoud community housing layout. The various fixed model inputs are summarized in Table 3-3. A detailed description of the DH grid model layout, components, and modes of operation, as well as additional information regarding modelling inputs and assumptions, can be obtained from Chapter 3 .

\subsubsection{Combined intervention simulation dispatch algorithms}

A simulation dispatch algorithm is developed to investigate the potential economic trade-offs between implementing community-wide supply and demand-side interventions in tandem within a community-owned energy system. In the current study, supply-side interventions consist of implementing a biomass driven $\mathrm{DH}$ grid and demand-side interventions consist of implementing building-based PERs. To limit the scope of the study, only PERs resulting in a positive net present value (NPV) across all BEMs for a given HES are considered. These PERs are classified into the following scenario lists:

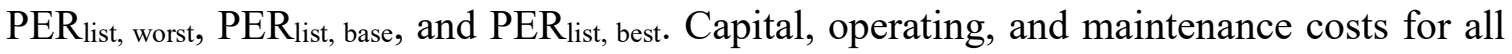
interventions are assumed to be paid for by the community. For any given combined intervention (CI) simulation, it is assumed that PERs are implemented on all community homes simultaneously. Similarly, it is assumed that all community homes are connected to the DH grid. Figure 4-1 shows the CI simulation dispatch algorithm that is repeated for each HES (worst, base, and best-case), as follows:

1- Select $H E S_{k}$ and corresponding $\mathrm{PER}_{\text {list,k}}$;

2- Select $\mathrm{PER}_{\mathrm{i}}$ from $\mathrm{PER}_{\text {list,k}}$ and update three BEM idf files to match the characteristics of the given PER;

3- Conduct EnergyPlus ${ }^{\mathrm{TM}}$ simulation for each idf file using 10-minute time steps for 1 year to obtain the annual heating load distribution (AHD). The AHDs 
corresponding to the three BEMs are combined to create a typical community AHD (typ $A H D)$ using the following expression:

$\left[\operatorname{typ} A H D_{i, k}\right]=P_{s} \cdot\left[\operatorname{semiAH} D_{i, k}\right]+P_{d} \cdot[\operatorname{det} A H D]+P_{r} \cdot\left[\operatorname{row} A H D_{i, k}\right]$ where $[\operatorname{semiAHD}],[\operatorname{det} A H D]$, and $[\operatorname{row} A H D]$ are the matrices corresponding to the semi-detached, detached, and row home annual heating load distributions, respectively. $P_{s}, P_{d}$, and $P_{r}$ represent the relative proportions of semi-detached, detached, and row homes encountered in the MoCreebec Eeyoud community. These values in the order given are equivalent to $56 \%, 28 \%$, and $16 \%$ (see Table 2-1). Although this simplified approach tends to homogenize spatial and temporal heating load variations along the DH grid, the method is sufficient for comparison purposes as these assumptions are constant across all scenarios. The typAHD is subsequently used to calculate AHDs for each DH grid building cluster;

4- Size components in the DH grid model and energy plant model based on the calculated peak loads obtained from the building cluster AHDs;

5- Conduct DH grid model simulation for each biomass energy plant technology considered using 10-minute time steps for 1 year to calculate the total annual primary energy requirements;

6- Store DH grid model simulation results as $C I_{i, k, p}$, where subscript $p$ represents the biomass energy plant technology under investigation. Repeat Steps 1 through 6 until all $\mathrm{PER}_{\mathrm{i}}$ within $\mathrm{PER}_{\text {list,k }}$ are analyzed. 


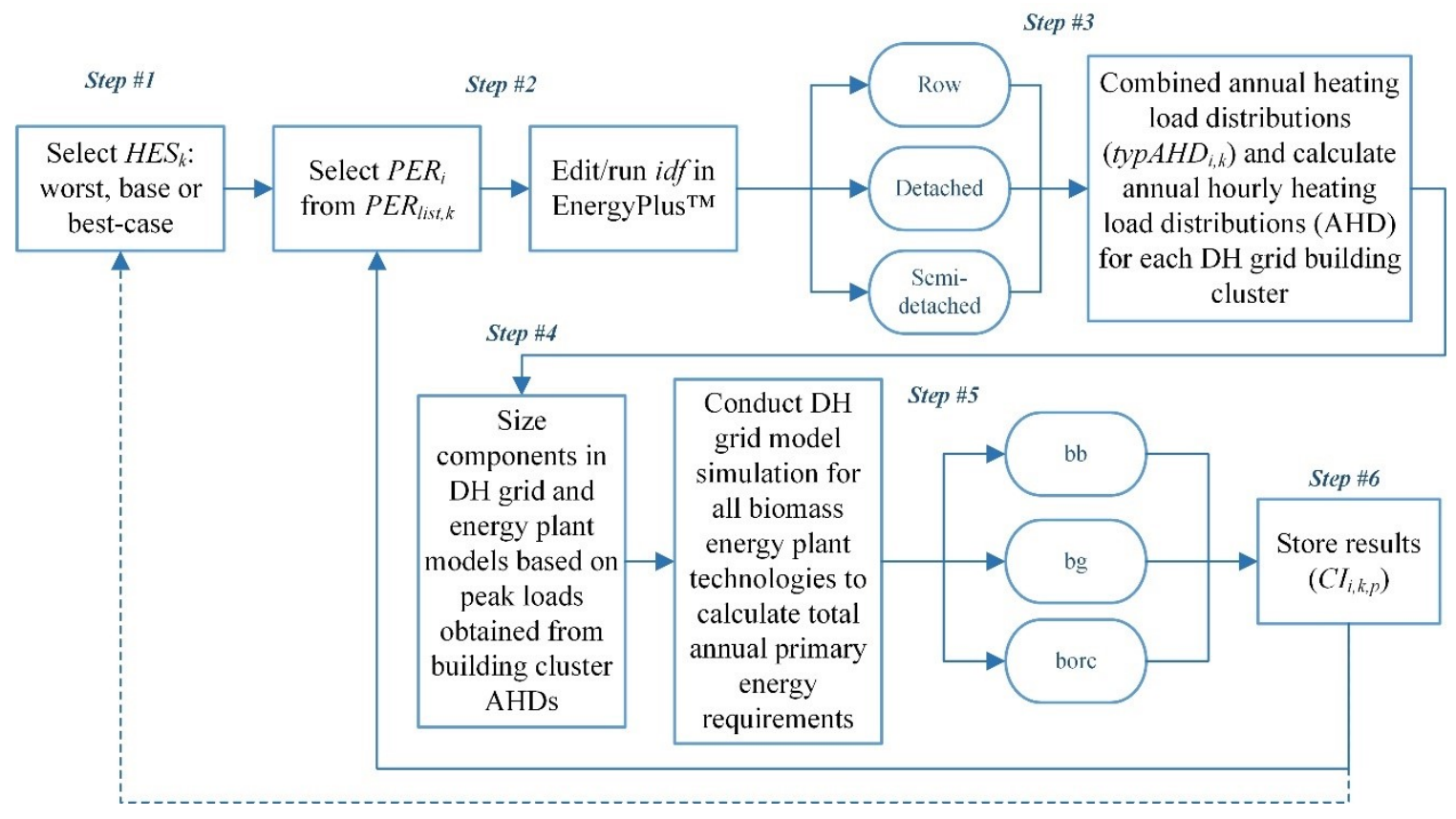

Figure 4-1: Combined intervention simulation dispatch algorithm used to assess the economic viability of implementing building-based PERs in remote community based biomass driven DH grids. The algorithm is repeated for each HES: worst, base, and bestcase.

Upon completing each CI simulation, the NPV of the energy system is calculated using an alternate form of Eq. (4.1) in which slight modifications are made to the Benefit $t_{i, k}$ and $\operatorname{Cost}_{i, k}$ terms. These modifications reflect the benefits and costs related to switching from a utility-owned diesel powered energy system to a community-owned biomass driven CHP grid energy system. The Benefit $t_{i, k}$ term is expressed as

$$
\text { Benefit }_{i, k, p}=c \operatorname{Tax} \cdot\left(A C E_{\text {diesel }(i, k)}-A C E_{D H(i, k, p)}\right)+C A E D_{i, k} \cdot C f
$$

where $A C E_{\text {diesel }(i, k)}\left(\mathrm{tCO}_{2}\right)$ and $A C E_{D H(i, k, p)}\left(\mathrm{tCO}_{2}\right)$ represent the annual $\mathrm{CO}_{2}$ emissions of a community powered by a diesel generator plant and a biomass driven DH grid, respectively, and $C A E D_{i, k}(\mathrm{MWh})$ represents the combined annual energy demand (i.e. heating and electricity) of all community buildings. The $\operatorname{Cost}_{i, k}$ term is given by

$$
\operatorname{Cost}_{i, k, p}=C C_{i, k, p}+C_{O \& M(i, k, p)}+C_{f u e l(i, k, p)}+C_{P u m p(i, k, p)}
$$


Table 4-3: Economic parameters used to compare the NPV from the implementation of building-based DSIs within a community-owned biomass driven DH grid energy system.

\begin{tabular}{cc} 
Economic Parameter & Value \\
\hline Discount rate & $6 \%$ \\
Project lifetime & 60 years \\
Regional carbon tax rate & $\$ 10 / \mathrm{tCO}_{2}$ \\
Community energy rate & $\$ 0.32 / \mathrm{kWh}$
\end{tabular}

where $C C_{i, k, p}(\$), C_{O \& M(i, k, p)}(\$), C_{f u e l(i, k, p)}(\$)$, and $C_{P u m p(i, k, p)}(\$)$ represent the CI capital cost (i.e. the cost associated with implementing all PERs, plus the cost of the DH grid and energy plant), the energy system operation and maintenance cost, the fuel cost, and the DH grid pumping electricity cost, respectively. A summary of the economic parameters and costs utilized to calculate NPV are shown in Table 3-5, 3-7 - 3-9, and 4-3. As in Chapter 4.2.2, OLS regression models are developed to analyze the NPV results for each BEM and HES.

\subsection{Results \& Discussion}

\subsubsection{Demand-side interventions}

Figure 4-2 shows the NPV as a function of annual energy savings (AES) incurred from implementing a wide range of PERs on the different BEMs (i.e. row, semi-detached, and detached) and HESs (i.e. worst, base, and best) considered in this study. The NPV is calculated assuming a community energy rate of $0.32 \$ / \mathrm{kWh}$ and a regional carbon tax rate of $\$ 0 / \mathrm{tCO}_{2}$. The OLS regression models as well as their associated $R^{2}$ value, y-intercept, $\mathrm{x}$-intercept (at $\mathrm{y}=0$ ), and regression coefficient (b) are also shown in Figure 4-2. Although all regression models for both the worst and base-case homes across all building archetypes show a positive correlation between annual energy savings and NPV (as indicated by the 
regression coefficient), best-case homes exhibit a negative correlation between these two parameters. For all HES-BEM combinations depicted in Figure 4-2, the x-intercepts provide a reasonable estimate of the annual energy savings incurred as a result of implementing cost-effective (i.e. where $N P V \geq 0$ ) PERs. All best-case scenario PERs are shown to be infeasible from an economic standpoint as the $\mathrm{x}$-intercepts corresponding to these scenarios are negative. Although the opposite holds true for the worst and base-case scenarios, annual energy savings corresponding to cost-effective PERs are consistently lower for the worst-case scenario than the base-case scenario. For each of these HESs in the given order, row home BEMs have the lowest $\mathrm{x}$-intercepts (1.82 and 2.85 MWh), followed by the semi-detached home BEMs (2.6 and 4.64 MWh), and detached home BEMs (2.83 and 23.66 MWh). The $R^{2}$ values corresponding to both base and best-case HESs in Figure 4-2 are indicative of low to moderate levels of statistical significance. Although these values demonstrate that AES as a single parameter is not an adequate predictor of the NPV of any given PER, OLS models developed from these data are useful for comparing relative differences between PERs implemented on residential buildings of varying archetypes and energy efficiency levels. 
a) Row

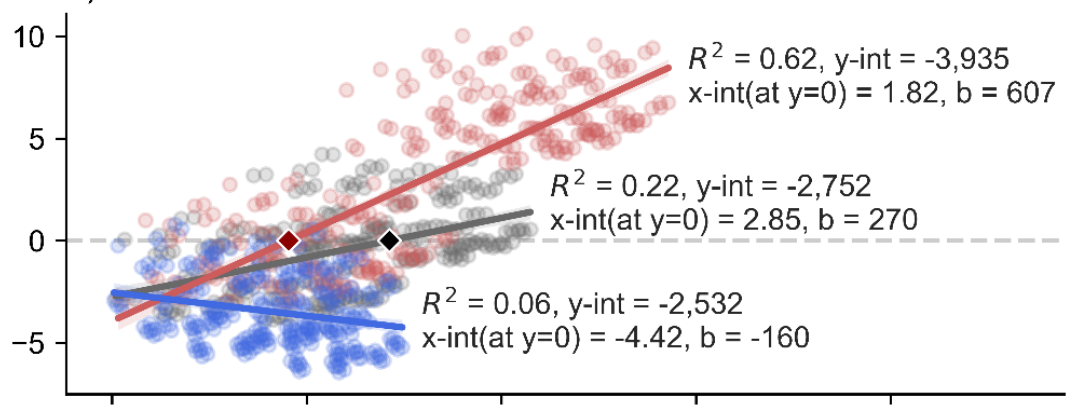

b) Semi-Detached

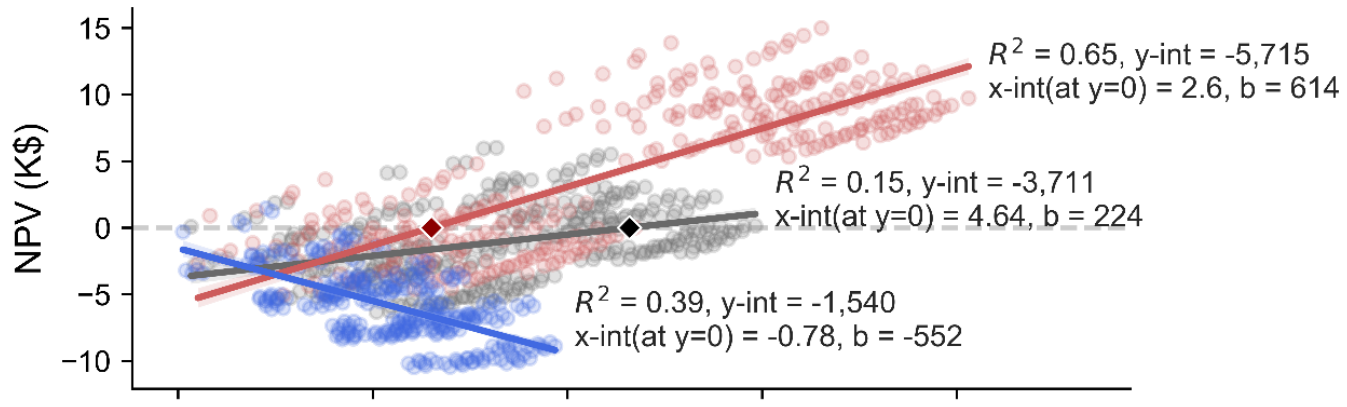

c) Detached

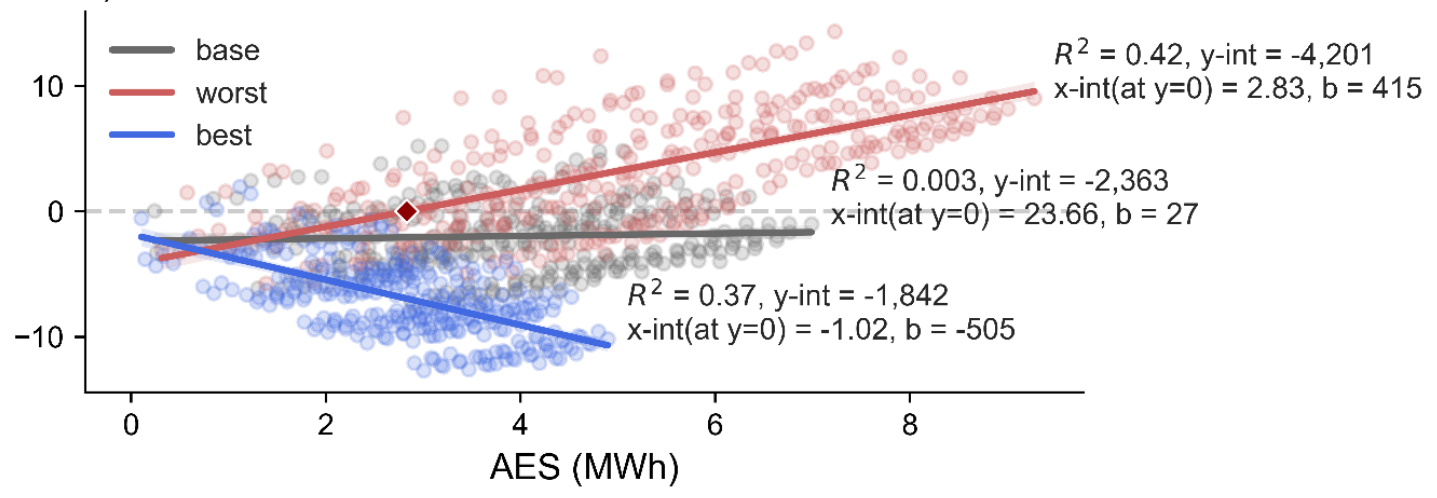

Figure 4-2: NPV (in K\$) as a function of AES (MWh) from implementing PERs on the different BEMs (i.e. row, semi-detached, and detached) and HESs (i.e. worst, base, and best) considered in this study. $R^{2}, y$-int, $x$-int $(a t y=0)$, and $b$ represent the coefficient of determination, $y$-intercept, $x$-intercept (where $N P V=0$ ), and regression coefficient, respectively.

The impacts of varying the regional carbon tax rate and community energy rate on the NPV of PERs implemented on the different BEMs and HESs are shown in Figure 4-3 and 4.4, respectively. Each box and whisker plot shown in these figures represents a statistical distribution of results obtained for all PERs considered. The horizontal bars in each plot 
from bottom to top indicate the minimum, lower quartile, median, upper quartile, and maximum values obtained, respectively.

a) Row

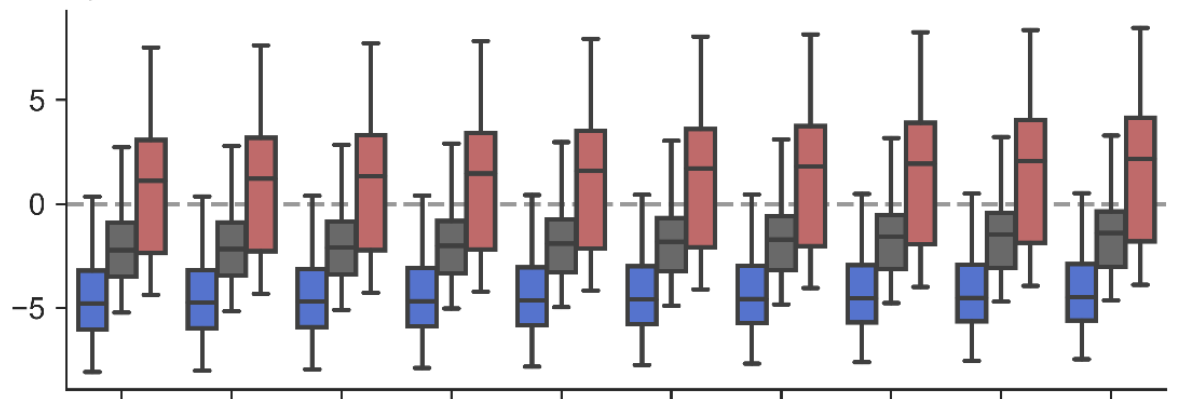

b) Semi-detached

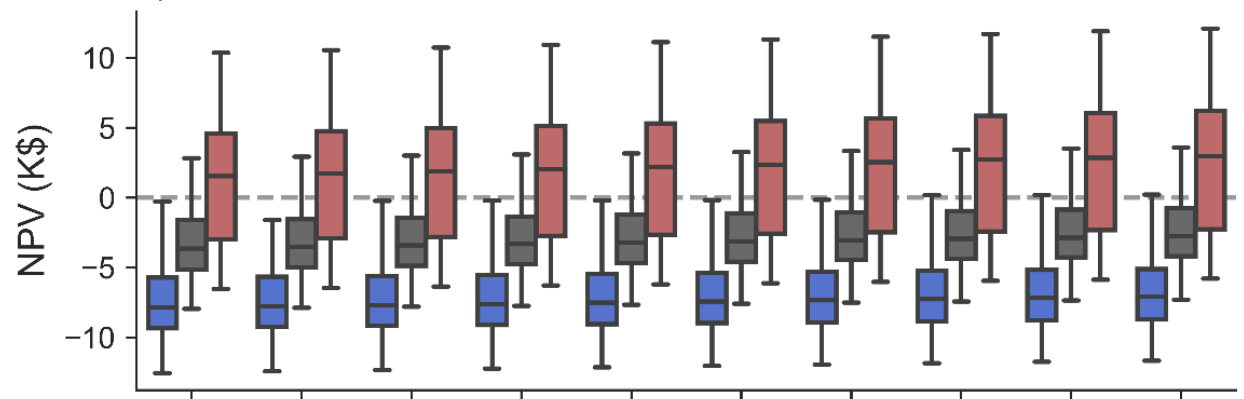

c) Detached

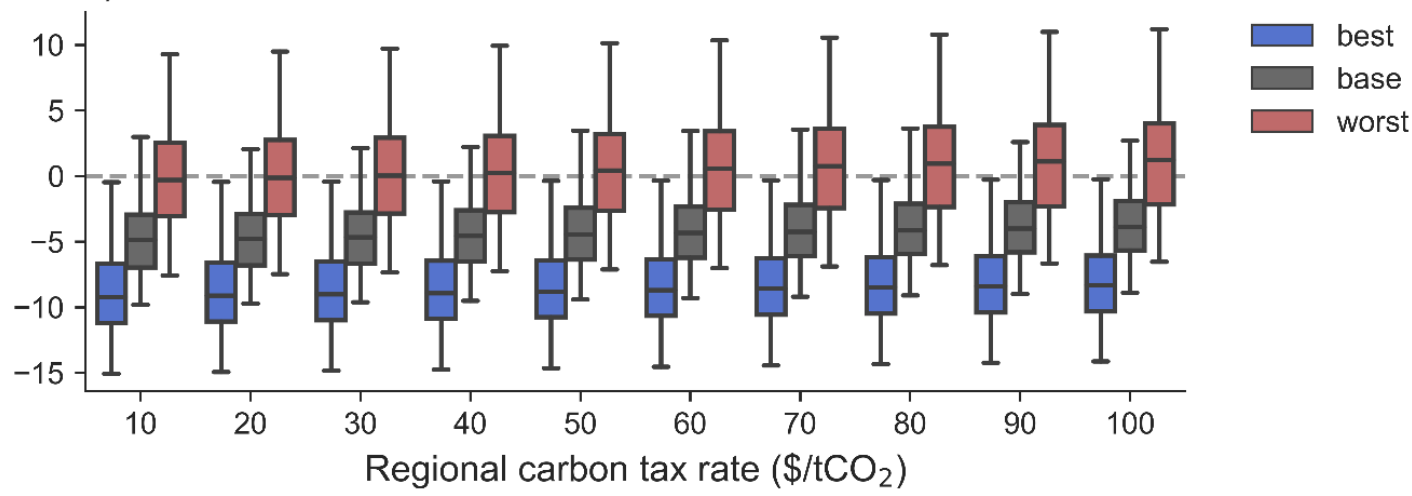

Figure 4-3: NPV of PERs by BEM (i.e. row, semi-detached, and detached) and HES (i.e. worst, base, and best) as a function of Regional carbon tax rate. 
a) Row

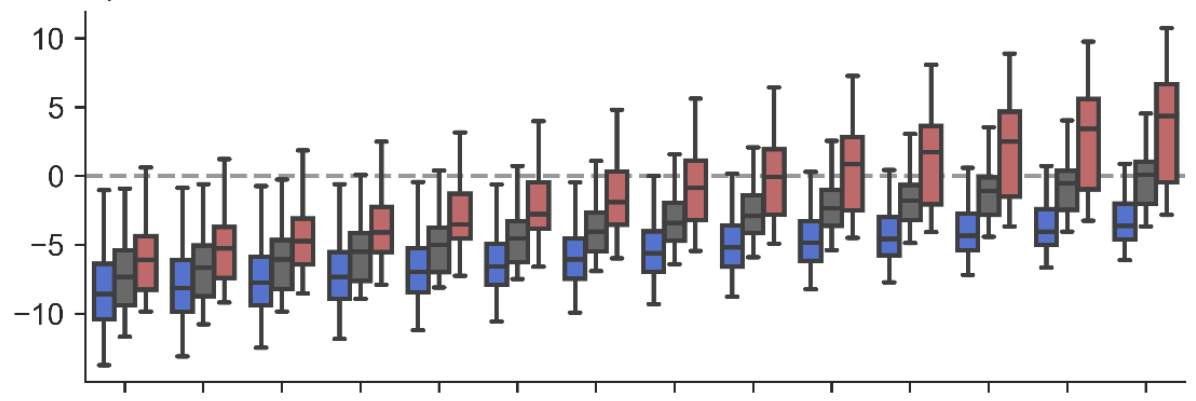

b) Semi-detached

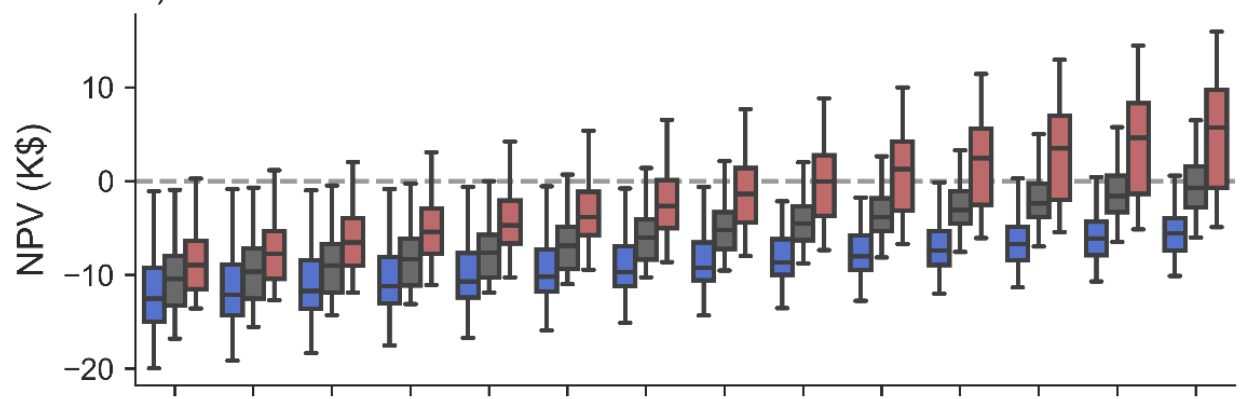

c) Detached

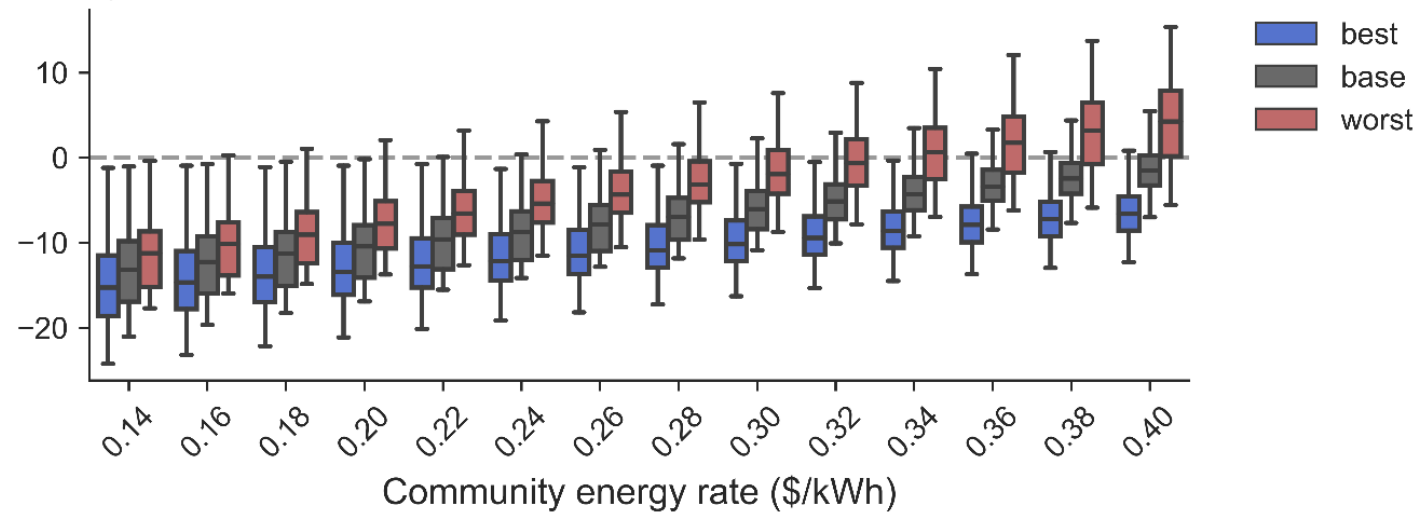

Figure 4-4: NPV of PERs by BEM (i.e. row, semi-detached, and detached) and HES (i.e. worst, base, and best) as a function of community energy rate

Figure 4-3 shows that as the regional carbon tax rate increases from $\$ 10$ to $\$ 100 / \mathrm{tCO}_{2}$, the NPV for all HESs and BEMs increases only marginally. The largest increase occurs for BEMs associated with the worst-case HES. The median NPV for this scenario across the range considered increases by $\$ 864, \$ 1,557$, and $\$ 1,094$ for the detached, semi-detached, and row home BEMs, respectively. Although these values demonstrate that increasing the carbon tax rate has a positive impact with regards to project economic viability, the actual 
dollar amounts are relatively low for a project with such a long lifetime (i.e. 30 years). Median NPVs for all BEMs associated with the base and best-case HESs are negative across the regional carbon tax rate considered, indicating that this parameter has little to no effect with regards to increasing the economic viability of any given PER.
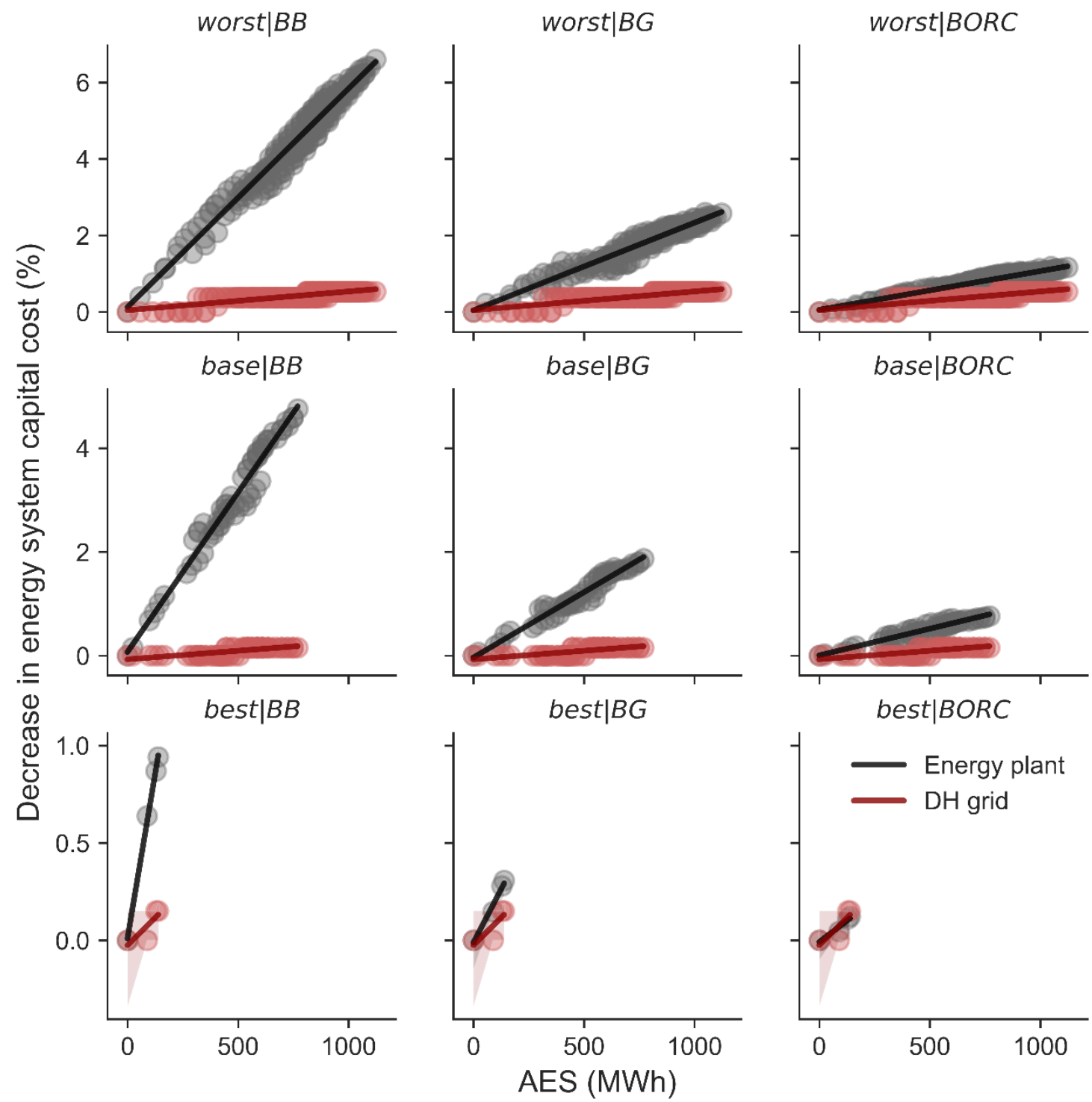

Figure 4-5: Percent decrease in energy system capital cost as a function of the annual energy savings (AES) incurred from implementing a wide range of PERs across each $H E S$ and considering three distinct biomass energy plant technologies (BB, $B G$, and $B O R C)$. 
Figure 4-4 shows that as the community energy rate increases from 0.14 to 0.40 \$/kWh, the NPV for all HESs and BEMs increases considerably. As in Figure 4-3, the largest increase occurs for BEMs associated with the worst-case HES. The median NPV for this scenario across the range considered increases by $\$ 15,624, \$ 14,663$, and $\$ 10,565$ for the detached, semi-detached, and row home BEMs, respectively. Furthermore, PERs implemented in this scenario for all BEMs only begin to be economically viable at community energy rates of roughly $0.32 \$ / \mathrm{kWh}$. Median NPVs for all BEMs associated with the base and best-case HESs are negative across the community energy rate considered.

\subsubsection{Combined intervention results for community-owned energy system}

Figure 4-5 shows the percent decrease in energy system capital cost (i.e. for both the energy plant and DH grid) as a function of the annual energy savings incurred from implementing a wide range of PERs across each HES and considering all three biomass energy plant technologies (i.e. $\mathrm{BB}, \mathrm{BG}$, and $\mathrm{BORC}$ ). The number of data points used to populate each of the sub-plots differs considerably for each HES as only PERs resulting in a positive NPV across all BEMs for a given HES are considered (see Chapter 4.2.4). As annual energy savings increase for all biomass energy plant technologies and HESs, the percent decrease in energy plant capital cost continuously exceeds that of the DH grid. A negligible percent decrease in capital cost is observed for the DH grid $(<1 \%)$ across all HESs and biomass energy plant technologies, whereas a much higher percent decrease is observed for the energy plant capital cost $(\sim 6.7 \%)$. The highest and lowest percent decreases in energy plant capital cost occur in the worst-case and best-case HESs, 
respectively. Similarly, the highest and lowest percent decreases occur in the BB and BORC energy plants in the same order.

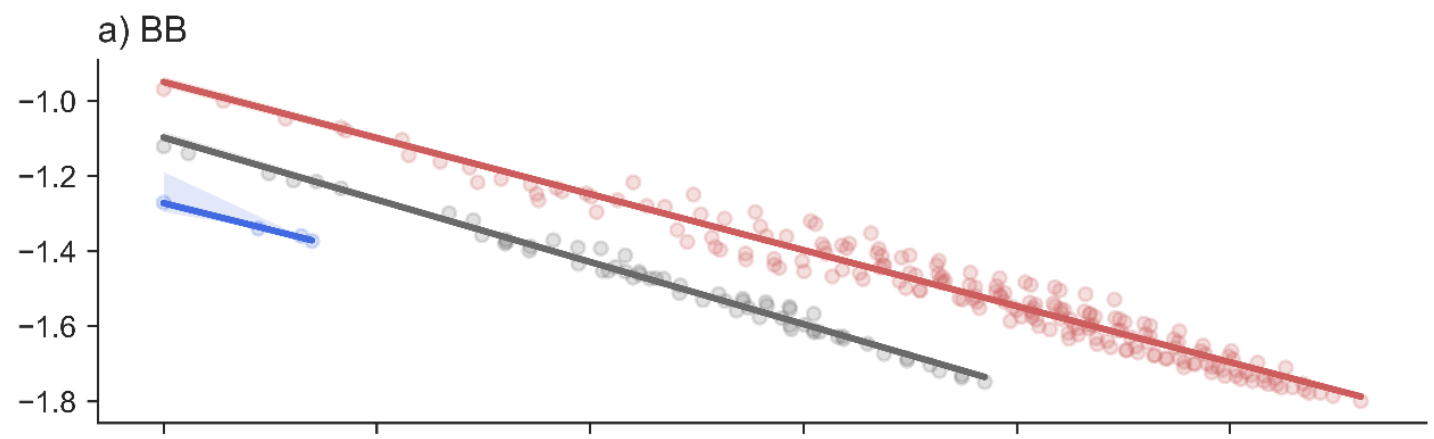

b) $B G$

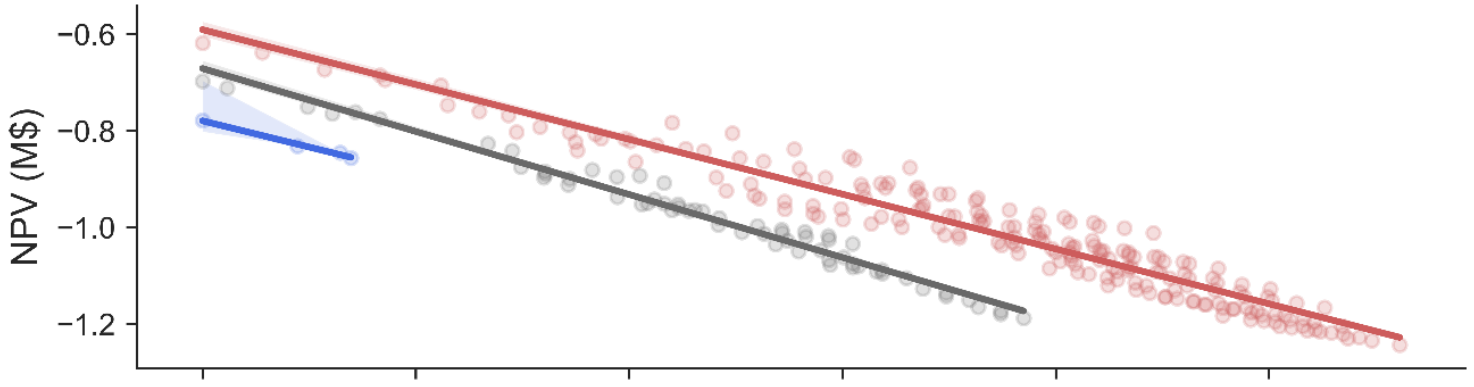

c) BORC

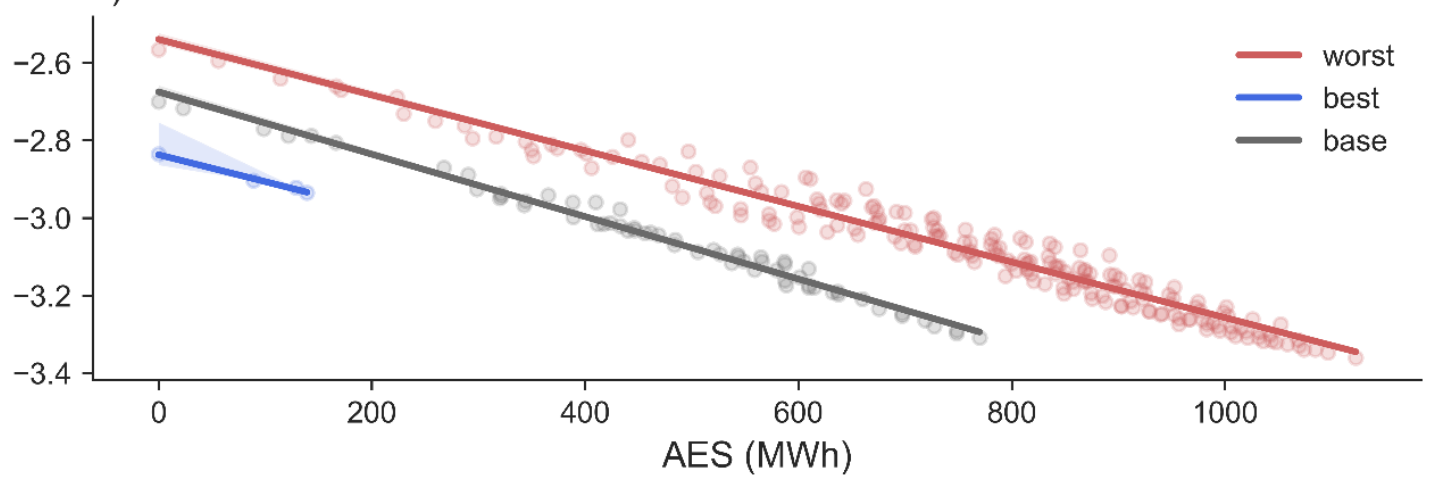

Figure 4-6: The CI NPV as a function of the annual energy savings (AES) incurred from implementing a wide range of PERs across each HES (worst, base, and best-case) and considering three distinct biomass energy plant technologies (BB, BG, and BORC).

Figure 4-6 shows the CI NPV as a function of the annual energy savings incurred from implementing a wide range of PERs across each HES and considering all three biomass 
energy plant technologies (i.e. BB, BG, and BORC). Therefore, each dot within the figure represents the NPV of the $C I_{i, k, p}$ and the AES of PER $i$, under HES $k$, and with energy plant $p$. As the annual energy savings increase for all biomass energy plant technologies and HESs, associated NPVs, all of which are negative, decrease continuously. These results indicate that for the current case study under the stated assumptions, combining community-wide PERs and a newly-built DH grid makes little economic sense. This finding is supported in a number of previous studies which demonstrate that DH grids only start to become economically viable at linear heating densities (LHD) that are greater than 1.2 MWh/m-year [80], [90]. The LHD of any given DH grid represents the annual heating energy supplied by the grid over its total piping length.

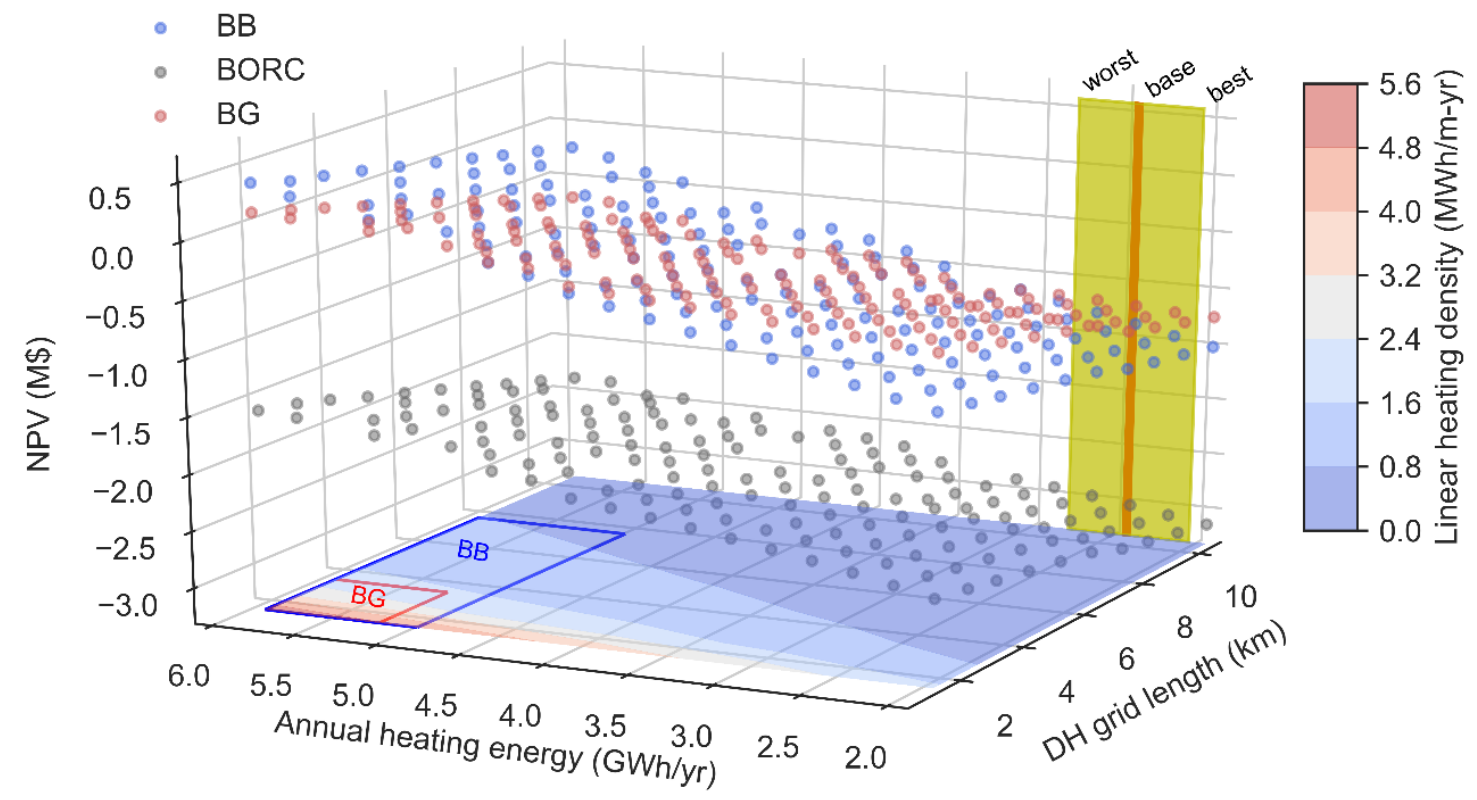

Figure 4-7: NPV associated with building a DH grid based energy system comprising three distinct biomass energy plant technologies (BB, $B G$, and BORC) as a function of annual heating energy and DH grid length. Corresponding linear heating density (LHD), as well as regions encompassing HES, are also shown for comparison. 
This concept is illustrated in Figure 4-7 which shows the NPV associated with building a DH grid based energy system comprising each of the three biomass energy plant technologies mentioned previously as a function of annual heating energy (supplied by the DH grid), and DH grid length. Both of these values are manually adjusted to create varying degrees of LHD. The annual heating energy range corresponding to the HESs analyzed in this study is provided in this figure as yellow and red bands. LHDs corresponding to this range vary between $0.19-0.27 \mathrm{MWh} / \mathrm{m}$-yr. These values are far below the $1.2 \mathrm{MWh} / \mathrm{m}$ yr feasibility guideline mentioned above. Results show that energy systems comprising BB and $\mathrm{BG}$ plants start to become economically viable (i.e. the $N P V \geq 0$ ) at LHDs that are greater than 0.8 and $1.6 \mathrm{MWh} / \mathrm{m}$-yr, respectively. The areas corresponding to these LHD ranges are depicted as blue and red rectangles in Figure 4-7. Energy systems comprising the BORC plant, on the other hand, are not economically viable under any of the conditions shown in this figure as the NPV is consistently less than zero.

\subsection{Policy Insights}

A number of insights are drawn from the current study. The following chapter addresses the key questions outlined in Chapter 4.1.3:

1) Under which conditions is it preferable to invest in building-based DSIs within an existing utility-owned energy system as opposed to investing in these interventions within a newly built community-owned biomass driven DH grid?

Implementing building-based DSIs in the form of PERs within a utility-owned energy system is shown to be consistently preferable to investing in these interventions within a newly built community-owned biomass driven DH grid from an economic standpoint. 
However, the former is only worth implementing when the community energy rate exceeds $0.32 \$ / \mathrm{kWh}$ (see Figure 4-4). This rate is considerably high and only typical of remote communities located in the Far North of Canada. Furthermore, the investigated buildingbased DSIs are much more economically attractive for low (worst-case) and mid (basecase) level efficiency homes. Some variability is also shown amongst the building archetypes. Larger floor area home archetypes such as the detached home provide significantly greater annual energy savings for any given PER, relative to both semidetached and row homes. This effect is primarily due to these buildings having a greater exterior envelope surface area relative to the other building types. Greater efficiency gains are therefore possible as a result of implementing PERs. The downside, however, is that larger capital expenditures are required resulting in low NPVs. Implementing PERs on row homes, on the other hand, consistently results in high NPVs. Contrary to detached homes, row homes have a smaller exterior envelope surface area, and as a result, smaller capital expenditures are required.

2) In which ways are the design considerations and capital cost of a newly built community-owned biomass driven DH grid impacted by the implementation of buildingbased DSIs?

Implementing PERs prior to building a community-owned biomass driven DH grid causes a significant drop in the capital cost of the energy plant relative to the DH grid (see Figure 4-5). This effect is more pronounced in energy systems comprising heat-only (BB) versus $\mathrm{CHP}(\mathrm{BG}$ and $\mathrm{BORC})$ plant technologies. The main reason for this difference is due to the way in which the energy plants are sized. Unlike CHP plants which are sized based on the peak electrical load, heat-only plants are sized based on the peak heating load which 
is more sensitive to the energy efficiency gains from implementing community-wide PERs. In the best of cases, energy plant capital costs are reduced by approximately $6.7 \%$. DH grid capital costs, on the other hand, are barely affected by the implementation of buildingbased DSIs as the physical grid layout (i.e. number of fittings and total length of pipe) remains relatively unchanged.

3) How does the economic viability of a newly built community-owned biomass driven DH grid vary as a function of the annual energy savings associated with the implementation of building-based DSIs?

Greater annual energy savings from the implementation of PERs are beneficial to community residents as building-level annual energy costs are significantly lowered. However, the opposite holds true from a community perspective as this decreased revenue results in a lower overall return-on-investment. For this reason, all PERs investigated in this study are shown to be infeasible from an economic standpoint (see Figure 4-6).

4) How do community energy density and DH grid length affect the economic viability of a newly built community-owned biomass driven DH grid?

Energy systems comprising $\mathrm{BB}$ and $\mathrm{BG}$ plants start to become economically viable at LHDs greater than 0.8 and $1.6 \mathrm{MWh} / \mathrm{m}$-yr, respectively (see Figure 4-7). Although these LHDs far exceed those of the current MoCreebec Eeyoud housing infrastructure layout, similar LHDs can potentially be achieved in small-scale DH grids when additional commercial and institutional buildings such as community centers, hospitals, and schools are connected. This approach has been used in several remote communities located across Canada to increase the economic viability of biomass driven DH grids [72], [79], [80]. Aside from the economic benefits, community-owned energy systems are desirable when 
additional community-wide benefits are sought such as lower greenhouse gas emissions, increased energy security, increased energy autonomy, and local employment generation. However, if the primary aim is to reduce the cost of energy to residential consumers, then residential building-based PERs within a utility-owned energy system are recommended.

\subsection{Closing remarks}

Three residential building energy models (row, semi-detached, and detached) were developed in EnergyPlus ${ }^{\mathrm{TM}}$ to represent typical housing archetypes found in northern remote communities. For each model, three housing efficiency scenarios (HES) consisting of a worst, base, and best case scenario were created using community housing energy audit data from the MoCreebec Eeyoud community located in northern Ontario, Canada. To assess the economic impacts of implementing building-based DSIs within a utilityowned energy system a number of PERs were implemented for each BEM and HES considered. To assess the economic impacts of implementing the above-mentioned PERs within a community-owned energy system, a community-scale biomass driven DH grid model was additionally developed using the numerical software tool Matlab ${ }^{\circledR} /$ Simulink ${ }^{\circledR}$. The following three biomass plant technologies were investigated: a biomass gasification CHP plant, a biomass heat-only boiler plant, and a biomass organic Rankine cycle CHP plant. A simulation dispatch algorithm was deployed to investigate the potential economic benefits of implementing PERs across these three biomass plant based energy systems. Results show that the implementation of PERs prior to building a community-owned biomass driven DH grid causes a significant drop in the energy plant capital cost, especially in energy systems comprising a heat-only DH boiler. On the other hand, negligible 
reductions in the capital cost of the $\mathrm{DH}$ grid are observed across all of the biomass energy plant technologies considered. Furthermore, from a purely economic standpoint, it is generally preferable for communities to invest in building-based demand-side interventions instead of a biomass driven district heating grid. However, results vary substantially depending on factors such as the community building layout, state of energy efficiency in community buildings, and energy rate paid by residents. For instance, community-owned biomass driven DH grids start becoming economically viable when $\mathrm{DH}$ grid linear heating densities surpass $0.8 \mathrm{MWh} / \mathrm{m}$-yr.

While this chapter has evaluated the economic trade-offs between supply and demandside interventions in isolated communities, there are several research questions and issues to be resolved, namely:

- What are the impacts associated with implementing residential electrical energy saving measures on district heated buildings? The building-based DSIs in this chapter focus exclusively on residential envelope energy retrofits, while electrical energy saving measures such as energy-efficient appliances, LED lighting, and smart thermostats are not considered. As CHP plants in this study are designed based on the peak electrical demand, the associated reductions in electricity consumption from implementing residential electrical energy saving measures could lead to larger reductions in energy plant capital cost of CHP plants relative to heat-only boilers. As such, the relationship between electrical saving measures and the economics of the CIs should be examined in further detail.

- Are community biomass driven DH grids more economical when they are additionally connected to commercial/institutional buildings? As mentioned 
earlier, biomass driven DH grids are potentially a viable option in isolated communities so long as the installed DH grid is of a sufficient linear heating density. Linear heating densities can be substantially increased by either lowering the number of grid connections and/or connecting to buildings with much larger energy demand (e.g. commercial and/or institutional buildings). Therefore, the investigation of a community biomass driven $\mathrm{DH}$ grid, connected to commercial buildings is warranted for future research. 


\section{Chapter 5: Summary of contributions}

This thesis explores the technical, economic, environmental, and socio-economic impacts of implementing several different supply and demand-side energy interventions in both remote and rural community energy systems. A summary of the contributions from each chapter of this thesis are outlined below:

\subsection{Building-based demand-side interventions: a multi-objective techno-} economic assessment of residential building envelope energy retrofits

This chapter presented a multi-objective analysis to find optimal solutions of packaged envelope energy retrofits (PER) that maximized annual energy savings, project economics, and thermal comfort. Three residential building energy models (BEM) (row, semidetached, and detached) were developed in EnergyPlus ${ }^{\mathrm{TM}}$ to represent typical residential buildings found in isolated communities. BEMs were equipped with a heat-only forced air furnace and passive cooling control of the blinds and windows. PERs included any combination of the following energy retrofits: upgraded doors and windows, improvements in insulation to the exterior and basement walls, as well as to the basement and attic floors. The main findings of this chapter are as follows:

- Regardless of building archetype (row, semi-detached, or detached), improvements to attic insulation and upgraded windows and doors are economically feasible energy retrofits that will increase both thermal comfort and annual energy savings. This is evident based on the solutions (i.e. the selected PERs) from the multi-object analysis. The selected PERs consistently included improvements to attic insulation 
as well as upgraded windows and doors across all building archetypes, and regardless of which techno-economic metric (annual energy savings, net present value, and thermal comfort) is prioritized (with the only exception being the semidetached home under the thermal comfort prioritized weighting scheme).

- Upgraded windows and improvements in insulation to the basement floor result in the highest annual energy savings $(14-15 \%)$ and increases in thermal comfort (11 $-21 \%$ ) across building archetypes.

- Only modest economic gains (i.e. net present value) occur in even the most economical PER implemented within a remote energy system. Furthermore, none of the PERs were found to be economically viable in rural energy systems. PERs with the largest net present value in remote energy systems for the row, semidetached, and detached homes are $\$ 4,507, \$ 6,433$, and $\$ 5,624$, respectively.

- The combined implementation of several envelope energy retrofits is preferred over the single installment of these energy retrofits in order to maximize net present value, thermal comfort, and annual energy savings.

\subsection{Supply-side interventions: quantifying the impacts of biomass driven district heating grids}

This chapter sought to compare the technical, economic, socio-economic, and environmental impacts of implementing biomass driven CHP grids in Canada's isolated communities. Models corresponding to both remote and rural community energy systems were constructed using the numerical software Matlab $\AA /$ Simulink ${ }^{\circledR}$. Five energy plant technology scenarios were presented which included a propane boiler plant, a biomass 
boiler plant, a biomass gasification CHP plant, a biomass organic Rankine cycle CHP plant, and a diesel CHP plant. The proposed scenarios were subsequently compared with the reference remote (i.e. diesel generation) and rural (i.e. electrical transmission grid connection) energy system scenarios. The main findings of this chapter are as follows:

- Biomass driven CHP grids are an economically attractive alternative for remote community energy systems; however, this is not the case for rural community energy systems. In remote community energy systems, biomass gasification (BG) CHP and biomass organic Rankine (BORC) cycle CHP plants result in reductions in LEC of approximately $45 \%$ and $4 \%$, respectively relative to the reference remote energy system scenario.

- The implementation of biomass energy technologies is preferable in remote energy systems relative to rural energy systems when costs associated with the electrical transmission grid (i.e. extension lengths exceeding $54 \mathrm{~km}$ ) are considered. Furthermore, at grid extension lengths of $100 \mathrm{~km}$ and $200 \mathrm{~km}$, LEC values corresponding to the remote BG CHP plant scenario are roughly $67 \%$ and $83 \%$ lower than that of the reference rural energy system scenario, respectively.

- Remote and rural energy systems containing biomass energy technologies experience considerable socio-economic benefits when carbon tax payments and local biomass production are considered. However, in fossil fuel-based energy systems, the opposite holds true. The reference remote energy system is shown to experience increases in LEC of $4 \%$ and $8 \%$ at regional carbon tax rates of $\$ 50$ and $\$ 100 /$ tonne of $\mathrm{CO}_{2}$, respectively. 
- Both remote and rural energy systems containing biomass energy technologies are relatively insensitive to variations in fossil fuel and grid electricity costs.

- Biomass energy systems result in low annual levels of $\mathrm{CO}_{2}, \mathrm{SO}_{2}$, and $\mathrm{NO}_{\mathrm{x}}$ emissions, however, are significant contributors of $\mathrm{PM}_{10}$ emissions.

\subsection{Towards a cost-effective remote community energy system: the economic trade-offs of building-based DSI implemented within a community-owned biomass driven DH grid}

This chapter examined the economic viability of implementing demand-side interventions (DSIs) in both utility-owned and community-owned centralized biomass isolated energy systems. The three residential BEMs analyzed in Chapter 2 were utilized to represent typical buildings encountered in isolated communities. For each BEM, a worstcase, base-case, and best-case housing efficiency scenario (HES) was presented. To assess the economic impacts of implementing DSIs on these HESs within a utility-owned energy system, the PERs from Chapter 2 were utilized. To assess the economic impacts of implementing PERs within a community-owned energy system, the community scale biomass driven DH grid model from Chapter 3 was employed. Three distinct biomass plant technologies were investigated: a heat-only biomass boiler, a BG CHP plant, and an ORC CHP plant. The main findings of this chapter are as follows:

- The implementation of building-based DSIs in the form of PERs within a utilityowned energy system is preferable to investing in these interventions within a newly built community-owned biomass energy system. However, PERs are only worth implementing within communities that have energy rates that exceed 0.32 
$\$ / \mathrm{kWh}$. Furthermore, the viability of building-based DSIs varies substantially based on building archetype, and housing efficiency levels.

- Implementing PERs prior to building a community-owned biomass driven DH grid causes a considerable drop (6.7\%) in the capital cost of the energy plant, while DH grid capital costs are barely affected.

- Though building-based DSIs result in beneficial annual energy savings for the community, they are detrimental to the economic success of the community-owned biomass energy system.

- Energy systems comprising biomass heat-only boilers and BG CHP plants start to become economically viable at linear heating densities greater than 0.8 and 1.6 $\mathrm{MWh} / \mathrm{m}-\mathrm{yr}$, respectively. 


\section{Chapter 6: Recommendations and future work}

Over the course of this research project, several research topics and unresolved issues remain, and warrant further study. Unresolved issues are discussed in detail at the end of Chapters 2 through 4 . Future work and recommendations are outlined as follows:

- The implementation of demand-response programs in order to better match diesel generation and energy demand of isolated communities in a more efficient manner could lead to potential energy savings. Demand-response programs come in many forms such as incentive-based programs (e.g. direct load control, curtailable load, etc.) or price-based programs (e.g. time-of-use tariffs, critical peak pricing, etc.). A detailed overview of demand-response programs, can be obtained from Ref. [91]. The implementation of these low-capital intensive programs could potentially result in cost-effective methods to reduce an isolated community's energy demand. It is also of interest to study these programs in greater detail within a communityowned biomass energy system to evaluate the techno-economic impacts on a biomass energy plant.

- It is well known that occupants play an integral role in the annual energy consumption of buildings [92], [93]. The studies in Chapter 2 and 4 assumed a constant weekly occupant usage pattern based on published databases [33]. However, it is unclear whether these published databases accurately capture the true occupancy behavior of isolated community residents. Further research should be conducted to investigate and understand the true occupancy patterns of these isolated community members. With more transparent data surrounding this topic, 
communities can strategically develop local incentive-based programs to reduce residential energy consumption through conscious and collaborative efforts.

- The supply-side interventions studied in this thesis have focused exclusively on transitioning an isolated community to alternative centralized sources of biomass energy. However, supply-side interventions could also involve the conversion of a building's decentralized heating plant to renewable energy technologies such as wood stoves, decentralized pellet boilers, ground-source heat pumps, or solar thermal heating.

- Further to the previous point, wood stoves are already utilized to a limited extend amongst the MoCreebec Eeyoud dwellings. Previous community based reports have recommended the increased use of these heating methods to reduce annual residential heating costs [1], [80]. However, these recommendations were based on a fairly rudimentary analysis. Therefore, a more thorough techno-economic assessment of the application and utilization of wood stoves would be warranted as it is a common heat source in many isolated communities across Canada. 


\section{Chapter 7: Conclusion}

This thesis evaluated the impacts of supply and demand-side interventions implemented in two main community energy system layouts commonly encountered in Canada's remote (i.e. off-grid) and rural (i.e. grid-connected) communities. The indigenous community of MoCreebec Eeyoud located in the northern subarctic town of Moose Factory, Ontario was utilized as the case study in the analysis. A multi-objective technoeconomic assessment of building-based demand-side interventions (DSI) in the form of packaged envelope energy retrofits (PER) was presented in Chapter 2. The multi-objective analysis sought to find the most cost-effective PERs that maximized both annual energy savings, occupant thermal comfort, and cost-effectiveness. In Chapter 3 the technical, economic, socio-economic, and environmental impacts of implementing biomass driven district heating (DH) grids in isolated communities were investigated and compared relative to conventional energy plant technologies found in both remote (i.e. diesel power plant based) and rural (i.e. electrical transmission grid based) communities. Lastly, Chapter 4 assessed the impacts of implementing a wide range PERs on the economic viability of community-owned biomass driven DH grids in remote community energy systems. Ultimately, the findings from this research were directed towards northern policymakers and community leaders seeking to tackle energy security, autonomy, and efficiency issues in remote and rural communities across Canada.

Results show that biomass driven $\mathrm{DH}$ grids are an economically attractive alternative for remote community energy systems with reductions in cost of up to $45 \%$ relative to conventional diesel power generation. On the other hand, in rural community 
energy systems, biomass driven DH grids are unable to economically outperform conventional grid electricity, unless the real cost of the electrical transmission grid is considered. However, based on economics alone, these communities should invest in building-based DSIs instead of a biomass driven DH grid. Building-based DSIs such as upgraded windows and improvements in insulation to the basement floor resulted in annual energy savings of up to $15 \%$. The associated financial and thermal comfort benefits of building-based DSIs are further increased when multiple energy retrofits were conducted simultaneously. The combination of these energy retrofits is shown to lead to optimal costeffective PERs that are able to maximize both annual energy savings and improvements in thermal comfort. However, these results vary substantially depending on factors such as differences in the building's archetype, the current energy efficiency level of community buildings, and the energy rate paid by residents. Although biomass driven DH grids are found to be financially unattractive in small low energy density communities, they are shown to be economically viable at DH grid linear heating densities in excess of 0.8 $\mathrm{MWh} / \mathrm{m}$-yr. These levels of linear heating density could be possible in more compact DH grids which are additionally connected to more energy dense loads within the community such as commercial and institutional buildings.

Results of the current study were also shared with the MoCreebec Eeyoud community and council members and subsequently published via a technical report available through the Carleton University website [80]. Major recommendations and takeaways from the report were the prioritization of energy efficiency measures in the form of building-based energy retrofits ahead of any supply-side intervention. The report further recommended the increased use of woody biomass heating by wood stoves in lieu of a 
biomass-based DH grid. However, as the community is seeking to relocate to southern Ontario, they are optimistic about the possibility of grid autonomy through the use of renewable energy technologies. 


\section{Appendix A}

Table A-1: Building energy models (row, semi-detached, and detached) casual gains and

\begin{tabular}{|c|c|c|c|c|c|c|c|}
\hline \multirow[b]{2}{*}{$\begin{array}{l}\text { Occupancy } \\
\text { Schedule }\end{array}$} & \multicolumn{7}{|c|}{ daily schedules } \\
\hline & $\begin{array}{c}\text { Lights } \\
\text { Schedule }\end{array}$ & $\begin{array}{c}\text { Range } \\
\text { Schedule }\end{array}$ & $\begin{array}{c}\text { Oven } \\
\text { Schedule }\end{array}$ & $\begin{array}{c}\text { Occupant } \\
\text { load Schedule }\end{array}$ & $\begin{array}{c}\text { Fridge } \\
\text { schedule }\end{array}$ & $\begin{array}{c}\text { Dishwasher } \\
\text { schedule }\end{array}$ & $\begin{array}{c}\text { Dryer } \\
\text { schedule }\end{array}$ \\
\hline $\begin{array}{c}\text { Number of } \\
\text { Occupants: } 4\end{array}$ & $\begin{array}{c}\text { Sensible load: } \\
840 \mathrm{~W}\end{array}$ & $\begin{array}{c}\text { Sensible load: } \\
554 \mathrm{~W}\end{array}$ & $\begin{array}{l}\text { Sensible load: } \\
600 \mathrm{~W}\end{array}$ & $\begin{array}{c}\text { Sensible load: } \\
\text { N/A }\end{array}$ & $\begin{array}{c}\text { Sensible load: } \\
141 \mathrm{~W}\end{array}$ & $\begin{array}{c}\text { Sensible load: } \\
316 \mathrm{~W}\end{array}$ & $\begin{array}{c}\text { Sensible load: } \\
400 \mathrm{~W}\end{array}$ \\
\hline Fraction & Fraction & Fraction & Fraction & Fraction & Fraction & Fraction & Fraction \\
\hline radiant: $N / A$ & radiant: 0.95 & radiant: 0.41 & radiant: 0.22 & radiant: 0.36 & radiant: 0.4 & radiant: 0.4 & radiant: 0.27 \\
\hline Through: & Through: & Through: & Through: & Through: & Through: & Through: & Through: \\
\hline $12 / 31$ & $12 / 31$ & $12 / 31$ & $12 / 31$ & $12 / 31$ & $12 / 31$ & $12 / 31$ & $12 / 31$ \\
\hline All days & All days & All days & All days & All days & All days & All days & Mon/Sun \\
\hline \multicolumn{8}{|l|}{ Percent } \\
\hline $\begin{array}{l}\text { occupancy } \\
\text { rate }(\%)\end{array}$ & $\begin{array}{l}\text { Percent of } \\
\text { load }(\%)\end{array}$ & $\begin{array}{l}\text { Percent of } \\
\text { load }(\%)\end{array}$ & $\begin{array}{c}\text { Percent of } \\
\text { load }\end{array}$ & $\begin{array}{l}\text { Sensible load } \\
\text { (W) }\end{array}$ & $\begin{array}{l}\text { Percent of } \\
\text { load (\%) }\end{array}$ & $\begin{array}{c}\text { Percent of } \\
\text { load }(\%)\end{array}$ & $\begin{array}{l}\text { Percent of } \\
\text { load }(\%)\end{array}$ \\
\hline Until 8:00 & Until 4:00 & Until 8:00 & Until 16:00 & Until 7:00 & Until 24:00 & Until 18:00 & Until 18:00 \\
\hline 1 & 0.1 & 0 & 0 & 70 & 1 & 0 & 0 \\
\hline Until 9:00 & Until 5:00 & Until 9:00 & Until 18:00 & Until 8:00 & & Until 20:00 & Until 20:00 \\
\hline 0.9 & 0.2 & 0.3 & 1 & 105 & & 1 & 1 \\
\hline Until 10:00 & Until 8:00 & Until 12:00 & Until 24:00 & Until 9:00 & & Until 24:00 & Until 24:00 \\
\hline 0.4 & 0.4 & 0 & 0 & 115 & & 0 & 0 \\
\hline Until 17:00 & Until 9:00 & Until 13:00 & & Until 16:00 & & & \\
\hline 0.25 & 0.2 & 0.5 & & 160 & & & \\
\hline Until 18:00 & Until 15:00 & Until 16:00 & & Until 17:00 & & & \\
\hline 0.3 & 0.1 & 0 & & 160 & & & \\
\hline Until 19:00 & Until 16:00 & Until 17:00 & & Until 18:00 & & & \\
\hline 0.5 & 0.2 & 0.6 & & 115 & & & \\
\hline Until 22:00 & Until 17:00 & Until 24:00 & & Until 21:00 & & & \\
\hline 0.9 & 0.4 & 0 & & 105 & & & \\
\hline Until 24:00 & Until 18:00 & & & Until 24:00 & & & \\
\hline \multirow[t]{11}{*}{1} & 0.6 & & & 70 & & & \\
\hline & Until 19:00 & & & & & & \\
\hline & 0.8 & & & & & & \\
\hline & Until 21:00 & & & & & & \\
\hline & 1 & & & & & & \\
\hline & Until 22:00 & & & & & & \\
\hline & 0.7 & & & & & & \\
\hline & Until 23:00 & & & & & & \\
\hline & 0.4 & & & & & & \\
\hline & Until 24:00 & & & & & & \\
\hline & 0.2 & & & & & & \\
\hline
\end{tabular}




\section{References}

[1] MacLeod Farley \& Associates, "MoCreebec Eeyoud Community Energy Plan," pp. $1-30,2015$.

[2] Independent Electricity System Operator, "Education and Capacity Building Program.” [Online]. Available: http://www.ieso.ca/Get-Involved/FundingPrograms/Education-and-Capacity-Building-Program/Overview. [Accessed: 13Jul-2020].

[3] Natural Resources Canada, "Explore Our Maps," Government of Canada. [Online]. Available: $\quad$ https://www.nrcan.gc.ca/earth-sciences/geography/atlascanada/explore-our-maps/16836. [Accessed: 14-Jul-2020].

[4] R. D. Bollman and H. A. Clemenson, "Structure and change in Canada's rural demography: An update to 2006," Rural and Small Town Canada Analysis Bulletin, 2008. [Online]. Available: https://www150.statcan.gc.ca/n1/pub/21-006-x/21-006x2007007-eng.htm. [Accessed: 16-Jul-2020].

[5] J. Royer, "Status of Remote/Off-grid Communities in Canada," Natural Resources Canada. Government of Canada, Ottawa, Canada, pp. 1-44, 2011.

[6] K. Karanasios and P. Parker, "Tracking the transition to renewable electricity in remote indigenous communities in Canada," Energy Policy, vol. 118, pp. 169-181, 2018.

[7] D. Heerema and D. Lovekin, "Power Shift in Remote Indigenous Communities." Pembina Institute, Calgary, Canada, pp. 1-65, 2019.

[8] Natural Resources Canada, "Clean Energy for Rural and Remote Communities (CERRC) Program," Government of Canada, 2018. [Online]. Available: 
https://www.nrcan.gc.ca/sites/www.nrcan.gc.ca/files/energy/pdf/CERRC

Webinar Mar72018.pdf. [Accessed: 16-Jul-2020].

[9] United Way of Bruce Grey, "Utility Needs in Bruce and Grey Counties," 2016.

[Online]. Available: https://unitedwayofbrucegrey.com/wpcontent/uploads/2016/08/Bruce-Grey-Utility-Assistance-report-2015-2016web.pdf. [Accessed: 16-Jul-2020].

[10] J. D. Stephen et al., "Biomass for residential and commercial heating in a remote Canadian aboriginal community," Renew. Energy, vol. 86, pp. 563-575, 2016.

[11] M. Harrestrup and S. Svendsen, "Heat planning for fossil-fuel-free district heating areas with extensive end-use heat savings : A case study of the Copenhagen district heating area in Denmark," Energy Policy, vol. 68, pp. 294-305, 2014.

[12] NRCan, RETScreen Software Online User Manual - Combined Heat \& Power Project Model. Canada: Natural Resources Canada, 2005.

[13] Polar Knowledge Canada, "Northern Housing Policy Recommendations," Government of Canada, 2019. [Online]. Available: https://www.canada.ca/en/polarknowledge/northern-housing-forum-knowledge-products/policyrecommendations.html. [Accessed: 21-Feb-2020].

[14] K. Sperling and B. Möller, "End-use energy savings and district heating expansion in a local renewable energy system - A short-term perspective," Appl. Energy, vol. 92, pp. 831-842, 2012.

[15] L. Gustavsson, A. Dodoo, N. L. Truong, and I. Danielski, "Primary energy implications of end-use energy efficiency measures in district heated buildings," Energy Build., vol. 43, no. 1, pp. 38-48, 2011. 
[16] K. LaFreniere, "Assessing Tradeoffs Between Solar Thermal and Wind Energy Integration in an Isolated Community Electrical-Thermal Grid.” M.A.Sc Thesis, Department of Mech. and Aero. Eng., Carleton University, Ottawa, Canada, pp. 1140, 2020.

[17] D. Lovekin and D. Heerema, "The True Cost of Energy in Remote Communities." Pembina Institute, Canada, pp. 1-7, 2019.

[18] A. Parekh, B. Mullally-pauly, and M. Riley, "The EnerGuide for Houses Program A Successful Canadian Home Energy Rating System," in Proc. of the ACEEE Summer Study on Energy Efficiency in Buildings, 2000, pp. 2.229-2.240.

[19] NRCan, "Tools for industry professionals," Natural Resources Canada, 2020. [Online]. Available: https://www.nrcan.gc.ca/energy-efficiency/energy-efficiencyhomes/professional-opportunities/tools-industry-professionals/20596. [Accessed: 21-Feb-2020].

[20] S. F. Gamtessa, "An explanation of residential energy-efficiency retrofit behavior in Canada," Energy Build., vol. 57, pp. 155-164, 2013.

[21] C. E. Hoicka, P. Parker, and J. Andrey, "Residential energy efficiency retrofits: How program design affects participation and outcomes," Energy Policy, vol. 65, pp. 594-607, 2014.

[22] C. E. Hoicka and P. Parker, "Assessing the adoption of the house as a system approach to residential energy efficiency programs," Energy Effic., vol. 11, no. 2, pp. 295-313, 2018.

[23] S. Cohen, C. Goldman, and J. Harris, "Energy savings and economics of retrofitting single-family buildings," Energy Build., vol. 17, no. 4, pp. 297-311, 1991. 
[24] B. Guler, A. S. Fung, M. Aydinalp, and V. Ismet Ugursal, "Impact of energy efficiency upgrade retrofits on the residential energy consumption in Canada," Int. J. Energy Res., vol. 25, no. 9, pp. 785-792, 2001.

[25] U. Filippi Oberegger, R. Pernetti, and R. Lollini, "Bottom-up building stock retrofit based on levelized cost of saved energy," Energy Build., vol. 210, 2020.

[26] Passive House Canada, "PHPP and Design PH Software," 2020. [Online]. Available: https://www.passivehousecanada.com/phpp-and-design-ph-software/. [Accessed: 21-Feb-2020].

[27] E. Asadi, M. G. da Silva, C. H. Antunes, and L. Dias, "A multi-objective optimization model for building retrofit strategies using TRNSYS simulations, GenOpt and MATLAB," Build. Environ., vol. 56, pp. 370-378, 2012.

[28] K. Nino Streicher, D. Parra, M. C. Buerer, and M. K. Patel, "Techno-economic potential of large-scale energy retrofit in the Swiss residential building stock," Energy Procedia, vol. 122, pp. 121-126, 2017.

[29] U.S. Department of Energy, "EnergyPlus," 2019. [Online]. Available: https://energyplus.net/. [Accessed: 21-Feb-2020].

[30] NREL, "Building Component Library," 2020. [Online]. Available: https://bcl.nrel.gov/. [Accessed: 11-Feb-2020].

[31] National Research Council Canada, "National Building Code of Canada 2015," 2015. [Online]. Available: https://nrc.canada.ca/en/certifications-evaluationsstandards/codes-canada/codes-canada-publications/national-building-code-canada2015. [Accessed: 08-Aug-2020].

[32] ASHRAE, ASHRAE handbook of fundamentals, Technical. Atlanta, USA: 
American Society for Heating, Refrigeration, and Air-Conditioning Engineers (ASHRAE), 2017.

[33] COMNET, “COMNET: Appendix C - Schedules,” New Buildings Institure, 2016. [Online]. Available: https://comnet.org/appendix-c-schedules. [Accessed: 02-Feb2020].

[34] S. Philip, “eppy 0.5.52: Scripting language for E+ idf files, and E+ output files," Python, 2019. [Online]. Available: https://pypi.org/project/eppy/. [Accessed: 21Feb-2020].

[35] NRCan, "ENERGY STAR® for New Homes Standard - Version 12.6,” 2015. [Online]. Available: https://www.nrcan.gc.ca/energy/efficiency/housing/newhomes/energy-starr-new-homes-standard/energy-starr-new-homes-standardversion-126/14178\#a4. [Accessed: 30-Dec-2019].

[36] RSMeans, Contractor's Pricing Guide: Residential Repair \& Remodeling Costs with RSMeans data. Rockland, USA: Gordian RSMeans data, 2018.

[37] NRCan, "ENERGY STAR ® Qualified Windows, Doors \& Skylights When Canadians want to reduce energy use and save money, they look for the ENERGY STAR symbol to identify," 2014. .

[38] P. O. Fanger, "Thermal Comfort-Analysis and Applications in Environmental Engineering," Copenhagen, 1970.

[39] ASHRAE, ANSI/ASHRAE Standard 55: Thermal Environmental Conditions for Human Occupancy. Atlanta, USA, 2017.

[40] B. W. Olesen, "International standards for the indoor envieonment. Where are we and do they apply worldwide?," Indoor Air, no. 14, pp. 18-26, 2004. 
[41] Hydro One, "Hydro One: Rates and billing," 2019. [Online]. Available: https://www.hydroone.com/rates-and-billing. [Accessed: 16-Jul-2019].

[42] EPA, External Combustion Sources. In: Stationary Point and Area Sources, AP 42. Compilation of Air Pollutant Emission Factors, vol. 1 (5th edn.), 5th editio. Washington, DC: US Environmental Protection Agency, 2003.

[43] J. Sotes, "A Clearer View on Ontario's Emissions: Electricity emissions factors and guidelines," The Atmospheric Fund, 2019. [Online]. Available: https://taf.ca/wpcontent/uploads/2019/06/A-Clearer-View-on-Ontarios-Emissions-June-2019.pdf.

[Accessed: 16-Jul-2020].

[44] Government of Canada, "Pricing pollution: how it will work," 2019. [Online]. Available: $\quad$ https://www.canada.ca/en/environment-climatechange/services/climate-change/pricing-pollution-how-it-will-work.html. [Accessed: 23-Feb-2020].

[45] A. L. Pisello and F. Asdrubali, "Human-based energy retrofits in residential buildings: A cost-effective alternative to traditional physical strategies," Appl. Energy, vol. 133, pp. 224-235, 2014.

[46] F. Preto, "Biomass Energy Background Paper (Yukon Energy Planning Charrette)," Yukon, Canada, 2011.

[47] M. Loeser and M. A. Redfern, "Balancing power supply and demand in remote offgrid regions by means of a novel micro-scale combined feedstock biomass generation plant," Int. J. energy Res., vol. 34, no. 11, pp. 986-1001, 2010.

[48] S. Thompson and B. Duggirala, "The feasibility of renewable energies at an off-grid community in Canada," Renew. Sustain. Energy Rev., vol. 13, no. 9, pp. 2740-2745, 
2009.

[49] Y. Zhu, W. Li, J. Li, H. Li, Y. Wang, and S. Li, "Thermodynamic analysis and economic assessment of biomass-fired organic Rankine cycle combined heat and power system integrated with CO2 capture," Energy Convers. Manag., vol. 204, p. 112310, 2020.

[50] R. Amirante, S. Bruno, E. Distaso, M. La Scala, and P. Tamburrano, "A biomass small-scale externally fired combined cycle plant for heat and power generation in rural communities," Renew. Energy Focus, vol. 28, pp. 36-46, 2019.

[51] Natural Resources Canada, “An Action Plan for Growing District Energy Systems Across Canada," Government of Canada, 2011. [Online]. Available: https://static1.squarespace.com/static/546bbd2ae4b077803c592197/t/58c83aad37c 581e14113a68d/1489517239056/CUIPublication.GrowingDistrictEnergy.pdf. [Accessed: 16-Jul-2020].

[52] EPA, "U.S. Environmental Protection Agency Combined Heat and Power Partnership,” Environ. Prot., no. September, 2017.

[53] A. M. Evans and A. J. Finkral, "From renewable energy to fire risk reduction: A synthesis of biomass harvesting and utilization case studies in US forests," $G C B$ Bioenergy, vol. 1, no. 3, pp. 211-219, 2009.

[54] J. Yablecki, E. L. Bibeau, and D. W. Smith, "Community-based model for bioenergy production coupled to forest land management for wildfire control using combined heat and power," Biomass and Bioenergy, vol. 35, no. 7, pp. 2561-2569, 2011.

[55] E. G. A. Forbes, R. J. Olave, C. R. Johnston, J. D. Browne, and J. Relf, "Biomass and bio-energy utilisation in a farm-based combined heat and power facility," 
Biomass and Bioenergy, vol. 89, pp. 172-183, 2016.

[56] D. Mertzis, P. Mitsakis, S. Tsiakmakis, P. Manara, A. Zabaniotou, and Z. Samaras, "Performance analysis of a small-scale combined heat and power system using agricultural biomass residues: The SMARt-CHP demonstration project," Energy, vol. 64, pp. 367-374, 2014.

[57] MathWorks, "MathWorks," $2020 . \quad$ [Online]. Available: https://www.mathworks.com/. [Accessed: 06-Jun-2020].

[58] Statistics Canada, "Electric Power Generation, Transmission, and Distribution," Electric Power Generation, Transmission, and Distribution, 2007. [Online]. Available: https://www150.statcan.gc.ca/n1/en/pub/57-202-x/57-202-x2007000eng.pdf?st=J-zhMt50. [Accessed: 16-Jul-2020].

[59] C. E. Baukal, Industrial Combustion Testing, 1st ed. Boca Raton, US: CRC Press, 2010.

[60] S. Ghafghazi, T. Sowlati, S. Sokhansanj, X. Bi, and S. Melin, "Life cycle assessment of base-load heat sources for district heating system options," Int. J. Life Cycle Assess., vol. 16, no. 3, pp. 212-223, 2011.

[61] EPA, "Biomass Combined Heat and Power Catalog of Techonologies," U.S. Environmental Protection Agency Combined Heat and Power Partnership, 2007. [Online]. Available: $\quad$ https://www.epa.gov/sites/production/files/201507/documents/biomass_combined_heat_and_power_catalog_of_technologies_v.1. 1.pdf. [Accessed: 25-Mar-2020].

[62] J. Duquette, A. Rowe, and P. Wild, "Thermal performance of a steady state physical pipe model for simulating district heating grids with variable flow," Appl. Energy, 
vol. 178, pp. 383-393, 2016.

[63] Urecon, "Urecon Detailed Specification - Hi-Temp System," 2020. [Online]. Available: http://www.urecon.com/documents/pdfs/specs/high_temp/EN-DS07E_HITEMP_Extruded_and_PE_cased_jacket_below_grade.pdf. [Accessed: 25Mar-2020].

[64] D. F. Burgess and R. O. Zerbe, "The most appropriate discount rate," J. Benefit-Cost Anal., vol. 4, no. 3, pp. 391-400, 2013.

[65] SNC Lavalin, "Unit Cost Estimates for Transmission Lines and Facilities in Northern Ontario and the Far North," Ontario Power Authority, 2011. [Online]. Available: http://www.ieso.ca/-/media/Files/IESO/Document-Library/regionalplanning/North-of-Dryden/App-1-1-3-Transmission-Unit-Cost-Study-SNCLavalin.pdf?la=en. [Accessed: 26-Mar-2020].

[66] S. Ghafghazi, T. Sowlati, S. Sokhansanj, and S. Melin, "Techno-economic analysis of renewable energy source options for a district heating project," Int. J. Energy Res., vol. 34, no. 12, pp. 1109-1120, 2010.

[67] P. R. Bhattarai and S. Thompson, "Optimizing an off-grid electrical system in Brochet, Manitoba, Canada," Renew. Sustain. Energy Rev., vol. 53, pp. 709-719, 2016.

[68] EPA, "Catalog of CHP Technologies," U.S. Environmental Protection Agency Combined Heat and Power Partnership, 2017. [Online]. Available: https://www.epa.gov/sites/production/files/2015-

07/documents/catalog_of_chp_technologies.pdf. [Accessed: 07-May-2020].

[69] Tenaska TrailBlazer Partners LLC, "Cooling Alternatives Evaluation for a New 
Pulverized Coal Power Plant with Carbon Capture,” 2011. [Online]. Available: https://www.globalccsinstitute.com/archive/hub/publications/24367/cooling-studyreport-2011-09-06-final-w-attachments.pdf. [Accessed: 25-Mar-2020].

[70] Cleaver Brooks, "Boiler efficiency guide," 2010. [Online]. Available: http://cleaverbrooks.com/reference-center/insights/Boiler Efficiency Guide.pdf. [Accessed: 07-Jul-2020].

[71] C. R. J. Frank, "The net benefits of low and no-carbon electricity technologies," Washington, DC, 73, 2014.

[72] D. Cherniak, V. Dufresne, L. Keyte, A. Mallett, and S. Schott, "Report on the State of Alternative Energy in the Arctic," Carleton University, 2015. [Online]. Available: https://curve.carleton.ca/08515c6b-3b39-4c41-ad7b-2c6306cf0379. [Accessed: 07Jul-2020].

[73] EIA, "EIA: faqs," U.S. Energy Information Administration. [Online]. Available: https://www.eia.gov/tools/faqs/faq.php?id=76\&t=11. [Accessed: 25-Mar-2020].

[74] E. Bowitz and M. Dang Trong, "The social cost of district heating in a sparsely populated country," Energy Policy, vol. 29, no. 13, pp. 1163-1173, 2001.

[75] E. A. Gilmore, L. B. Lave, and P. J. Adams, "The costs, air quality, and human health effects of meeting peak electricity demand with installed backup generators," Environ. Sci. Technol., vol. 40, no. 22, pp. 6887-6893, 2006.

[76] Wataynikaneyap Power, "Watay Power," 2019. [Online]. Available: https://www.wataypower.ca/. [Accessed: 27-Mar-2020].

[77] Canada Energy Regulator, “Canada’s Renewable Power Landscape 2017 - Energy Market Analysis," 2017. [Online]. Available: https://www.cer- 
rec.gc.ca/nrg/sttstc/lctrct/rprt/2017cndrnwblpwr/ghgmssn-

eng.html?=undefined\&wbdisable=true. [Accessed: 31-Mar-2020].

[78] Federation of Canadian Municipalities (FCM), "Rural challenges, national opoortunity," $2018 . \quad$ [Online]. Available: https://fcm.ca/sites/default/files/documents/resources/report/rural-challengesnational-opportunities.pdf. [Accessed: 27-Mar-2020].

[79] Canadian Electricity Association, "Kwadacha Biomass Project - Canada’s First-ofits-Kind Biomass Facility,” 2019. [Online]. Available: https://electricity.ca/lead/centre-of-excellence/kwadacha-biomass-project-canadasfirst-of-its-kind-biomass-facility/. [Accessed: 28-Mar-2020].

[80] J. Coady, K. LaFreniere, J. Russell, J.-P. Chabot, J. Duquette, and S. Schott, "Sustainable energy options: For the future of MoCreebec Eeyoud," Final Proj. Rep. Present. 2019 First Nations Energy Symp. by MoCreebec Eeyoud Chief Counc., pp. $1-64,2019$.

[81] AECOM, "Reducing the capital cost of district heat network infrastructure." Energy Technologies Institute, Loughborough, UK, pp. 1-21, 2017.

[82] N. Le Truong, A. Dodoo, and L. Gustavsson, "Effects of energy efficiency measures in district-heated buildings on energy supply," Energy, vol. 142, pp. 1114-1127, 2018.

[83] A. Joelsson and L. Gustavsson, "District heating and energy efficiency in detached houses of differing size and construction," Appl. Energy, vol. 86, pp. 126-134, 2009.

[84] E. Zvingilaite and O. Balyk, "Heat savings in buildings in a 100\% renewable heat and power system in Denmark with different shares of district heating," Energy 
Build., vol. 82, pp. 173-186, 2014.

[85] K. Difs, M. Bennstam, L. Trygg, and L. Nordenstam, "Energy conservation measures in buildings heated by district heating e A local energy system perspective," Energy, vol. 35, no. 8, pp. 3194-3203, 2010.

[86] J. Coady and J. Duquette, "A techno-economic assessment of residential building energy retrofits in Canada's remote communities: A case study [Accepted]," in Proc of IBPSA Canada's eSim 2021 Conf, 2020.

[87] J. Coady and J. Duquette, "Quantifying the impacts of biomass driven combined heat and power grids in northern rural and remote communities [Under Review]," Renew. Sustain. Energy Rev., 2020.

[88] J. Perktold, S. Seabold, and J. Taylor, "statsmodel v0.11.1 statistical models, hypothesis tests and data exploration," 2020. [Online]. Available: https://www.statsmodels.org/stable/index.html. [Accessed: 13-May-2020].

[89] T. Agami Reddy, Applied Data Analysis and Modeling for Energy Engineers and Scientists. New York, NY: Springer, 2011.

[90] A. Dalla Rosa, R. Boulter, K. Church, and S. Svendsen, "District heating (DH) network design and operation toward a system-wide methodology for optimizing renewable energy solutions (SMORES) in Canada: A case study," Energy, vol. 45, no. 1, pp. 960-974, 2012.

[91] N. G. Paterakis, O. Erdinç, and J. P. S. Catalão, "An overview of Demand Response : Key-elements and international experience," Renew. Sustain. Energy Rev., vol. 69, no. September 2015, pp. 871-891, 2017.

[92] W. O. Brien, B. Gunay, and F. Tahmasebi, "Special issue on the fundamentals of 
occupant behaviour research," vol. 10, pp. 439-443, 2017.

[93] H. B. Gunay, W. O. Brien, and I. Beausoleil-morrison, "Implementation and comparison of existing occupant behaviour models in EnergyPlus," vol. 9, no. 6, pp. $567-588,2016$. 